UNIVERSIDADE DE SÃO PAULO

Faculdade de Saúde Pública

\title{
Efeito da SuPlementaÇÃo COM Óleo de PeiXe E Vitamina E no Perfil Lipídico de DOIS Diferentes Grupos ÉTNICOS DE MULHERES COM DISLIPIDEMIAS NO Climatério
}

\section{LIANIA ALVES LUZIA}

Tese apresentada ao Programa de Pós-Graduação em Saúde Pública da Universidade de São Paulo para obtenção do Título de Doutor em Saúde Pública.

Área de Concentração: Nutrição

Orientadora: Professora Associada Elizabeth A.F.S. Torres

Co-Orientador: Professor Associado José Mendes Aldrighi

São Paulo

2008

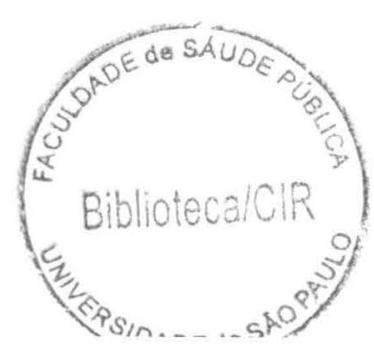




$$
49795 / 2008 \text { doe }
$$

É expressamente proibida a comercialização deste documento tanto na sua forn impressa como eletrônica. Sua reprodução total ou parcial é permitida exclusivamen para fins acadêmicos e científicos desde que na reprodução figure a identificação autor, título, instituição e ano da tese/dissertação. 
"Não basta saber, precisamos aplicar.

ãa basta estar disposto, precisamos fazer."

Leonardo da Vinci 
Dedicatória

Aos meus pais, Oswaldo e Luzia, por serem sempre tão presentes na minha vida.

Aos meus filhos, Lucas e Olguinha, que em sua inocência infantil me deram ensinamentos ao nível de doutores. Por eles a vida sempre terá um brilho especial! 


\section{AGRADECIMENTOS}

A DEUS, presença constante na minha vida.

À minha orientadora Professora Associada Elizabeth Aparecida Ferraz da Silva Torres, pela amizade, confiança, incentivo e orientação concedida. Sempre disposta a me ajudar elucidando minhas dúvidas, me ouvindo nos momentos difíceis e nos momentos de conquistas.

Ao meu Co-orientador Professor Associado José Mendes Aldrighi, entusiasta da saúde da mulher. Por sua dedicação constante, incentivo e conselhos valiosos, sem os quais esse estudo não teria alcançado os seus objetivos.

Às pacientes do Programa Saúde da Família, que são mulheres maravilhosas e sem as quais essa pesquisa não teria acontecido.

À Dra. Eny e Dra Shirley Cristina de Abreu, brilhante parceria, que junto com a equipe de enfermeiras e agentes comunitárias do PSF de Pindamonhangaba nos socorreram em momento decisivo.

À Professora Dra. Nágila Damasceno, pela amizade, disponibilidade e conselhos valiosos desde os primeiros momentos desse trabalho. 
À Rosana Soares, que foi incansável em solucionar as dúvidas técnicas, por sua amizade e preciosa ajuda nas análises bioquímicas.

À Geni Sampaio, brilhante profissional e amiga de todas as horas, pelo incentivo, apoio e ajustes finais dessa tese.

Às amigas Ana Paula e Isis Tande, doutorandas do laboratório de Nutrição Humana, que foram prestativas e indispensáveis para a realização deste trabalho.

Às amigas Aurora Cabral e Ana Carolina Schmitt e a todo o pessoal da saúde da mulher no climatério pela amizade, apoio e seriedade na pesquisa.

Às amigas Yara, Carol Zavatte, Ruth, Marina, Marcela, Emília, Simone (ex-bromato), Silvio e todos do laboratório de Bromatologia, cada um teve o seu momento especial e necessário (nas complexas discussões metodológicas e nas nossas pausas para o lanchinho da tarde...).

À Renilda, Ângela e todo o pessoal do Aprimoramento e da seção de Pós-graduação pela paciência, apoio e amizade.

Às minhas irmãs Oswania e Marilania, que sempre foram exemplo de determinação carinho e estímulo.

Ao Dezinho (in memória), por querer muito esse momento... Tenho certeza que de onde estiver, sempre torcerá por mim. 
Às empresas RELTHY e SUNFLOWER que forneceram as cápsulas para a realização deste estudo.

Ao Conselho Nacional de Desenvolvimento Científico e Tecnológico $(\mathrm{CNPq})$ e à Fundação de Amparo à pesquisa do Estado de São Paulo (FAPESP) pelo apoio financeiro.

Por fim, a todos aqueles que acreditaram em mim e compartilharam comigo essa caminhada. Valeu a força, a torcida, o sorriso, a cobrança, as alegrias e tristezas, o choro, a paciência, a compreensão... A todos vocês, meu sincero obrigado! 


\section{ÍNDICE}

\section{LISTA DE TABELAS}

LISTA DE FIGURAS

\section{LISTA DE SIGLAS E ABREVIATURAS}

\section{RESUMO}

\section{SUMMARY}

CAPÍTULO 1 - Revisão da Literatura ................................................................. 1

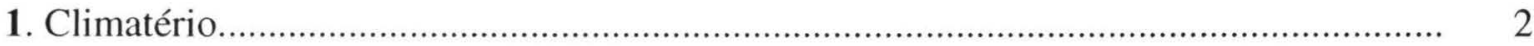

1.1. Fisiologia do Climatério........................................................................................ 4

1.2. Doenças Cardiovasculares................................................................................................. 6

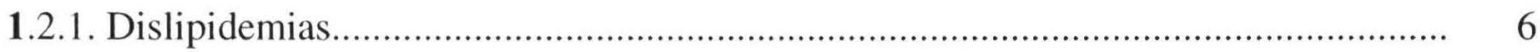

1.2.2. Impacto Econômico................................................................................................. 14

1.2.3. Doenças cardiovasculares e climatério......................................................................... 16

1.3. Ácidos Graxos Poliinsaturados......................................................................................... 18

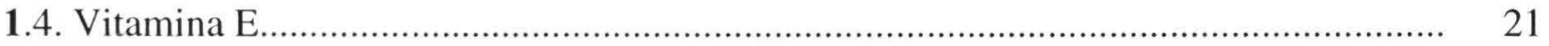


CAPÍTULO 2 - Efeito da suplementação com óleo de peixe e vitamina E no perfil

lipídico de dois grupos étnicos de mulheres com dislipidemias no climatério.

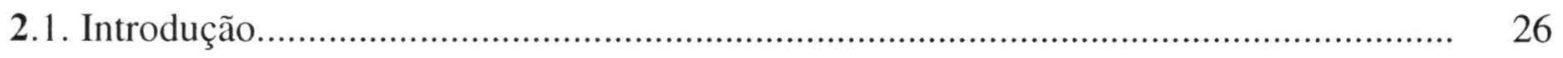

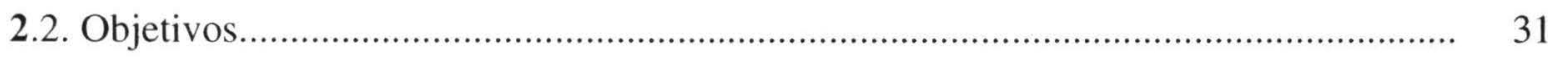

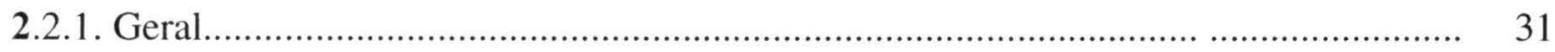

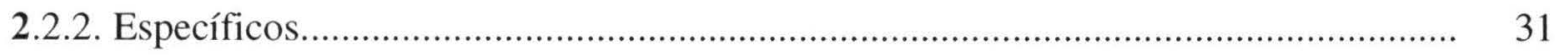

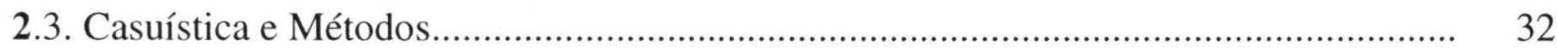

2.3.1. População de Estudo.............................................................................................. 32

2.3.2. Considerações Éticas........................................................................................... 33

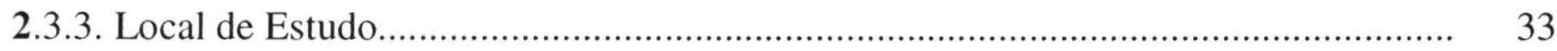

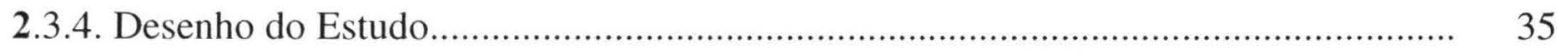

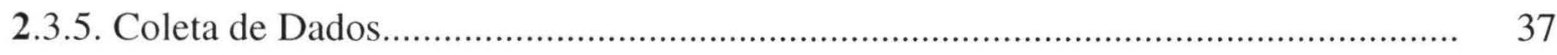

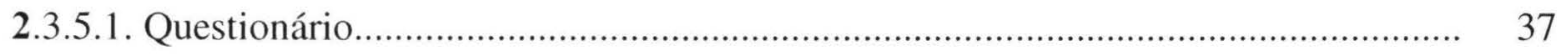

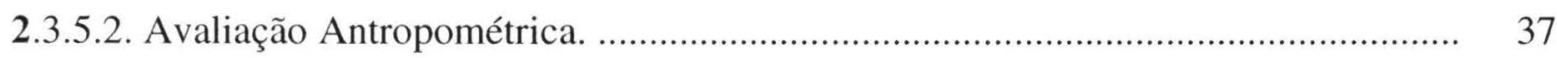

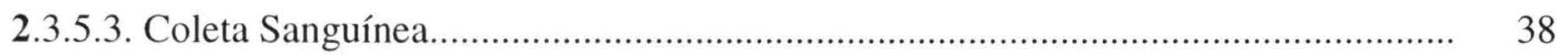

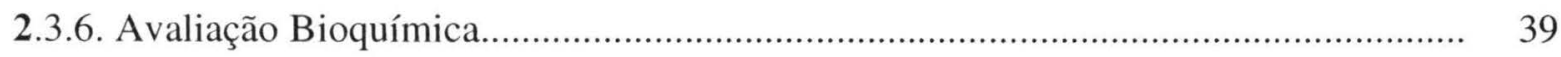

2.3.6.1. Determinação de Lipídios Plasmáticos..................................................................... 39

2.3.6.2. Determinação de Ácidos Graxos........................................................................... 40

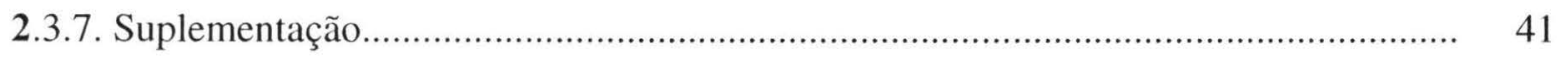

2.3.7.1. Cápsulas de Óleo de Peixe ..................................................................................... 42

2.3.7.1.1. Parâmetros analisados no óleo de Peixe................................................................. 42

2.3.7.2. Cápsulas de Vitamina E....................................................................................... 43

2.3.7.3. Cápsulas de Placebo............................................................................................ 43

2.4. Método Estatístico....................................................................................................... 44

2.5. Resultados e Discussão............................................................................................ 46

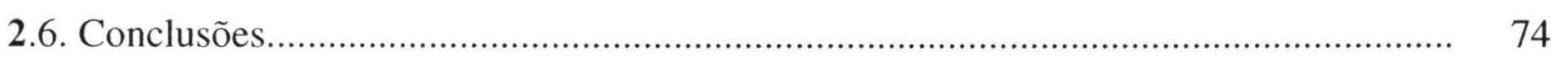


CAPÍTULO 3 - Peroxidação lipídica e avaliação de auto-anticorpos anti LDL oxidada

no plasma em dois grupos étnicos de mulheres com dislipidemias no climatério.

3.1. Introdução.

3.2. Objetivos 81

3.2.1. Geral. 81

3.2.2. Específicos. 81

3.3. Casuística e Métodos 82

3.3.1. População e Local de Estudo. 82

3.3.2. Desenho do Estudo 82

3.3.3. Critérios de Seleção e Exclusão. 82

3.3.4. Variáveis do Estudo 83

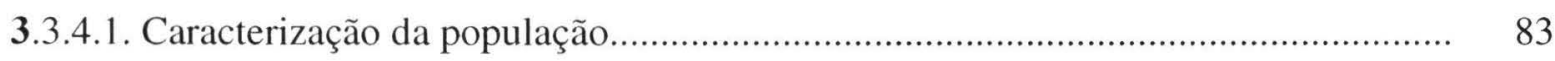

3.3.4.2. Variáveis Bioquímicas.................................................................................... 83

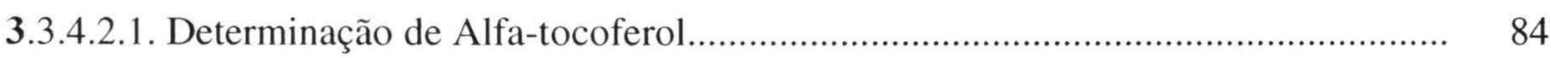

3.3.4.2.2. Mensuração de substâncias reativas ao ácido tiobarbitúrico (TBARS)................ 85

3.3.4.2.3. Detecção de auto-anticorpos anti-LDL.......................................................... 86

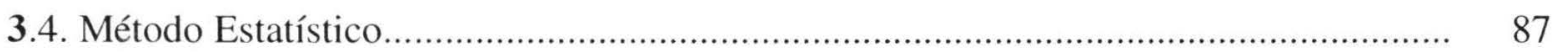

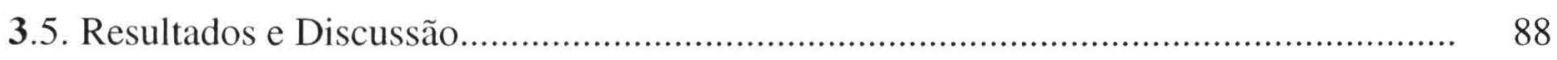

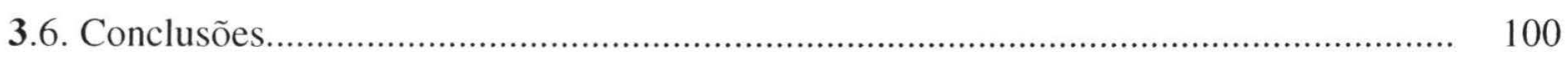

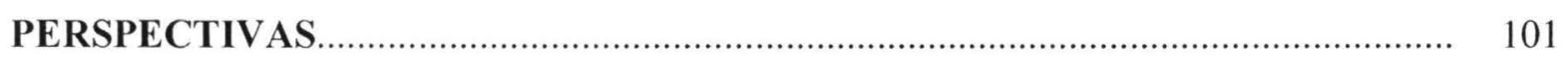

REFERÊNCIAS BIBLIOGRÁFICAS................................................................... 102 ANEXOS 


\section{LISTA DE TABELAS E GRÁFICOS}

Capítulo 2

Pág.

Tabela 1- População de estudo segundo etnia e suplementação. ............................... 48

Gráfico 1 - Boxplot da população segundo idade e suplemento..................................... 49

Tabela 2 - Dados antropométricos e comportamentais da população de estudo............. 50

Tabela 3 - Medidas resumo dos biomarcadores sanguíneos segundo etnia, suplemento e momento de coleta

Tabela 4 - Resultados inferenciais (p) na comparação de TG (mg/dL), HDL (mg/dL) e VLDL (mg/dL), segundo etnia, suplemento e momento de coleta.

Tabela 5 - Resultados inferenciais (p) na comparação de teores de colesterol (mg/dL), segundo suplemento e momento de coleta......

Tabela 6- Resultados inferenciais (p) na comparação de IRC segundo etnia, suplemento e momento de coleta. Pindamonhangaba - SP, 2007.

Tabela 7 - Resultados inferenciais (p) na comparação de IRC segundo momento de coleta.

Gráfico 2 - Valores de IRC, segundo etnia, suplemento e momento de coleta. 64

Gráfico 3 - Teores de LDL (mg/dL), segundo etnia, suplemento e momento de coleta

Tabela 8 - Resultados inferenciais (p) na comparação de LDL (mg/dL), segundo momento de coleta.

Tabela 9 - Resultados inferenciais (p) na comparação de LDL (mg/dL), segundo etnia e suplemento.

Tabela 10 - Proporção de ácidos graxos no plasma (\%) dos grupos experimentais nos momentos M1, M2 e M3.

Tabela 11 - Resultados inferenciais (p) na comparação do AGMI (\%) e $\omega-6$ (\%), segundo etnia, suplemento e momento de coleta.

Tabela 12 - Resultados inferenciais na comparação do AGS segundo momento de coleta, suplemento e etnia - Pindamonhangaba - SP, 2007.

Gráfico 4 - Distribuição dos valores médios de AGS (\%), segundo momento de coleta, etnia e suplemento.

Tabela 13 - Resultados inferenciais (p) na comparação do P/S, $\omega-3$ (\%) e $\omega-6 / \omega-3$, segundo etnia, suplemento e momento de coleta. 
Tabela 14 - Resultados inferenciais (p) na comparação do P/S, $\omega-3$ (\%) e $\omega-6 / \omega-3$, segundo momento de coleta - Pindamonhangaba - SP.

Tabela 15 - Resultados inferenciais (p) na comparação do AGPI (\%), segundo momento de coleta e suplemento - Pindamonhangaba - SP, 2007.

Gráfico 5 - Distribuição dos valores médios de AGPI (\%), segundo momento de coleta e suplemento

\section{Capítulo 3}

Gráfico 1 - Distribuição do grupo de estudo, segundo etnia e suplemento.

Tabela 1 - LDL, parâmetros oxidativos e alfa tocoferol plasmático.

Tabela 2 - LDL (mg/dL), segundo momento de coleta.

Gráfico 2 - Boxplots da LDL (mg/dL), segundo etnia, suplemento e momento de coleta.

Tabela 3 - Resultados inferenciais na comparação de detecção de auto-anticorpos anti LDL-ox (mg/mL), segundo momento de coleta e suplemento

Tabela 4 - Resultados inferenciais na comparação de detecção de auto-anticorpos anti LDL-ox (mg/mL), segundo momento de coleta e etnia.....

Gráfico 3 - Distribuição dos valores médios de deteç̧ão de auto anticorpos anti$\mathrm{LDL}^{-}(\mathrm{mg} / \mathrm{mL})$, segundo momento de coleta e etnia.

Tabela 5 - Resultados inferenciais na comparação de $\alpha$-tocoferol $(\mu \mathrm{mol} / \mathrm{L})$, segundo etnia, suplemento e momento de coleta.

Tabela 6 - Resultados inferenciais na comparação de $\alpha$-tocoferol ( $\mu \mathrm{mol} / \mathrm{L})$ e momento de coleta.

Tabela 7 - Resultados inferenciais na comparando TBARS $(\mu \mathrm{mol} / \mathrm{L})$, segundo momento de coleta e suplemento.

Gráfico 4 - Valores médios de TBARS $(\mu \mathrm{mol} / \mathrm{L})$, segundo momento de coleta e suplemento.

Tabela 8 - Resultados inferenciais na comparação do TBARS $(\mu \mathrm{mol} / \mathrm{L})$, segundo etnia e suplemento 


\section{LISTA DE FIGURAS}

Capítulo 1

Pág.

Figura 1- Estágios do Climatério..........................................................................

Figura 2 - $\quad$ Número de óbitos por capítulos da CID-10 - Brasil - 1996....................... 6

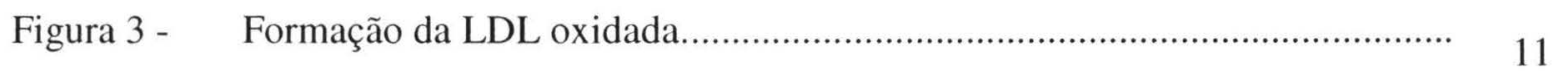

Figura 4 - $\quad$ Percentual de internações e gastos por DCV (CID 9 - cap. VII)................... 15

Figura 5 - Mediadores bioquímicos potentes envolvidos na inflamação, infecção, lesão tecidual, modulação do sistema imune e agregação plaquetária......... 21

Figura 6 - Mediadores bioquímicos menos potentes que a do $\omega 6$, que atuam no processo anti-inflamatório e não inibem o sistema imune............................. 21

Figura 7 - $\quad$ Estrutura molecular dos tocoferóis............................................................ 22

\section{Capitulo 2}

Figura 1 - Mapa do município de Pindamonhangaba - SP

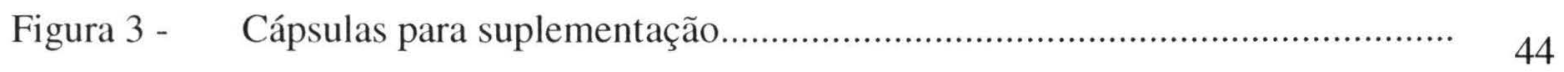

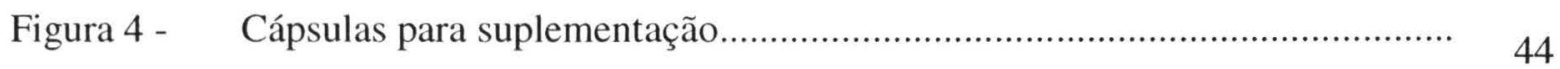




\section{LISTA DE SIGLAS E ABREVIATURAS}

AHA $=$ American Heart Association

AGMI = Ácidos graxos monoinsaturados

AGS = Ácidos graxos saturados

AGPI = Ácidos graxos poliinsaturados

$\mathrm{CG}=$ Cromatografia Gasosa

$\mathrm{CT}=$ Colesterol total

DATASUS = Dados do Sistema Único de Saúde

DCV $=$ Doenças Cardiovasculares

DHA = Ácido graxo docosahexaenóico

EDTA $=$ Etileno-diamino-tetracético

$\mathrm{EPA}=$ Ácido graxo eicosapentaenóico

$\mathrm{ERO}=$ Espécies reativas de oxigênio

FDA $=$ Food and Drug Administration

FEBRASGO = Federação Brasileira das Associações de Ginecologia e Obstetrícia

FSH = Hormônio folículo estimulante

GMP $=$ Good Manufacturing Practice

HDL = Lipoproteína de alta densidade

HDL-C = Lipoproteína de alta densidade associada ao colesterol

HPLC $=$ Cromatografia líquida de alta eficiência

IBGE = Instituto Brasileiro de Geografia e Estatística

LDL = Lipoproteína de baixa densidade

LDL-C = Lipoproteína de baixa densidade associada ao colesterol

LDL-ox = Lipoproteína de baixa densidade oxidada

LH $=$ Hormônio luteinizante

M0 = Momento zero

M1 = Momento um

M3 = Momento três

NAMS = North American Menopause Society

NCEP $=$ National Cholesterol Education Program 
OMS = Organização Mundial de Saúde

OTC $=$ Over Counter Pharmaceuticals

$\mathrm{pH}=$ Potencial hidrogeniônico

PSF = Programa Saúde da Família

$\mathrm{S} 1=$ Suplemento 1

$\mathrm{S} 2=$ Suplemento 2

S3 = Suplemento 3

$\mathrm{SBC}=$ Sociedade Brasileira de Cardiologia

SIM = Sistema de Informações Sobre Mortalidade

SPSS $=$ Statistical Pachage for the Social Science

$\mathrm{TG}=$ Triglicérides

TBARS $=$ Teste do ácido tiobarbitúrico

TRH = Terapia de reposição hormonal

VLDL = Lipoproteína de densidade muito baixa

$\omega-3=$ Ômega 3

$\omega-6=$ Ômega 6 


\section{RESUMO}

Luzia LA. Efeito da suplementação com óleo de peixe e vitamina $\mathbf{E}$ no perfil lipídico de dois diferentes grupos étnicos de mulheres com dislipidemia no climatério. São Paulo: 2008 [Tese de Doutorado em Saúde Pública - Faculdade de Saúde Pública da USP].

Considerando as diferenças étnicas existentes em relação às dislipidemias e o impacto destas sobre o risco das doenças cardiovasculares em mulheres no climatério, tornou-se imperioso intervenções preventivas, visto que com o aumento da expectativa de vida esta população viverá mais de 40 anos após a menopausa. Objetivo: Investigar o efeito da suplementação com óleo de peixe em cápsula associado ou não a vitamina E sobre o perfil lipídico e o estresse oxidativo de mulheres negras e brancas com dislipidemia no climatério. Casuística e Métodos: Durante três meses, 29 mulheres negras e 30 brancas receberam suplementação com óleo de peixe e vitamina E. Todas foram submetidas à determinação sérica de lipídios, lipoproteínas, ácidos graxos, auto-anticorpos anti LDLox e alfa-tocoferol em três momentos. Resultados: Triglicérides ( $\mathrm{p}=0,496)$, HDL-C $(\mathrm{p}=0,827)$ e VLDL $(\mathrm{p}=0,599)$ não foram influenciados pela etnia. De outra forma; valores da LDL-C nas mulheres de etnia branca, suplementadas com óleo de peixe combinado com vitamina $\mathrm{E}$ sofreram redução $(\mathrm{p}<0,001)$. Títulos de auto-anticorpos anti LDL-ox foram altos em mulheres brancas no baseline $(\mathrm{p}<0,001)$, porém diminuíram após a suplementação em ambas as etnias. Teores de alfa tocoferol foram influenciados pelo momento de coleta em ambas as etnias ( $\mathrm{p}=0,002$ e p=0,003). Conclusĩes: O óleo de peixe combinado com vitamina $\mathrm{E}$ foi o suplemento que demonstrou maior poder hipolipemiante. A etnia não foi um fator de diferença para a dislipidemia, mas demonstrou diferenças quando relacionada ao suplemento $(\mathrm{p}=0,005)$ e lipoproteínas isoladas $(\mathrm{p}<0,001)$.

Descritores: climatério, etnia, ômega 3, antioxidantes, dislipidemias, auto-anticorpos anti-LDLox. 


\section{SUMMARY}

Luzia LA. Effect of fish oil and vitamin E supplementation on lipids profile in two different ethnic groups of dyslipidemic women in the climacteric. São Paulo: 2008 [Tese de Doutorado em Saúde Pública - Faculdade de Saúde Pública da USP].

Background: Considering ethnic differences regarding dyslipidemia in the world population and the impact of these on the risk of cardiovascular diseases associated to the increase of life expectation, woman will live more than 40 years after menopause, became very important preventive interventions. Objective: To investigate the effect of fish oil supplementation associated or not with vitamin E, in the lipid profile and the stress oxidative of black and white women with dyslipidemia in the climacteric. Methods: For three months, 29 black women and 30 white were randomly assigned to receive supplementation with placebo or fish oil associated or not with vitamin E. Plasmatic levels of lipids, lipoproteins, fatty acids, auto antibodies anti-oxLDL and alpha tocopherol were analyzed in three moments. Results: In relation to the triglycerides $(\mathrm{p}=0,496)$, HDL-C $(\mathrm{p}=0,827)$ and VLDL $(\mathrm{p}=0,599)$ differences were not verified among the ethnicity. It was different from the basal LDL-C which white women supplemented with fish oil with vitamin $E$ showed reduction of values $(\mathrm{p}<0,001)$. When auto-antibodies anti LDL-ox was analyzed, white women presented higher levels in the basal $(\mathrm{p}<0,001)$, however after supplementation decreased in both ethnicity. Alpha tocopherol contents were influenced by the time of collection in both ethnicities ( $p=0,002$ and $p=0,003)$. Conclusions: Fish oil with vitamin $E$ was the supplement that demonstrated better hypolipidemic effect. Ethnicity was not a factor of difference for dyslipidemia, but it demonstrated differences when related to the supplement $(p=0,005)$ and isolated lipoproteins $(\mathrm{p}<0,001)$.

Descriptors: climacteric, ethnicity, PUFA n-3, antioxidants, dyslipidemia, auto antibodies anti-oxLDL 
CAPÍTULO 1

Revisão da Literatura 


\section{CLIMATÉRIO}

Originária do grego "klimakter", a palavra climatério significa degrau e, representa a etapa do desenvolvimento humano que marca a transição da idade adulta à senescência (CIORNAI, 1999), ou seja, o climatério, marca a transição do período reprodutivo para o não reprodutivo. Essa fase tem início por volta dos 35 anos e caracteriza-se por uma série de fenômenos clínicos, biológicos e endócrinos (NOTELOVITZ et al., 1986). Essas manifestações são polimorfas e mostram-se em associações e freqüências variáveis decorrentes, não só da exaustão dos folículos ovarianos, mas também da desincronização dos sinais neuronais do hipotálamo e sistema nervoso central (ALDRIGHI et al., 2005).

Como o conceito de climatério tinha sido proposto didaticamente por NOTELOVITZ et al (1986) e não se baseava em estudos que envolvessem a relação idade, perfil endócrino e ciclos menstruais, GRACIA et al (2005), após exaustivas investigações clínico-laboratoriais propuseram a mudança da nomina climatério para estágios de transição menopausal e pós-menopausa. Os autores observaram que a transição menopausal tem início ao redor dos 37 anos, momento que surgem as primeiras irregularidades menstruais, e término na menopausa, última menstruação da vida da mulher cujo diagnóstico é sempre retrospectivo, necessitando de 12 meses consecutivos de amenorréia. Nesse período, que é longo, as concentrações de estrogênios flutuam e as de hormônio folículo estimulante (FSH) aumentam numa tentativa de estimular a produção estrogênica.

Apesar da média de idade para menopausa ser por volta dos 50 anos, é possível que haja diferenças entre os países desenvolvidos e os em desenvolvimento (OMS, 
1996). Nos Estados Unidos a média de idade para ocorrência da menopausa é de 51,3 anos (AVIS \& MCKINLAY, 1991). No Brasil, a média etária de instalação da menopausa é de 48,6 anos (ALDRIGHI et al., 2005). A pós-menopausa, por sua vez, inicia na menopausa se estendendo até o fim da vida.

Segundo PEDRO et al. (2003) o baixo nível sócio-econômico, reduzido peso e tabagismo são alguns dos fatores que poderiam adiantar o advento da menopausa; o número de gestações, o uso de contraceptivos hormonais e outros fatores têm sido responsabilizados por postergar o final da idade reprodutiva, porém a cerca disso existem controvérsias (NAMS, 2007).

Em 1990, havia no mundo aproximadamente 467 milhões de mulheres com 50 anos ou mais, e projeções populacionais do Banco Mundial apontam que em 2030 essa população alcançará 1,2 bilhões (OMS, 1996); ademais em 2030 a expectativa de vida nos países desenvolvidos será de 81 anos, e de 78 anos nos países em desenvolvimento (OMS, 2006). Com isso, a mulher após a menopausa viverá mais 30 a 40 anos.

Informações do DATASUS (2001) demonstram que no Brasil, a população feminina com 50 anos ou mais atingiu 14.508.639 mulheres. No estado de São Paulo o aumento dessa população, na mesma faixa etária, no período entre 1980 e 1998 foi cerca de $70 \%$, passando de 1.725 .380 para 2.936 .352 , devido à evolução na expectativa de vida da mulher brasileira, que hoje é de 72,3 anos (IBGE, 2001).

Apesar de alguns profissionais da área de saúde afirmarem que a menopausa deve ser tratada como uma etapa normal do ciclo biológico feminino, do mesmo modo que a menarca, ela ficou estigmatizada como fase de privação (AMARAL, 2002). No entanto, esse período não deve ser visto como um sinal de declínio, mas sim como um fenômeno salutar que pode sinalizar um momento altamente positivo no qual o objetivo maior é avaliar e sanar as reais necessidades de saúde (ALDRIGHI et al., 2002). 
De fato, a vulnerabilidade da mulher às doenças cardiovasculares após a menopausa é evidente. Esses dados são ratificados em diferentes séries da literatura e, no Brasil, estatística do Sistema de Informação da Mortalidade (SIM) mostra que a principal causa de óbito entre as brasileiras no climatério são as doenças do aparelho circulatório (BRASIL, 2005).

Concomitante a isso, as desigualdades étnico-raciais vêm adquirindo grande relevância na produção de diferentes perfis de doença. Nas mulheres negras, entre 40 e 69 anos de idade, a taxa de mortalidade por doenças cerebrovasculares (115 por 100 mil) é cerca de duas vezes maior do que entre brancas (58 por 100 mil). Da mesma forma, a mortalidade por doença hipertensiva e por diabete melito é muito mais expressiva entre as mulheres negras. Apesar dessa realidade, as desigualdades étnico-raciais, no âmbito da saúde têm sido pouco investigadas no Brasil (CHOR e LIMA, 2005).

O exposto leva o climatério à condição de importante tema de saúde pública, pois cuidados preventivos adequados poderão trazer benefícios propiciando melhor qualidade de vida a esse grupo populacional (LORENZI et al., 2005; LIMA, 2005).

\subsection{FISIOLOGIA DO CLIMATÉRIO}

Fisiologicamente, a menopausa representa a última menstruação da mulher. Em um período variável, de meses ou anos, antes da última menstruação, a mulher costuma apresentar sintomas sugestivos de que algumas modificações estão ocorrendo em seu organismo. Antes da instalação da menopausa e com a instabilidade hormonal, as alterações do ciclo menstrual são as primeiras manifestações clínicas. Na fase prévia à menopausa os ciclos encurtam-se ou alongam-se em sete ou mais dias e após, quando a amenorréia dura por um período de dois a onze meses, caracteriza-se a transição menopausal (GRACIA et al., 2005). São classificadas na menopausa mulheres com 
ausência de ciclo menstrual por um período superior a 12 meses e valores de hormônio folículo estimulante $(\mathrm{FSH}) \geq 20 \mathrm{mUL} / \mathrm{mL}$, hormônio luteinizante $\mathrm{LH} \geq 15 \mathrm{mUL} / \mathrm{mL}$ e estradiol $\leq 50 \mathrm{ng} / \mathrm{mL}$ (NAMS 2004 in GRACIA et al., 2005) A deficiência de estrogênio ocorre devido ao esgotamento folicular ovariano, fenômeno natural do envelhecimento e tem como marcador endócrino a diminuição da inibina B. Segundo ALDRIGHI et al. (2005) essa fase corresponde ao início do climatério, tendo início aos 40 anos e se estendendo até os 65 anos. Após a menopausa os níveis de estrogênio são praticamente nulos, o que contribui para o aparecimento das doenças crônicas como diabetes, doenças cardiovasculares, e osteoporose.

A Sociedade Norte Americana de Menopausa (NAMS, 2002) delimitou o climatério em sete estágios, dos quais cinco precedem e dois sucedem o período menstrual final (Figura 1).

\begin{tabular}{|c|c|c|c|c|c|c|c|c|}
\hline & & & & \multicolumn{5}{|c|}{ Final do periodo menstrual } \\
\hline Estágios & -5 & -4 & -3 & -2 & -1 & & +1 & +2 \\
\hline \multirow[t]{3}{*}{ Terminologia } & \multicolumn{3}{|c|}{ reprodutivo (pré-menopausa) } & \multicolumn{2}{|c|}{ transição menopausal } & \multicolumn{3}{|c|}{ pós-menopausa } \\
\hline & inicial & & tardio & inicial & tardio & & icial & tardio \\
\hline & & & & \multicolumn{5}{|c|}{ perimenopausa } \\
\hline Duração & \multicolumn{3}{|c|}{ variável } & \multicolumn{2}{|c|}{ variável } & 음 & 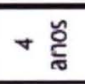 & $\begin{array}{c}\text { até a fim } \\
\text { da vida }\end{array}$ \\
\hline Ciclo menstrual & $\begin{array}{l}\text { yariável } \\
\text { a regular }\end{array}$ & \multicolumn{2}{|c|}{ regular } & $\begin{array}{c}\text { duraçào } \\
\text { variável ( }>7 \\
\text { dias } \\
\text { diferente } \\
\text { do normal) }\end{array}$ & $\begin{array}{c}\text { falha } \geq 2 \\
\text { ciclos e } \\
\text { intervalo de } \\
\text { amenorréia } \\
\geq 60 \text { dias } \\
\end{array}$ & 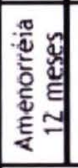 & \multicolumn{2}{|c|}{ inexistente } \\
\hline $\begin{array}{l}\text { Nivel de } \\
\text { hormônio foliculo } \\
\text { estimulante (FSH) }\end{array}$ & \multicolumn{2}{|c|}{ Normal } & $\uparrow$ & & 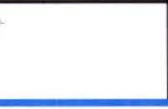 & \multicolumn{3}{|c|}{$\uparrow$} \\
\hline
\end{tabular}

Figura 1 - Estágios do Climatério - Fonte: NAMS (2002) 


\subsection{DOENÇAS CARDIOVASCULARES}

As doenças cardiovasculares (DCV) são aquelas que alteram o funcionamento do sistema circulatório. Vários são os fatores de risco envolvidos em sua gênese. Entre estes, o sedentarismo, hipertensão, diabetes e dislipidemias ocupam papel relevante. No Brasil, dados do Sistema de Informação de Mortalidade (BRASIL 2005) mostram que a principal causa de óbito entre as brasileiras no climatério são as doenças do aparelho circulatório, a mortalidade causada por DCV em adulto de 50 anos e mais é de $2.554,7$ óbitos por 100.000 habitantes. (Figura 2).

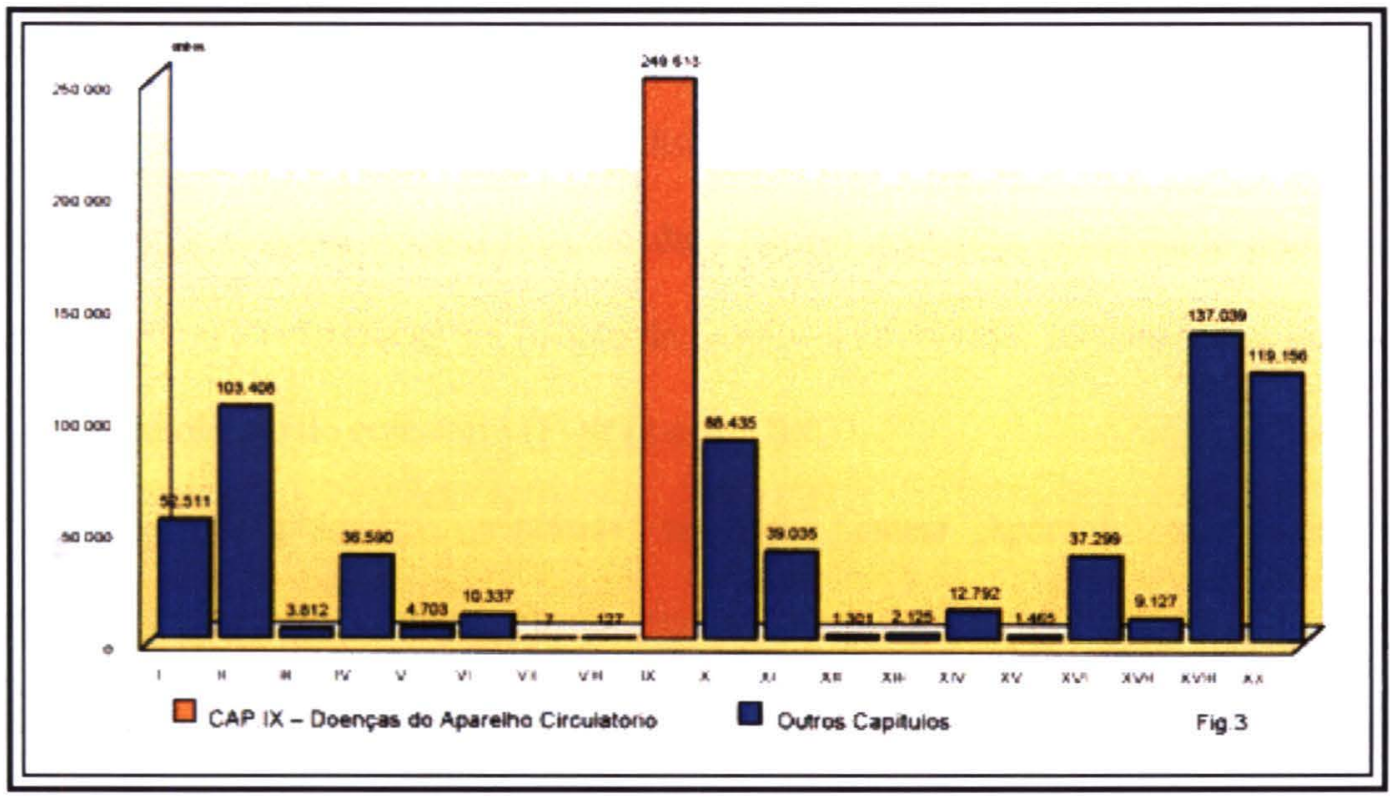

Figura 2 - Número de óbitos por capítulos da CID-10 - Brasil - 2002

\subsubsection{Dislipidemias}

\section{Lipídios}

Juntamente com as proteínas e os carboidratos, os lipídios são macronutrientes de importância biológica que podem ser sintetizados no organismo, com exceção dos ácidos graxos essenciais. Os lipídios são transportados por lipoproteínas que se classificam de acordo com suas densidades ou mobilidade eletroforética. Há uma correspondência entre 
essas duas classificações: a lipoproteína de muito baixa densidade (VLDL) corresponde à fração pré-beta de eletroforese em papel; a lipoproteína de baixa densidade (LDL) corresponde à fração beta da eletroforese em papel e a lipoproteína de alta densidade (HDL) corresponde à fração alfa da classificação eletroforética e contém, principalmente, ésteres de colesterol depositado no seu interior (NCEP, 2001).

\section{$\underline{\text { Dislipidemias }}$}

As dislipidemias podem ser definidas como modificações no transporte de lipídios, que resultam de alterações metabólicas na síntese ou na degradação das lipoproteínas plasmáticas, que alteram as concentrações dos seus diferentes componentes na circulação (NCEP, 2001).

De acordo com a etiológia as dislipidemias podem ser primárias e secundárias. As primárias têm sua origem relacionada a fatores genéticos envolvendo mutações que podem alterar as estruturas e a função de proteínas envolvidas na síntese, na homeostase e no metabolismo do colesterol (FORTI et al. 2003).

As dislipidemias primárias ou sem causa aparente são classificadas genotipicamente ou fenotipicamente através de análises bioquímicas. Na classificação genotípica, se dividem em monogênicas, causadas por mutações em um só gene e poligênicas, causadas por associações de mutações múltiplas que isoladamente não seriam de grande repercussão (SBC, 2007).

A classificação fenotípica ou bioquímica considera os valores do colesterol total (CT), lipoproteína de baixa densidade associada ao colesterol (LDL-C), triglicérides (TG) e lipoproteína de alta densidade associada ao colesterol (HDL-C). E de acordo com essa classificação as dislipidemias se inserem em diferentes categorias: I Hipercolesterolemia isolada, elevação isolada da LDL-C; II - Hipertrigliceridemia isolada, elevação isolada dos triglicérides; III - Hiperlipidemia mista, quando há 
aumento de ambos LDL-C e TG; IV - diminuição isolada da HDL-C ou associada ao aumento de LDL-C ou TG, ainda fazendo parte dessa classificação está o aumento de lipoproteína (a) $[\mathrm{Lp}(\mathrm{a})]$ que pode estar associada ou não à elevação de colesterol e triglicérides isolados ou associados. No entanto, embora a [Lp(a)] esteja envolvida na aterogênese, os numerosos polimorfismos da apo (a) e as limitações metodológicas da sua dosagem limitam acentuadamente sua utilização de rotina (SBC, 2007).

As chamadas dislipidemias secundárias são causadas por doenças e/ou por medicamentos utilizados para diversas enfermidades (hipotireoidismo, diabete melito, síndrome nefrótica, insuficiência renal crônica, obesidade, alcoolismo, icterícia obstrutiva). Da mesma forma, altas doses de diuréticos, betabloqueadores, corticosteróides e anabolizantes podem levar às dislipidemias secundárias (FORTI et al, 2003).

Segundo SANTOS (1999), após o diagnóstico confirmado de dislipidemias e, antes do início de terapia medicamentosa, deve-se controlar a concentração sérica do colesterol por meio de atividades físicas e mudanças nos padrões alimentares. O diagnóstico de dislipidemias secundárias tem se tornado cada vez mais freqüente possivelmente decorrente do aumento da expectativa de vida fazendo com que as comorbidades sejam elevadas (SBC, 2007); outro fator de alta relevância é a incidência de obesidade, cada vez mais precoce na população (OMS, 2006).

Ainda sob o ponto de vista fisiopatológico, as lipoproteínas variam em tamanho: quanto maiores, menor a densidade. Em ordem de densidades crescentes e tamanhos decrescentes a enumeração seria: quilomícrons, quilomícrons remanescentes, VLDL, IDL, LDL e HDL (SBC, 2007).

Os quilomícrons são as lipoproteínas plasmáticas responsáveis pelo transporte dos lipídios da dieta absorvidos pelo intestino. Eles possuem a mesma via metabólica da 
VLDL produzidas pelo fígado. Semelhante à VLDL, os quilomícrons são submetidos à ação da enzima lipase lipoprotéica na parede dos capilares (ALVES et al., 2004).

A importância dessa partícula está na sua função de transporte dos lipídios provenientes da dieta para os músculos e tecidos adiposos para que possam ser utilizados como substrato energético ou de armazenamento (CHOPRA e THURNHAM, 1999).

Após sofrer processo de lipólise, os quilomícrons dão origem a partículas menores: os remanescentes de quilomícrons; estes são considerados lipoproteínas aterogênicas e, sua remoção mais lenta está diretamente relacionada com a doença arterial coronariana (MARANHÃO et al., 1995).

A VLDL é produzida pelo fígado e contém altas concentrações de triglicérides, parte deles provenientes da dieta e transportados pelos quilomícrons. A principal função dessa partícula é fornecer lipídios para os tecidos periféricos. A ação da lípase lipoprotéica faz com que triglicérides associados às partículas de VLDL sejam degradados a ácidos graxos livres, captados pelas células, essa perda induz as partículas de VLDL à transformação de modo progressivo em IDL e posteriormente em LDL (CHOPRA e THURNHAM, 1999).

A LDL humana é uma partícula constituída de lipídios e proteínas tipicamente isoladas por ultra centrifugação entre as densidades de 1,019 e 1,063g/mL (GOTTO et al., 1988). Sua forma é esférica com diâmetro entre 19 e $25 \mathrm{~nm}$ e peso molecular de 2,5 milhões de daltons (STEINEROVA et al., 2001), de acordo com o tamanho e carga duas subclasses de LDL no plasma podem ser identificadas, fenótipo A e B; o primeiro caracteriza-se por predominância de partículas grandes e leves e, o segundo apresenta partículas pequenas e densas, associadas às concentrações plasmáticas de triglicérides elevadas e HDL-C reduzido, conferindo uma característica mais aterogênica. 
A partícula da LDL contém cerca de 2700 moléculas de ácidos graxos, sendo que metade desses ácidos são polinsaturados com predominância do ácido linoléico (C18:2) e ácido araquidônico (C20:4) e uma quantidade pequena de ácido docosahexaenóico (C22:6) (ESTERBAUER et al., 1987). Os antioxidantes associados à lipoproteína são de natureza lipossolúvel e o mais abundante é o $\alpha$-tocoferol (6 a 8 moléculas por partícula de LDL). Outros antioxidantes presentes na LDL incluem o $\gamma$-tocoferol, ubiquinol-10, $\beta$ caroteno, licopeno, criptoxantina e $\alpha$-caroteno, no entanto esses antioxidantes ocorrem em baixas concentrações (menos de uma molécula por partícula de LDL).

A importância dessa partícula reflete no fato de que em níveis plasmáticos elevados ela é considerada um dos principais fatores de risco para o desenvolvimento de doença aterosclerótica cardiovascular. A hipótese da resposta à injúria da aterosclerose propõe que o primeiro passo na aterogênese seja a disfunção endotelial induzida pela ação dos fatores de risco, em especial, pela exposição do endotélio vascular à LDL oxidada (LDL-ox) (ROSS e GLONSET, 1996) (Figura 3).

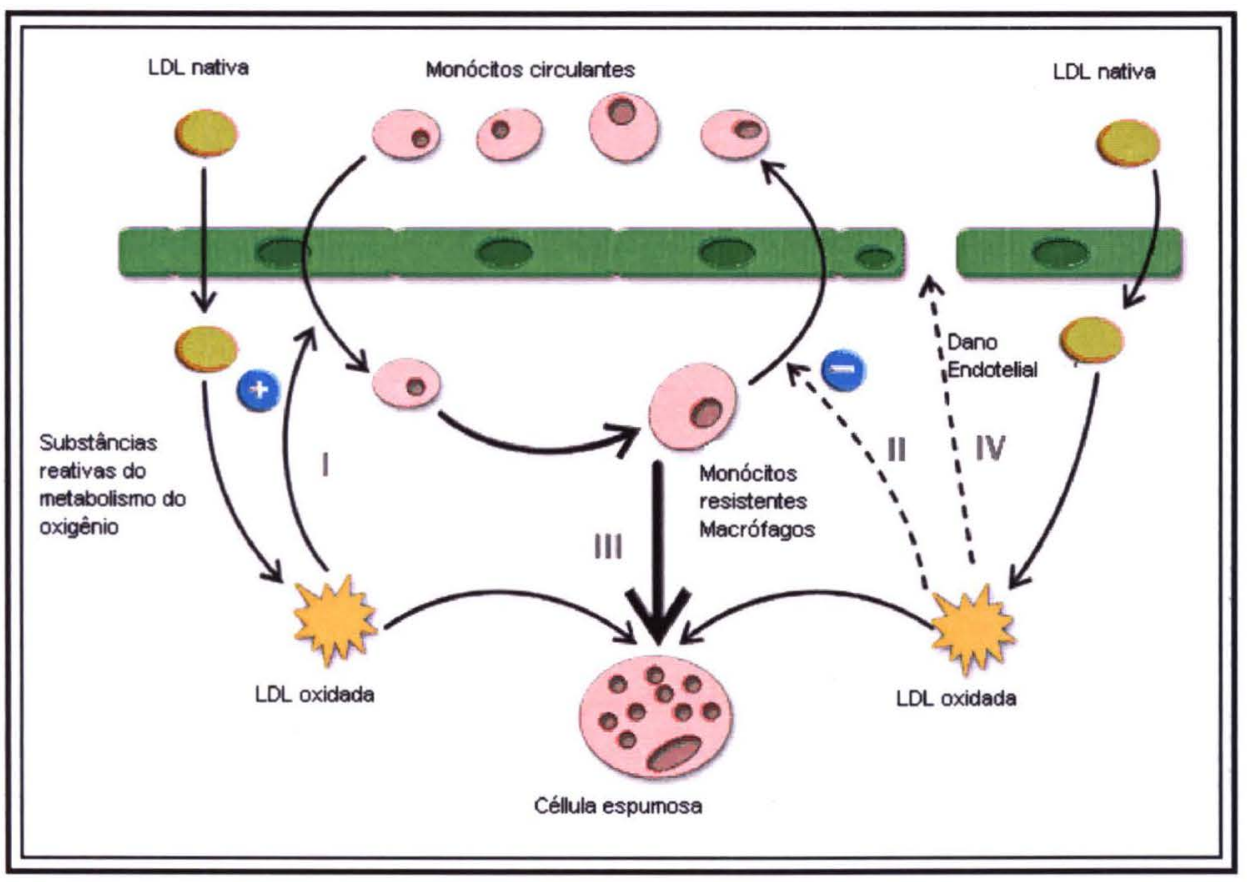

Figura 3 - Formação da LDL oxidada 
A fração lipoprotéica conhecida como HDL é constituída por um grupo de partículas originalmente obtidas por ultracentrifugação do plasma, com densidade entre 1,063 e $1,25 \mathrm{~g} / \mathrm{ml}$. Assim, as HDL são as menores partículas (7-17 nm de diâmetro) e as mais densas $(1,063<\mathrm{d}<1,25 \mathrm{~g} / \mathrm{ml})$ das frações lipoprotéicas plasmáticas. A HDL é sintetizada no fígado e intestino originando a HDL nascente.

A lipólise do QM e da VLDL e a captação de lipídios das células periféricas contribuem para a formação da HDL madura na corrente sangüínea.

Ao contrário das outras lipoproteínas, a HDL apresenta relação inversa com o risco cardiovascular, devido sua função anti-aterogênica associada ao transporte reverso de colesterol, inibição da expressão das moléculas de adesão, atividades antiinflamatórias e antioxidantes, sendo que a atividade antioxidante está ligada à presença da enzima paraoxonase (CHOPRA e THURNHAM, 1999; RYE et al., 1999; VAN HIMBERGEN et al., 2005).

ROLAND e MARANHÃO (1993) e EMERSON e MARANHÃO (2004) sugeriram, em seus estudos, que a capacidade de captação de lipídios e o tamanho da partícula de HDL estão associados à ação cardioprotetora. Entretanto, a remoção da HDL do plasma se dá por processo complexo: a maioria dos constituintes é removida separadamente e apenas uma fração da HDL é metabolizada como partícula intacta; além disso, o processo metabólico da HDL tem papel importante na composição, na forma, no tamanho e na carga de superfície das partículas, sendo o responsável pela heterogeneidade das HDL plasmáticas (BRINTON, 2003).

Em estudo recente LIMA e COUTO (2006) demonstraram que o mecanismo de remoção da circulação das proteínas presentes na HDL é bem menos compreendido do que aquele que ocorre com os lipídios associados à partícula; o fenômeno de 
remodelamento plasmático ocorre mais rapidamente do que o tempo de permanência da HDL na circulação (três a cinco dias), sendo o principal responsável pelo metabolismo dessa fração lipoprotéica.

\section{Estresse Oxidativo e Peroxidação Lipídica}

O estresse oxidativo é uma condição celular ou fisiológica de elevada concentração de espécies reativas de oxigênio (EROs) que causam danos moleculares às estruturas celulares, com conseqüente alteração funcional e prejuízo das funções vitais em diversos tecidos ou órgãos (HALLIWELL e CROSS, 1994). As células estão continuamente produzindo radicais livres e EROs como parte do processo metabólico, no entanto o efeito deletério do estresse oxidativo varia consideravelmente de um ser vivo para o outro de acordo com a idade, o estado fisiológico e a dieta (NIESS et al., 1999).

Na última década, estudos têm demonstrado que as causas para esses danos podem ser endógenas ou exógenas tais como exposição ambiental aos oxidantes, ingestão inadequada de antioxidantes ou desordens enzimáticas que levariam a um nível patogênico de danos oxidativos (SIES et al., 2005).

Dentro desse contexto, THOMAS (2003) havia relatado que uma dieta rica em frutas e hortaliças fornece variedades de antioxidantes que atuam de forma benéfica. Por outro lado, substâncias como pesticidas, toxinas vegetais e derivados de microorganismos, bem como os lipídios polinsaturados podem atuar produzindo efeitos pró-oxidantes, pois devido a suas múltiplas duplas ligações os ácidos graxos polinsaturados são excelentes alvos para ataque de radicais livres (HALLIWELL e GUTTERIDGE, 1999; NORNERG e ARNÉR, 2001).

Na dieta humana há uma quantidade significativa de lipídios; eles são suscetíveis ao ataque por radicais livres e a sua oxidação pode ser muito deletéria devido à 
continuidade como uma reação em cadeia, dessa forma, são bons marcadores bioquímicos e têm sido utilizados na determinação de eficácia de antioxidantes naturais (WANASUNDARA e SHAHIDI, 1998). Por outra via, na ausência de antioxidantes apropriados, os ácidos graxos polinsaturados formam radicais livres e podem ter um efeito pró-oxidante significativo levando à depleção da vitamina E, como também ao aumento dos produtos de oxidação (MEYDANI, 1996), daí ser necessário um controle dos níveis de antioxidantes para acompanhar um consumo elevado de ácidos graxos polinsaturados, uma vez que estudos referenciais de caráter prospectivos confirmam os efeitos benéficos dos ácidos graxos polinsaturados (FALUDI et al., 2001). Entretanto, os mesmos autores relatam que esses estudos estão sujeitos a criticas, pois são de caráter observacional e avaliaram o consumo dos ácidos eicosapentanóico e docosahexaenóico por estimativa

A LDL, principal carreadora do colesterol plasmático, é protegida da oxidação pela paraoxonase presente no plasma humano, a qual é uma esterase associada ao HDL que pode hidrolisar e reduzir os peróxidos lipídicos nas lipoproteínas e nas lesões ateroscleróticas (AVIRAM et al., 1998). Pelo fato da oxidação da LDL na parede arterial ser um evento chave no início da aterogênese, os agentes que possam prevenir a oxidação dessa lipoproteína poderiam atenuar o desenvolvimento da aterosclerose.

Em estudos elucidando a relação de lipoproteína oxidada e aterosclerose HULTHE e FAGERBERG (2002) mostraram que a LDL modificada por oxidação in vivo apresenta características inflamatórias e isso favorece a ativação de citocinas e agentes quimiotáticos que são associados à aterosclerose.

A detecção da LDL oxidada, de auto-anticorpos e anti-lipoproteínas oxidadas têm confirmado a presença de lipoproteína oxidada in vivo, assim como a participação do sistema imunológico nos processos de dislipidemias e DCV (YLA-HERTUALA, 
1994). Adicionalmente, evidências sugerem que níveis elevados de auto-anticorpos anti LDL oxidada estão correlacionados com a progressão das DCV em humanos (SWEETS et al., 2001; INOUE, et al., 2001).

\subsubsection{Impacto econômico}

Diversos indicadores de saúde apontam as doenças cardiovasculares como uma das principais causas de aposentadorias, internações e mortalidade. No Brasil, as DCV contribuem significativamente como grupo causal de mortalidade em todas as regiões.

Segundo dados do sistema de informações sobre mortalidade do DATASUS (Ministério da Saúde), em 2002 o coeficiente de mortalidade por doenças cardiovasculares era de aproximadamente 442/100 mil habitantes (MANSUR et al., 2002).

Em dados mais atuais, a região Sudeste demonstrou o maior coeficiente de mortalidade por doenças do aparelho circulatório (207 mortes por 100 mil habitantes), enquanto a média brasileira no mesmo ano foi de 169 mortes/100 mil habitantes (BRASIL, 2005).

LOTUFO (1998) comparou a mortalidade entre oito capitais brasileiras com a de vários países e concluiu que o índice de mortalidade por DCV no Brasil foi o mais elevado, sendo que o percentual registrado para o sexo feminino foi maior que em todos os outros países. E ainda com relação ao Brasil, os dados de mortalidade por DCV mostram que houve um decréscimo em óbitos a partir de 1985, contudo a participação relativa das doenças cardiovasculares continua sendo a mais importante dentre as causas de óbito (MANSUR et al., 2001).

O ônus econômico das doenças cardiovasculares cresceu exponencialmente nas últimas décadas. Entre 1991 e 2000 os custos hospitalares atribuídos às DCV 
aumentaram 176\%, custando, aproximadamente, novecentos milhões de dólares ao sistema público de saúde em hospitalização no ano de 2000 , representando a $3^{\text {a }}$ causa de permanência hospitalar prolongada. Em 2005 os gastos do Ministério da Saúde com morbidades hospitalares das doenças do aparelho circulatório, em mulheres de 35 a 64 anos foi em torno de 350 milhões de reais (DATASUS, 2005).

E, seguindo as estatísticas dos países desenvolvidos e em desenvolvimento, também no Brasil, as doenças do sistema circulatório constituem a principal causa de óbito (32\%), sendo as doenças isquêmicas do coração responsáveis por até $80 \%$ dos episódios de morte súbita (BRASIL, 2005) (Figura 4).

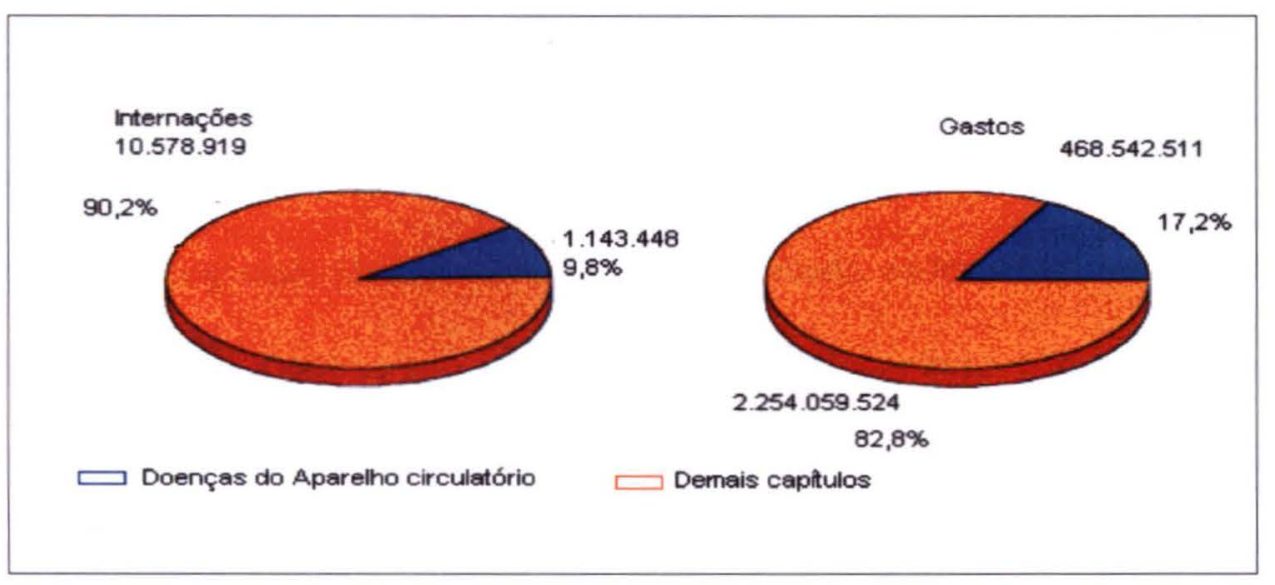

Figura 4 - Percentual de internações e gastos por DCV (CID 9 - cap. VII). Fonte - MS. (2002).

Segundo ARAÚJO e FERRAZ (2005), outro componente do impacto econômico não mensurado pelos formuladores de políticas de saúde é o custo indireto representado por improdutividade, absenteísmo e morte prematura decorrentes das doenças cardiovasculares.

Estatísticas recentes demonstram que em cada cinco brasileiros em idade adulta, um tem concentração de colesterol acima de $200,0 \mathrm{mg} / \mathrm{dL}$, ou seja 38,9 milhões de indivíduos têm colesterol classificado como limítrofe ou alto. Esses valores representam 
$21,6 \%$ da população brasileira e aproximam o Brasil das estatísticas norte americanas onde $25 \%$ da população tem níveis de colesterol total acima de $200 \mathrm{mg} / \mathrm{dL}$ (SBC, 2007).

De encontro aos fatos, dados estatísticos da Organização Mundial da Saúde (OMS) indicam que o aumento na incidência das DCV tende a persistir, agravando as condições de saúde dos países em desenvolvimento (OMS, 2006).

\subsubsection{Doenças cardiovasculares e climatério}

$\mathrm{Na}$ mulher as doenças cardiovasculares, que têm como as principais consequiências o infarto do miocárdio e o derrame cerebral, estão associadas de forma bem evidente, ao climatério. O infarto é decorrente da aterosclerose, que por sua vez, está relacionada a vários fatores de risco: dislipidemias, hipertensão arterial, diabete melito, tabagismo, obesidade, déficits nutricionais, sedentarismo, estresse e climatério. Com isso, o tratamento dos distúrbios da menopausa tornou-se multiprofissional englobando terapêutica psicológica, ambiental, física, ocupacional, medicamentosa e também alimentar (com ou sem adição de suplementos) (HALBE e FONSECA, 2000).

Estudos, como o de ALDRIGHI e ASAKURA (2001), elucidam esse mecanismo relatando que sob o ponto de vista epidemiológico, o hipoestrogenismo na mulher no climatério é o grande responsável pela alteração do perfil lipídico, estando já bem estabelecida a associação positiva entre esse fator e as doenças cardiovasculares. Corroborando com esses relatos TORNG et al. (2002) explicaram que nessa fase, em relação ao sistema cardio e cerebrovascular, o perfil lipídico sofre alterações aterogênicas: o colesterol total se eleva, principalmente após a menopausa; o HDL-C diminui em uma média de $13 \%$. Ainda no mesmo estudo, os autores esclarecem que isso ocorre porque os estrógenos oferecem uma proteção sobre o sistema vascular, 
diminuindo o risco de acidente vascular cerebral (risco relativo de 0,69 ) e de morte por acidente vascular cerebral (risco relativo de 0,37 ).

O estudo REGRESS comprovou que a redução significativa de CT e LDL-C decorrente do uso de hipolipemiantes levam à diminuição do número e duração dos episódios isquêmicos (SOLIMENE, 2000). Em estudo anterior, JOUSILAHTI et al. (1996) mostraram que em muitas populações o CT aumenta com o avanço da idade. Entre os homens, esse aumento cessa entre 45 e 50 anos, enquanto entre as mulheres, o aumento advindo com a menopausa continua acentuado até a idade de 60 a 65 anos.

SANTOS (2001) apoiando-se em dados da AMERICAN HEART ASSOCIATION (AHA, 2001) reafirmou o fato de indivíduos, grupos sociais ou etnias com dietas onde o percentual de gordura saturada é grande apresentarem níveis elevados de colesterol sérico e maior incidência de aterosclerose coronariana e aórtica em relação aos que consomem menor quantidade desse nutriente.

Sob essa ótica, a Sociedade Brasileira de Cardiologia (SBC, 2007) indica as dislipidemias, de forma contundente a elevação da LDL-C, como fatores fundamentais de risco para as DCV e importante indicador de doença isquêmica coronariana.

A obesidade, também decorrente do hipoestrogenismo constitui importante fator de risco cardiovascular; há uma relação quase linear entre índice de massa corpórea (IMC) e risco de DCV, a partir de um valor $\geq 25 \mathrm{~kg} / \mathrm{m}^{2}$. Esse risco, porém, não parece se distribuir de modo homogêneo em relação à idade e ao gênero podendo declinar com a idade e ser maior nas mulheres. Esse fato ficou evidente nos estudos de Framingham, (HO et al. 1993) e Nurse's Health Study (TANASESCU et al., 2004).

No tocante à faixa etária, as coronariopatias acometem indivíduos do sexo feminino com um retardo de cerca de 10 anos em relação à população masculina, 
tornando-se a maior causa de mortalidade entre mulheres acima de 50 anos (CONTI et al., 2002).

Em relação ao hábito de fumar YUSUF et al. (2004), investigando fatores de risco para infarto no miocárdio em 52 países, concluíram que indivíduos fumantes apresentam alterações em marcadores inflamatórios e hematológicos e nos componentes da coagulação. Em ambos os sexos, o risco de desenvolver infarto agudo do miocárdio é três vezes maior em pacientes que continuam a fumar após um evento coronariano, comparativamente a pacientes que abandonam o fumo, independente da faixa etária.

\subsection{ACIDOS GRAXOS POLINSATURADOS}

Os ácidos graxos polinsaturados (AGPI) possuem alto valor energético, além disso, têm grande importância pelo seu papel farmacológico. Pesquisas mostram que é de grande relevância a sua participação nas reações inflamatórias e ressaltam o fato de estarem diretamente relacionados à resistência imunológica, distúrbios metabólicos, processos trombóticos e doenças neoplásicas (COLI et al., 2003), notadamente o ácido linoléico e $\alpha$-linolênico, por não serem sintetizados pelo organismo constituem-se em ácidos graxos polinsaturados essenciais (AGPE).

Por sua vez, os AGPE compõem uma classe de moléculas que não podem ser geradas pelo organismo, mas que são necessárias ao seu funcionamento. Neste grupo encontram-se os ácidos graxos polinsaturados com a primeira dupla ligação ocorrendo no terceiro ou no sexto átomo de carbono a partir do carbono metílico terminal, $\omega$-3 e $\omega$ 6, respectivamente. A essencialidade destas famílias para os mamíferos, em geral, se dá uma vez que o organismo animal necessita de dessaturases que insiram duplas ligações entre os carbonos 3-4 e 6-7 na porção terminal da molécula de ácido graxo (CURI et al., 1997). 
Os principais representantes da família $\omega$-3 são o ácido $\alpha$-linolênico ou ALA (18:3 $\omega$-3), o ácido eicosapentaenóico ou EPA (20:5 $\omega$-3) e o ácido docosahexaenóico ou

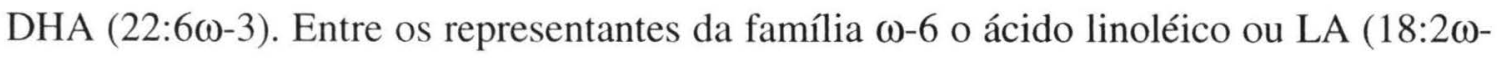
6) e o ácido araquidônico ou AA (20:4 $\omega$-6) são considerados os mais expressivos.

O ácido linolênico tem como principais fontes as plantas e animais marinhos, principalmente os fitoplânctons, as algas e os óleos de peixes. Os fitoplânctons, que se constituem na base da cadeia alimentar dos oceanos, sintetizam os ácidos eicosapentaenóico (EPA) e docosahexaenóico (DHA), os quais são encontrados em grande concentração nos óleos de peixes e em peixes de águas frias e profundas, principalmente cavala, sardinha, salmão e truta (CONOR, 2000; LUZIA et al., 2003; MARKI et al., 2003).

Por outro lado os ácidos graxos polinsaturados, por possuírem em sua estrutura química dupla ligações, são alvos preferenciais da peroxidação lipídica, resultando em radicais livres lesivos aos tecidos (LAIDLAW e HOLUB, 2003).

\section{Estrutura química e metabolismo}

Os AGPI eicosapentaenóico (20:5

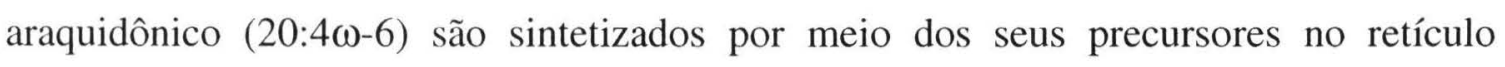
endoplasmático liso, especialmente no fígado, por sucessivas reações de dessaturações (oxidação com formação de duplas ligações) e alongamentos (CURI et al., 2002).

O ácido linoléico (18:2 $\omega$-6) forma o $\gamma$-linolênico (18:3 $\omega$-6), que é convertido em ácido araquidônico (20:4 $\omega$-6). Este é precursor da síntese de eicosanóides. Os eicosanóides são produzidos nos tecidos, sendo responsáveis pela formação especificamente das prostaglandinas da série 2, tromboxano A (TXA) e leucotrienos da série 4 , mediadores bioquímicos potentes envolvidos na inflamação, infecção, lesão tecidual, modulação do sistema imune e agregação plaquetária. Em outra via, o ácido $\alpha$ - 
linolênico (18:3 $\omega$-3) é convertido, de forma lenta em ácido eicosapentaenóico (EPA) e docosahexaenóico (DHA), precursores de mediadores químicos menos potentes, as prostaglandinas da série 3, tromboxano A e leucotrienos da série 5, que atuariam no processo anti-inflamatório e não inibiriam o sistema imune (CURI et al., 2002).

A produção da prostaciclina é favorecida pela ação dos ácidos graxos $\omega$-3, que têm os efeitos opostos aos $\omega$-6 e atuam na prevenção da formação de coágulos e na vasodilatação (MAHAN e SCOTT-STUMP, 1993). Por esse motivo, considera-se que os ácidos graxos $\omega$-3 têm papel maior no mecanismo de defesa do sistema imune, enquanto que os ácidos graxos $\omega$-6 participam de forma mais efetiva do processo inflamatório (Figuras 5 e 6).

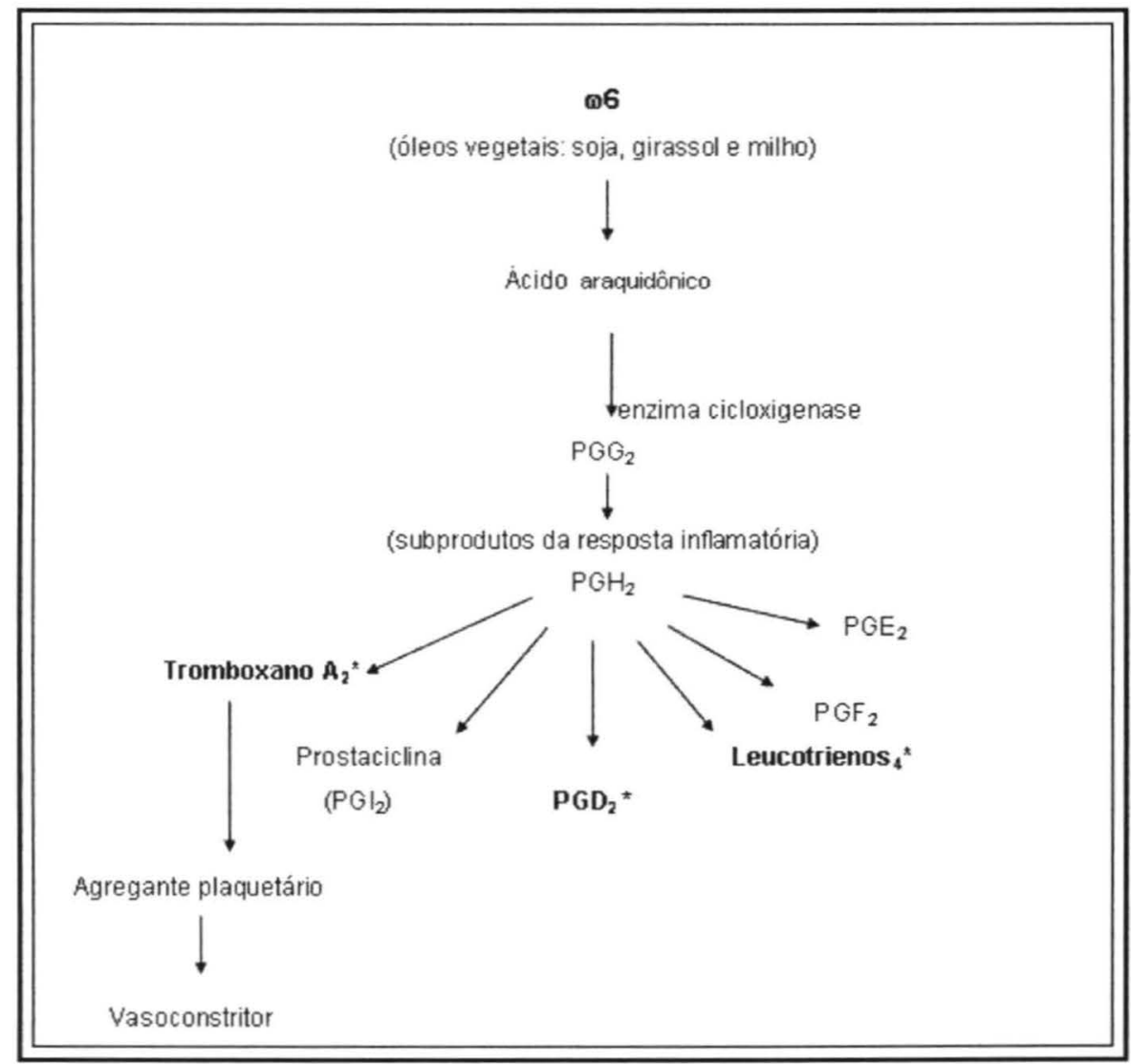

Figura 5 - Mediadores bioquímicos potentes envolvidos na inflamação, infecção, lesão tecidual, modulação do sistema imune e agregação plaquetária. 


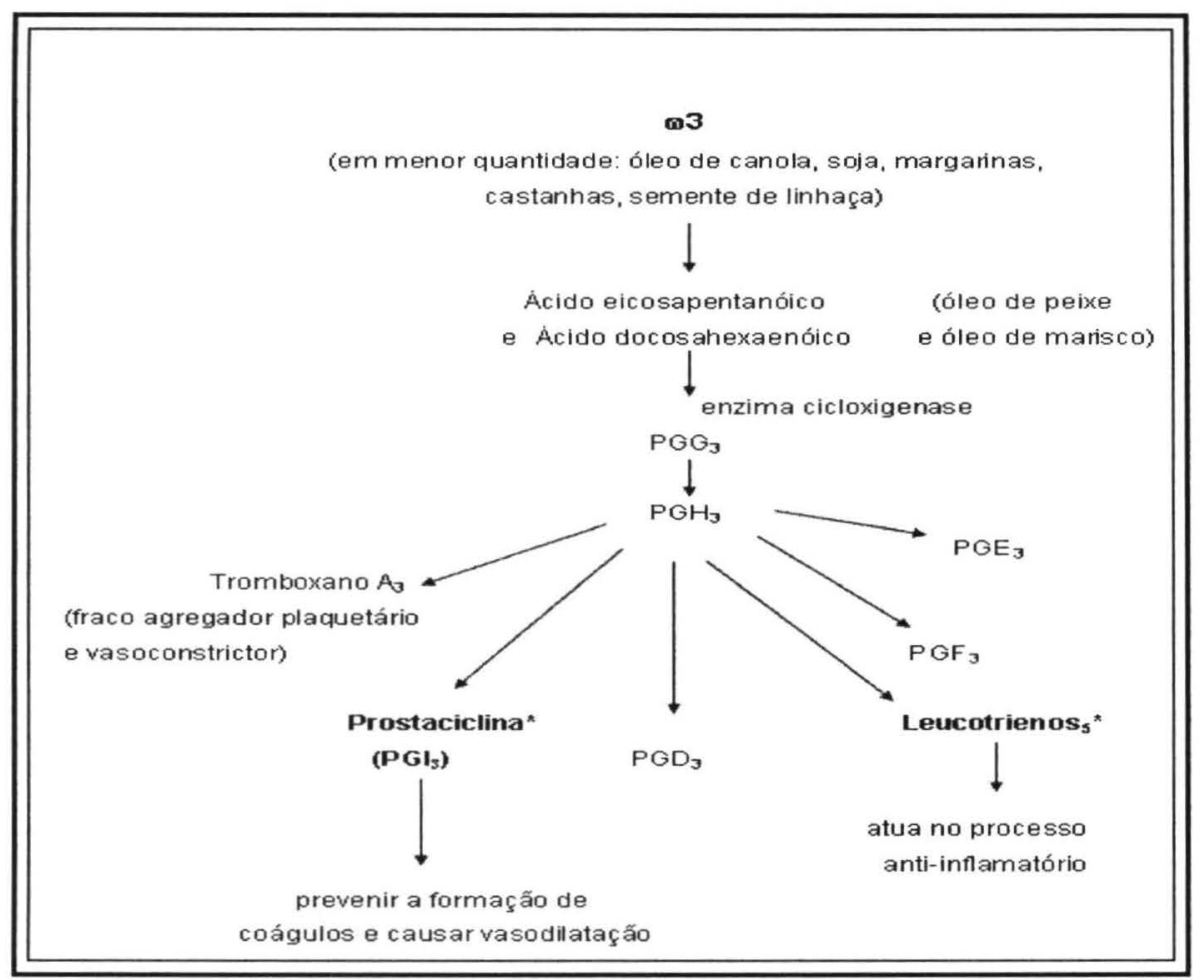

Figura 6 - Mediadores bioquímicos menos potentes que a do $\omega 6$, que atuam no processo antiinflamatório e não inibem o sistema imune.

\subsection{VITAMINA E}

Vitamina E é um termo genérico usado para designar todos os tocoferóis e tocotrienóis e que possuem atividade biológica. Os tocoferóis e tocotrienóis que ocorrem naturalmente incluem as formas $d-\alpha, d-\beta, d-\gamma$ e $d-\delta$, todos possuem uma cadeia lateral fitil saturada e um grupo hidroxila no anel cromanol promovendo suas diferenças (WU et al., 1999) (Figura 7). 


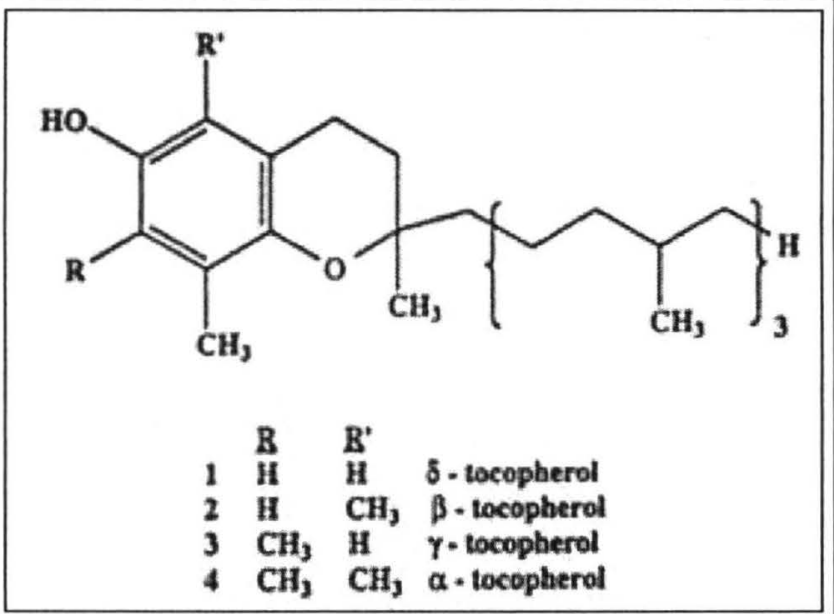

Figura 7 - Estrutura molecular dos tocoferóis

No tocante ao metabolismo, a vitamina $\mathrm{E}$ age como o principal antioxidante lipossolúvel presente no plasma e nos tecidos. Análises estruturais mostraram que as formas de suas moléculas incluem quatro tocoferóis $(\alpha, \beta, \gamma$ e $\lambda)$ e quatro tocotrienóis $(\alpha, \beta, \gamma$ e $\lambda)$. O $\alpha$-tocoferol é a forma mais abundante dessa vitamina e tem a maior atividade biológica. Presente na partícula LDL, ele rompe ligações e bloqueia a reação em cadeia da peroxidação lipídica ao seqüestrar radicais peroxila intermediários. A diminuição nos níveis de vitamina E pode indicar aumento da exposição ao estresse oxidativo (SCHWEDHELM, 2003).

A atividade antioxidante da vitamina $\mathrm{E}$ tem levado muitos pesquisadores a estudar sua capacidade de prevenir doenças crônicas, principalmente aquelas que se acreditam ter um componente de estresse oxidativo, como as doenças cardiovasculares (DCV), aterosclerose e câncer (RUMLEY et al., 2004; SAMEERA et al. 2007).

Com esse objetivo, SUN et al. (1997) adicionaram $\alpha$-tocoferol à dieta de coelhos hipercolesterolêmicos e observaram diminuição significativa na oxidação da LDL e nas lesões ateroscleróticas na aorta.

Pacientes do sexo masculino hipercolesterolêmicos que fizeram administração de vitamina E concomitante com sinvastatinas foram acompanhados em trabalho de 
NEUNTEUFL et al. (1998). Os autores concluíram que a vitamina E promoveu resultados mais efetivos quanto ao aumento de função endotelial da artéria braquial, comparando com a administração apenas da droga.

STAMPFER et al. (1993), em estudo de observação prospectivo, relataram que o consumo diário de 200 UI de vitamina $\mathrm{E}$ foi associado à redução de $40 \%$ no risco de coronariopatias e que o consumo de 100 UI diárias da mesma vitamina reduziu a progressão da doença coronariana já existente. Mediante esses fatos, há tendência em se acreditar que o efeito antioxidativo protetor para DCV só é obtido com o consumo mínimo diário. No entanto, autores observaram que 100 UI de vitamina E é uma quantidade impossível de ser conseguida somente pela dieta (O'KEEFE et al.,1996); o restante teria que ser alcançado com suplementação (MEYDANI, 2000).

O enriquecimento da LDL com $\alpha$-tocoferol parece proteger essa lipoproteína de modificações oxidativas in vitro (BERLINER et al., 1996), no entanto os autores afirmam que são controversos os resultados dos estudos de intervenção.

No tocante ao metabolismo, sabe-se que a absorção máxima de vitamina E ocorre no intestino delgado e depende de emulsificação, solubilização, difusão por meio da camada de água, permeação pelos eritrócitos, incorporação às partículas de lipoproteínas e transporte da mucosa para a circulação (BIANCHINI-PONTUSCHKA e PENTEADO, 2003). Segundo os mesmos autores, poucos estudos reportaram absorção incompleta de vitamina $\mathrm{E}$ em humanos saudáveis, no entanto alguns fatores dietéticos têm sido apontados como redutores da sua biodisponibilidade.

Tabagismo também tem sido apontado como fator redutor da biodisponibilidade de vitamina E, segundo BERLINER \& HEINECKE (1996) a concentração sangüínea de vitaminas antioxidantes, em especial a vitamina E, parece estar diminuída nos tecidos 
arteriais de fumantes, devido, provavelmente, ao aumento dos requerimentos teciduais nesses indivíduos, ocasionado pelo elevado estresse oxidativo.

Tem-se estabelecido que, tanto em animais quanto em humanos, um aumento na ingestão de lipídios insaturados, especialmente AGPI, acelera a depleção e aumenta os requerimentos de vitamina $\mathrm{E}$ devido ao fato desses ácidos estarem concentrados, preferencialmente, nas membranas celulares, onde eles têm uma capacidade de seqüestrar certa quantidade de vitamina $\mathrm{E}$ para manter sua estabilidade oxidativa (MOURÃO et al., 2005).

A despeito da ação protetora para DCV relacionada à vitamina $\mathrm{E}$, os autores EICHHOLZER et al. (2001) citaram em sua revisão bibliográfica estudos epidemiológicos que não encontraram associação significativa entre ingestão de $\alpha$ tocoferol e diminuição de doenças cardiovasculares. Os autores consideram que os resultados para vitamina E quanto à prevenção de DCV são ainda inconclusivos. 
CAPÍTULO 2

Efeito da suplementação com óleo de peixe e vitamina $E$ no perfil lipídico de dois grupos étnicos de mulheres com dislipidemias no climatério 


\section{APÍTULO 2 - Efeito da suplementação com óleo de peixe e vitamina E no} perfil lipídico de dois grupos étnicos de mulheres com dislipidemias no climatério

\subsection{INTRODUCÃO}

A partir dos anos 60 com a entrada da mulher no mercado de trabalho, e conseqüentemente com maior exposição ao estresse, fumo e maus hábitos alimentares, a taxa de mortalidade, tendo como causa as doenças cardiovasculares (DCV) rapidamente se elevou (SOUZA, 2005).

A saúde da mulher no climatério e após esse período, é um campo de pesquisas em expansão, tanto no que se refere à prática médica como na investigação científica de várias áreas do conhecimento. Trata-se de uma área de grande importância e impacto social especialmente em países em desenvolvimento (PEDRO et al, 2003).

Atualmente as doenças cardiovasculares constituem a mais importante causa de morte e incapacidade em ambos os sexos em todas as regiões do país e no mundo ocidental (CASTANHO et al. 2001; NAHAS, 2001; BOUCHARD, 2003). No Brasil, em 1999, as cardiopatias contribuíram como causa em $32 \%$ de todos os óbitos (DATASUS, 2005).

A morte causada por DCV é maior em homens (39\%) que na população do sexo feminino entre 45 e 64 anos, entretanto depois dessa faixa etária a taxa de mortalidade por DCV em mulheres ultrapassa a apresentada pelo sexo masculino em 22\% (NCHS, 1997) e supera doenças como câncer de mama e AIDS (BERWANGER, 2005). FELDMAN (1996) relatou que os níveis séricos de colesterol em mulheres na pósmenopausa, excedem aos apresentados pelos homens e, além disso, os níveis de triglicérides podem aumentar de 50 a $75 \%$ com a idade. 
O início da equivalência nas taxas de eventos cardiovasculares entre os sexos coincide com o advento da menopausa e conseqüentemente com a privação estrogênica (BRENNER, 1988; ALDRIGHI et al., 2005; SANCHES et al., 2006).

Dados fornecidos pelo NCHS (2005) demonstram que a prevalência de DCV em mulheres negras entre 45 e 64 anos é de 13,5\%, superior à apresentada por mulheres brancas na mesma faixa etária, que se encontra por volta de $12,1 \%$.

Aproximadamente $2 / 3$ das mulheres que sofrem morte súbita por DCV não apresentam sintomas prévios. Em mulheres negras brasileiras as mortes por DCV são $34 \%$ maiores que em mulheres de etnia branca, entre os motivos mais alarmantes estão a prevalência aumentada das dislipidemias, obesidade e diabetes (WAJINGARTEN et al, 2004).

Diversos estudos epidemiológicos, a partir do estudo de Framingham têm fornecido dados que permitiram uma maior compreensão dos riscos envolvidos na etiologia das doenças cardiovasculares (CERVATO et al., 1997; MACAMBIRA et al., 2001; AVEZUM et al., 2005).

Outro estudo de semelhante importância foi o INTERHEART (YUSUF et al., 2004), com delineamento caso-controle, no qual foi avaliada, de forma sistematizada, a importância de fatores de risco para doença arterial coronariana ao redor do mundo (252 centros em 52 países dos cinco continentes). Nessa avaliação nove fatores de risco explicaram mais de $90 \%$ do risco atribuível para infarto agudo do miocárdio (IAM): tabagismo, juntamente com dislipidemia compreendeu mais de dois terços deste risco.

No Brasil o estudo de referência é o AFIRMAR (PIEGAS et al., 2003) desenvolvido em 104 hospitais de 51 cidades brasileiras, onde os resultados foram, praticamente, os mesmos encontrados no INTERHEART. Com esses dados, 
corroboraram-se as evidências de que a predisposição de fatores de risco para DCV no Brasil é muito semelhante àquela observada em países da Europa e América do Norte.

\section{Suplementação}

Em várias partes do mundo, diversos são os trabalhos relativos ao papel do pescado na alimentação humana, por ser uma fonte rica em ácidos graxos polinsaturados, principalmente aqueles da família ômega-3 ( $\omega-3)$ (HEARN et al., 1987; ACKMAN, 1989a; NETTLETON e EXLER, 1992; FALUDI et al, 2001; LUZIA et al., 2003). Pesquisas indicam que os ácidos pertencentes à família $\omega-3$, particularmente o ácido eicosapentaenóico (EPA) interferem na produção de prostaglandina trombótica e tromboxano (BRONSGEEST-SCHHOUTE et al., 1981; BUDOVSKI, 1981; GOODNIGHT et al., 1982) ou são transformadas em prostaglandinas antitrombóticas (DYERBERG, 1978; NEDDLEMAN et al., 1979; DYERBERG et al., 1986). Em altas doses (4 a $10 \mathrm{~g} /$ dia) reduzem os níveis de triglicérides (TG) e aumentam discretamente o HDL-C. Podendo, entretanto, aumentar o LDL-C. Em portadores de doença arterial coronária, a suplementação de $1 \mathrm{~g}$ /dia de $\omega$-3 em cápsulas, reduziu em $10 \%$ os eventos cardiovasculares (infarto do miocárdio e acidente vascular cerebral) (VON SCHACKY et al., 1999).

O desequilíbrio no metabolismo das lipoproteínas é o mais evidente fator de risco para o desenvolvimento das DCV. Os fatores dietéticos desempenham papel relevante para o estabelecimento dessas disfunções. Estudos relacionados com dietas suplementares de peixes ou óleos de peixes (FOULON et al., 1999; FALUDI et al., 2001; NELSEN-VERGILI, 2003) e derivados de $\omega$-3 (FALUDI et al., 2001; NELSENVERGILI, 2003) documentam os efeitos benéficos dos ácidos graxos polinsaturados, 
além disso, nesses últimos anos têm surgido no mercado vários suplementos à base de óleo de peixe e/ou derivados.

Os dados apresentados por institutos de pesquisas mostram que a ingestão recomendada para os ácidos graxos essenciais sofre alguma variação. De acordo com a Food and Agriculture Organization (FAO) esse valor é em torno de 3\% para o ácido linoléico e de $0,5 \%$ a $1,0 \%$ da energia total da dieta para o ácido linolênico. As recomendações do Food and Nutrition Board of the National Academies (Institute of Medicine - USA, 2002) são para ingestão de ácidos graxos essenciais em torno de $10 \%$ do total de lipídios na dieta, sendo que este valor varia de 5 a $10 \%$ para os ácidos graxos $\omega-6$ e de 0,6 a 1-2\% para os ácidos graxos $\omega$-3. O National Institute of Health, em Workshop realizado em abril de 1999 em Bethesda (Maryland, USA), recomendou que a ingestão ideal de $\omega-3$ para adultos sob uma dieta de 2000 kcal deve ser de $2,22 \%$. No Brasil, a ANVISA recomenda ingestão diária de 500 a 1000 mg (ANVISA, 1995).

A AMERICAN HEART ASSOCIATION (AHA) tem confirmado a importância incontestável das fibras alimentares, peixes e antioxidantes na prevenção e controle das DCV. Em relação aos lipídios, determinou que para indivíduos com DCV pré-existente o consumo deve ser em torno de $25 \%$ a $35 \%$, com teor menor que $7 \%$ de saturados, até 10\% de polinsaturados e menor que $200 \mathrm{mg}$ de colesterol por dia (AHA, 2001).

Além de recomendar o consumo diário de peixe, a AHA sugeriu a sua alternância com suplemento à base de peixe em cápsula (aproximadamente $900 \mathrm{mg} / \mathrm{dia}$ ), com o objetivo de sanar ou diminuir a carência de ingestão de pescado em alguns indivíduos com intolerância ao seu sabor (AHA, 2001).

KRIS-ETHERTON et al. (2003) relataram que suplemento de EPA e DHA (1 a 4 g/dia) pode reduzir a taxa de triglicérides de $20 \%$ a $40 \%$. 
Conhecendo a menopausa como fator de risco para DCV, FOLSON e DEMISSIE (2004) acompanharam a taxa de mortalidade em mulheres pós-menopausadas com ingestão aumentada de peixes e óleo de peixes. Os autores encontraram diminuição no risco para DCV, porém essa relação não foi independente.

Em relação às dislipidemias e prevenção da aterosclerose a SBC, em sua IV Diretriz, confirmou o benefício do uso dos ácidos graxos da família $\omega$-3 como terapia adjuvante na hipertrigliceridemia ou em substituição aos fibratos, niacina ou estatinas em pacientes intolerantes (SBC, 2007).

Os efeitos hipolipidêmicos, antitrombóticos e antiinflamatórios dos AGPI da família $\omega$-3 têm sido extremamente estudados em diversos modelos e populações. Poucos são os estudos que, no Brasil, se preocuparam com a etnia na menopausa. Esses indícios aliados ao fato da população feminina na menopausa apresentar altos níveis de eventos cardíacos, confirmaram a relevância do tema e nos motivaram a realizar um estudo que investigasse o efeito da suplementação com óleo de peixe em cápsula, combinado ou não com vitamina E, no perfil lipídico de mulheres brancas e negras com dislipidemias no climatério. 


\subsection{OBJETIVOS}

\subsubsection{Geral}

Investigar o efeito da suplementação com óleo de peixe em cápsula, combinado ou não com vitamina E, no perfil lipídico de mulheres brancas e negras com dislipidemias no climatério.

\subsubsection{Específicos}

\section{Avaliar:}

- Perfil lipídico da população de estudo;

- Relação entre etnia e suplementação com ácidos graxos polinsaturados e,

- O efeito da suplementação com ácidos graxos. 


\subsection{CASUÍSTICA e MÉTODOS}

\subsubsection{População de estudo}

O presente estudo foi realizado por período de três meses (90 dias), em grupo de pacientes voluntárias formado por mulheres com dislipidemias no climatério, sendo 29 de etnia negra e 30 de etnia branca. Todas foram selecionadas por meio de prontuários cedidos por três unidades do Programa Saúde da Família (PSF) de Pindamonhangaba. Esse grupo foi submetido à suplementação com $1000 \mathrm{mg} /$ dia de óleo de peixe em cápsula, combinada ou não com 400 mg/dia de vitamina E, também em cápsula.

Critérios de inclusão da população. Mulheres com idade entre 40 e 65 anos, de etnia branca ou negra, residentes na cidade de Pindamonhangaba e cadastradas no PSF do município. Deveriam ter diagnóstico de hipercolesterolemia isolada (CT > 220 $\mathrm{mg} / \mathrm{dL}$ ) e/ou hipertrigliceridemia isolada ( $\mathrm{TG}>150 \mathrm{mg} / \mathrm{dL}$ ) de acordo com o valor de referência desejável determinado pela IV Diretriz Brasileira de dislipidemia (SBC, 2007).

Critérios de exclusão da população: Mulheres de etnia oriental, com ocorrência atual ou pregressa de diabete melito, doenças hepáticas, doenças renais, diarréias crônicas, fazendo uso de estatinas e/ou outros fármacos que interferissem nos lipídios plasmáticos, fazendo uso de suplemento à base de óleo de peixe, também foram excluídas mulheres em terapia de reposição hormonal, com diagnóstico de hipotiroidismo, grávidas e com dificuldade de locomoção. 


\subsubsection{Considerações éticas}

As pacientes elegíveis receberam visitas domiciliares das agentes comunitárias que tiveram como objetivo convidá-las para participação no estudo. Na data agendada, em reunião coletiva foram orientadas sobre os objetivos da pesquisa e os procedimentos a serem utilizados. Todas receberam a garantia de que a participação seria gratuita, o suplemento seria doado, a participação não seria obrigatória e que a recusa em participar ou desistência, em qualquer momento, não afetaria a rotina do atendimento no PSF. Foi assegurada confidencialidade dos dados e garantia de receberam retorno sobre os resultados das análises bioquímicas, em reuniões realizadas durante o período da suplementação. As dúvidas que persistiram foram esclarecidas em consultas individuais e, em seguida, as mulheres que aceitaram participar da pesquisa assinaram o termo de consentimento pós-informado seguindo as normas do Conselho Nacional de Saúde no que se refere à Ética em pesquisas com Seres Humanos (CNS - BRASIL, 1996).

O presente estudo foi analisado e aprovado pelo Comitê de Ética em Pesquisa da Faculdade de Saúde Pública da Universidade de São Paulo (ANEXO 1). O consentimento esclarecido por escrito ou impressão digital foi obtido de todas as participantes do estudo (ANEXO 2).

\subsubsection{Local de estudo}

O município de Pindamonhangaba situa-se na região central do Vale do Paraíba, leste do Estado de São Paulo. A área urbana conta com $176,45 \mathrm{~km}^{2}$ e a rural com 342,45 $\mathrm{Km}^{2}$; a população segundo censo demográfico de 2000 é de 126.026 habitantes, sendo 63.149 do sexo feminino (Figura 1). 


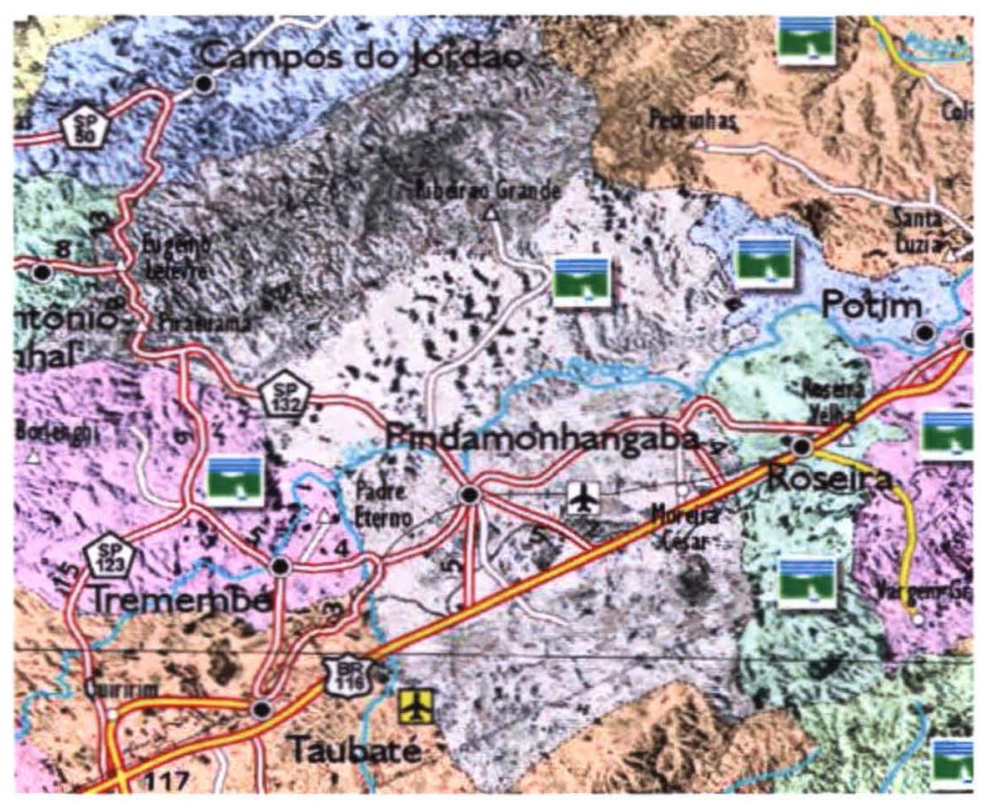

Figura 1 Mapa do município de Pindamonhangaba - SP

A população de estudo foi selecionada entre todos os prontuários e cadastros de pacientes atendidas no Programa Saúde da Família do Município.

Esse Programa teve início em 1994, como uma estratégia proposta pelo governo federal aos municípios para promover a atenção básica. O PSF é tido como uma das principais ações de reorganização dos serviços e de reorientação das práticas profissionais neste nível de assistência, promoção da saúde, prevenção de doenças e reabilitação.

O PSF de Pindamonhangaba está, atualmente, estruturado com 14 Unidades de Saúde da Família e 56 profissionais de saúde (14 médicos, 14 enfermeiros e 28 auxiliares de enfermagem, além de equipes de agentes comunitários), cobrindo 35.502 pessoas, destas 3.566 mulheres com idade entre 35 e 69 anos (BRASIL 2005b). 


\subsubsection{Desenho do estudo}

O estudo foi do tipo randomizado controlado por placebo, com coletas de dados primários (PEREIRA, 1995; FILHO e ROUQUAYRIOL, 2003).

Oitenta e sete mulheres com idade entre 40 e 65 anos, participantes do Grupo de Dislipidemia do PSF foram sondadas quanto à concordância em participar do estudo.

Embora não haja evidências de risco para consumo de ácidos graxos polinsaturados e $\alpha$-tocoferol na dosagem recomendada neste estudo, foi aconselhado às participantes que interrompessem o consumo, caso sentissem algum desconforto clínico.

\section{$\underline{\text { Fases de execução do estudo }}$}

A seleção das pacientes dentro dos critérios de inclusão do estudo foi realizada por meio dos prontuários cedidos pelas unidades de PSF.

1. Agendamento de reunião inicial, explicando todos os procedimentos do estudo (ANEXO 3). Ao final, assinatura do termo de compromisso de participação através do consentimento pós-informado (ANEXO 2);

2. Consulta 1 - agendada para coleta de sangue das pacientes participantes do estudo (baseline);

3. Após a confirmação dos níveis alterados de colesterol total e frações e triglicérides, ocorreu a divisão aleatória de três grupos de estudo para cada etnia (Momento 0);

4. Fornecimento de cápsulas placebo, cápsulas de óleo de peixe e cápsulas de vitamina E, com as devidas orientações de uso; e realização do questionário e medidas antropométrica (ANEXO 4);

5. Acompanhamento para certificação do consumo (foi feito durante todo o período por meio de visitas domiciliares realizadas pelas agentes comunitárias das Unidades de PSF envolvidas); 
6. Consulta 2 - agendada para coleta de sangue das pacientes participantes do estudo (45 dias - Momento 1);

7. Na mesma consulta, fornecimento das cápsulas placebo, cápsulas de óleo de peixe e de vitamina $E$, com as devidas orientações de uso e,

8. Consulta 3 - agendada para coleta de sangue das pacientes participantes do estudo. (90 dias - Momento 2).

Os momentos determinados para a suplementação estão demonstrados no fluxograma abaixo:
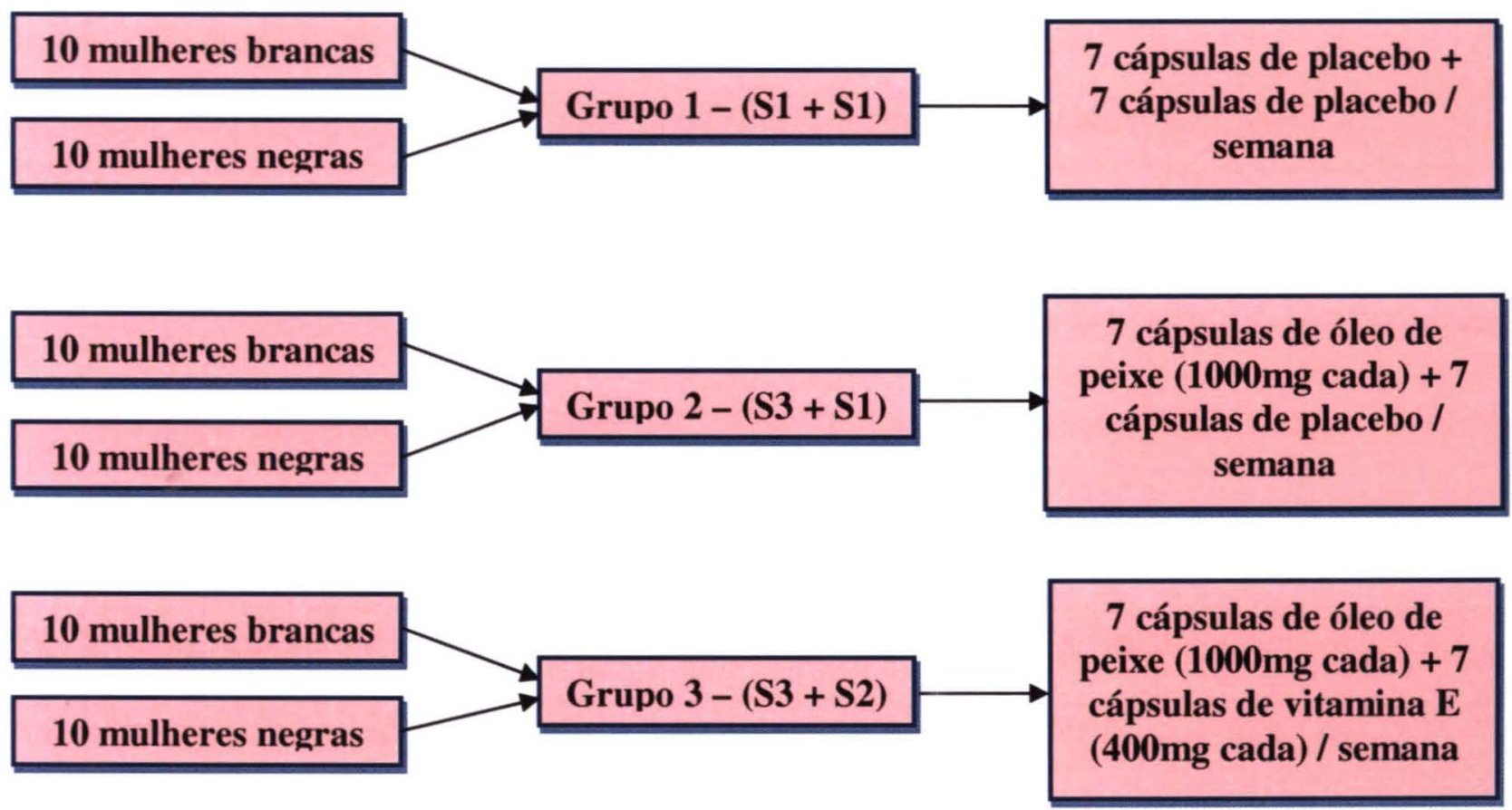

S1 + S1 - Grupo controle (placebo); S3 + S1 - Grupo com intervenção à base de óleo de peixe e cápsula placebo;

$\mathbf{S 3}+\mathbf{S 2}$ - Grupo com intervenção à base de óleo de peixe combinado com vitamina $\mathrm{E}$. 


\subsubsection{Coleta de dados}

A partir do termo de consentimento pós-informado, devidamente assinado por todas as mulheres incluídas na população de estudo, seguindo as normas do Conselho Nacional de Saúde no que se refere à Ética em pesquisas com Seres Humanos (CNS BRASIL, 1996) foram seguidos os procedimentos do protocolo da pesquisa.

\subsubsection{Questionário}

O Questionário foi aplicado a todas as participantes do estudo e estruturado com as seguintes informações: identificação (nome e endereço), características demográficas (idade, escolaridade em anos de estudos, ocupação atual, renda mensal per-capita, raça/etnia auto-referida), estilo de vida (tabagismo, consumo de bebidas alcoólicas e atividade física), dados antropométricos, história médica (tempo de dislipidemia, uso de medicamentos, doenças prévias e/ou associadas, tratamentos) (ANEXO 4).

\subsubsection{Avaliação Antropométrica}

Após o preenchimento do questionário, foram aferidas as medidas de peso $(\mathrm{kg})$, altura $(\mathrm{cm})$, circunferência abdominal $(\mathrm{cm})$ e quadril $(\mathrm{cm})$. As participantes se encontravam sem calçados e usando roupas leves. O peso foi aferido por meio de balança para adultos com escala antropométrica, capacidade $150 \mathrm{~kg}$., precisão de 100 gramas. A medida de altura foi determinada através de estadiômetro com capacidade de 80 a $220 \mathrm{~cm}$; tolerância $\pm 2 \mathrm{~mm}$ em $220 \mathrm{~cm}$ e resolução em milímetros. As medidas foram feitas em duplicata e a média foi utilizada para o cálculo do Índice de Massa Corporal (IMC) em kg/m², de acordo com critérios preconizados pela OMS (1997): baixo peso $(<18,5)$; eutrófico $(18,5$ a 24,9$)$; sobrepeso $(25,0$ a 29,9$)$ e obesidade $(\geq$ $30,0)$. 
As medidas dos perímetros da cintura e do quadril foram realizadas com fita métrica inelástica. A tomada da medida de circunferência abdominal foi realizada à altura da cicatriz umbilical, em ortostase e ao final de uma expiração suave, com a paciente em pé e em posição ereta, o abdome se encontrava relaxado, os braços ao lado do corpo e os pés juntos. A medida do quadril foi obtida colocando-se a fita métrica ao redor da região do quadril, na área de maior protuberância sem comprimir a pele (GROOT e STAVEREN, 1980).

\subsubsection{Coleta sangüínea}

A coleta de sangue foi realizada para determinação dos índices séricos iniciais (baseline) dos seguintes parâmetros: colesterol e suas frações, triglicérides e ácidos graxos. Os mesmos parâmetros foram analisados no meio da intervenção (45 dias) e repetidos ao final da intervenção (90 dias), para detectar as alterações ocorridas.

As amostra de sangue foram coletadas por punção venosa periférica, em um total de $20 \mathrm{~mL}$, por paciente, pelo sistema vacutainer. Sendo a coleta de sangue para análise dos parâmetros bioquímicos o único procedimento (método) que poderia ter representado risco ao paciente, cabe mencionar que o procedimento foi efetuado em cabines individuais, com utilização de material descartável e profissional habilitado para realização da coleta, seguindo padrões pré-estabelecidos de segurança, o que praticamente eliminou qualquer risco maior.

O sangue foi colhido sob EDTA (ácido etileno diamino-tetra-acético 1,0 mg/mL) (BD - Brasil) e em tubos gel seco. Os pacientes obedeceram 12 horas de jejum, visando reduzir as modificações oxidativas durante o armazenamento $\left(-20^{\circ} \mathrm{C}\right)$. Os tubos com plasma, destinados à análise de $\alpha$-tocoferol foram envoltos em papel alumínio para proteção da luz, mantido sob refrigeração em caixas isotérmicas e centrifugados em até uma hora após a coleta. No laboratório de bioquímica o sangue passou por 
centrifugação (3.000rpm/15 minutos/temperatura ambiente), $1 \mathrm{~mL}$ do plasma foi aliqüotado em microtubos de eppendorff e nessas alíquotas foram acrescentados os seguintes inibidores de protease: aprotinina $(10,0 \mu \mathrm{g} / \mathrm{mL})$, benzamidina $(10,0 \mu \mathrm{g} / \mathrm{mL})$, fluoreto de fenilmetilsulfonila-PMSF $(5,0 \mu \mathrm{g} / \mathrm{mL})$ e antioxidante 2,6 di-ter-butil-phidroxitolueno BHT $(100,0 \mu \mathrm{g} / \mathrm{mL})$. Todos os reagentes foram de marca Sigma Chemical ${ }^{\circledR}($ ST, Louis, MO, USA).

Os resíduos biológicos não utilizados no experimento foram descartados seguindo Normas de Segurança Laboratorial (OMS, 2004).

\subsubsection{Avaliação Bioquímica}

As análises de perfil lipídico foram realizadas no Laboratório Municipal de Pindamonhangaba (Laboratório Dr. Paulo Emílio d'Alessandro)

A partir do plasma sangüíneo obtido foram realizadas as seguintes análises bioquímicas: Colesterol total (CT), triglicérides (TG), frações de HDL-C. E calculadas as frações de LDL-C e VLDL-C, assim como o índice de Castelli I.

2.3.6.1 Determinação de lipídios plasmáticos:

- Colesterol Total e Triglicérides

As análises de colesterol total (CT), e triglicérides (TG) foram realizadas de forma automatizada em aparelho de marca ROCHE/HITACHI 912 Analyzer System, obedecendo ao método enzimático-colorimétrico, utilizando "Kits" bioquímicos da marca Roche ${ }^{\circledR}$.

- Frações de HDL-C

As análises referentes à HDL-C foram realizadas de forma automatizada em aparelho de marca ROCHE/HITACHI 912 Analyzer System, obedecendo ao método enzimático-colorimétrico, utilizando “Kits” bioquímicos da marca Roche ${ }^{\circledR}$. A dosagem 
do colesterol HDL-C foi realizada mediante a separação, por precipitação seletiva, das demais lipoproteínas e no sobrenadante, separado por centrifugação, onde as HDL se encontram.

- Frações de LDL-C e VLDL-C

Para encontrar os valores de LDL-C e VLDL-C, utilizou-se cálculo baseado na equação de FRIEDEWALD* (SBC, 2001):

\section{LDL-C $=$ CT $-($ HDL-C + TG/5)* $\quad$ VLDL-C $=$ TG/5}

A formula é aplicada se a concentração de triglicérides for menor que $400 \mathrm{mg} / \mathrm{dL}$.

- Índice de Castelli I

O índice de Castelli I foi determinado como a razão entre o CT e HDL-C (CASTELI et al, 1983).

\subsubsection{Determinação de ácidos graxos:}

\section{Esterificação e quantificação dos ácidos graxos.}

A extração e a separação dos lipídios foram realizadas de acordo com MARMER e MAXWELL (1981). Os ácidos graxos foram determinados por meio da saponificação de alíquotas de extrato lipídico, onde $100 \mathrm{~mL}$ de lipídios foram metilados de acordo com o método de METCALFE et al. (1966). Para isso, foi tomada uma alíquota de $100 \mu \mathrm{L}$ de plasma, em seguida adicionou-se $4 \mathrm{~mL}$ de $\mathrm{NaOH}$ metanólico $(0,5$ N) à amostra, após esse procedimento a amostra foi homogeneizada e mantida em banho-maria sob ebulição (2 minutos), após resfriamento imediato foi adicionado à amostra $3 \mathrm{~mL}$ de trifluoreto de boro - Metanol $\mathrm{BF}_{3}$ (Merck), agitou-se levemente e novamente a amostra foi levada ao banho-maria sob ebulição (2 minutos). Em seguida na amostra resfriada de imediato, foram adicionados $3 \mathrm{~mL}$ de solução saturada de cloreto de sódio $(\mathrm{NaCl})$, os tubos foram agitados levemente e a eles adicionados $3 \mathrm{~mL}$ 
de Hexano (grau HPLC), separou-se a fase superior e novamente adicionou-se $3 \mathrm{~mL}$ de Hexano (grau HPLC) separando-se uma vez mais a fase superior que em seguida foi evaporada em atmosfera de nitrogênio até um volume aproximado de $1 \mathrm{~mL}$, este foi armazenado $\left(-26^{\circ} \mathrm{C}\right)$ em vials modelo 0221-34 274-91 com tampa e septo (SHIMADZU).

O perfil de ácidos graxos foi determinado em cromatógrafo a gás marca SHIMADZU, CG-2010, equipado com coluna capilar SP 2560 da SUPELCO de 100m de comprimento e $0,25 \mathrm{~mm}$ de diâmetro interno e espessura do filme $0,2 \mu \mathrm{m}$, o hidrogênio foi utilizado como gás de arraste com fluxo de $1,5 \mathrm{~mL} / \mathrm{min}$. As temperaturas do injetor e do detector foram de $250^{\circ} \mathrm{C}$ e $260^{\circ} \mathrm{C}$, respectivamente. A programação de temperatura da coluna foi de $140^{\circ} \mathrm{C}$ inicial com um acréscimo de $4^{\circ} \mathrm{C} / \mathrm{min}$, até atingir

um platô de $240^{\circ} \mathrm{C}$, permanecendo nessa temperatura por 15 minutos. A razão de divisão "split" utilizado foi de 1:50.

O padrão utilizado foi uma mistura de trinta e sete ésteres metílicos de ácidos graxos - 47885 (Sigma Chemical Co).

O volume de injeção foi de $1 \mu \mathrm{L}$, por injetor automático AOC $20 \mathrm{i}$.

Os resultados foram expressos como \% do total de ácidos graxos presentes na amostra.

\subsubsection{Suplementação}

A suplementação oral foi realizada com cápsulas gelatinosas moles (CGMs) tipo gel "soft". As cápsulas foram obtidas por processo mecânico de precisão, o que garante faixa bastante estreita de variação de peso. Foram confeccionadas a partir da dissolução na solução de gelatina com corantes farmacêuticos hidrossolúveis em quantidade 
mínimas. Os conteúdos de preenchimento foram devidamente formulados, isentos de bolhas ou ar incorporados.

\subsubsection{Cápsulas óleo de peixes}

As cápsulas de óleo de peixes foram fornecidas pela Sunflower Indústria e Laboratório Fitoterápico situada no município de Araçoiaba da Serra - SP, a 100 km da cidade de São Paulo.

Os produtos fornecidos pela empresa são naturais e fabricados de acordo com as Boas Práticas de Fabricação (BPF) e o Sistema HACCP (Análise de Perigos e Pontos Críticos de Controle).

As cápsulas pertenciam ao lote 030207 , fabricação em 01/2007 com validade de 3 anos, tendo com técnico responsável Ricardo de Araújo Santos CRF - SP: 28488.

O produto foi envasado e acondicionado em frascos brancos opacos de polietileno, com tampa lacre da marca Frascolex, modelo All 100 com capacidade de $100 \mathrm{~mL}$. Cada frasco recebeu 60 cápsulas e foi devidamente etiquetado e distribuído à população.

2.3.7.1.1 Parâmetros analisados no óleo de peixe

- Determinação de ácidos graxos:

A extração e separação dos lipídios foram realizadas de acordo com MARMER e MAXWELL (1981). Tomou-se uma amostra aleatória das cápsulas óleo de peixe (10 cápsulas), seu conteúdo foi misturado e homogeneizado e dessa alíquota foram retirados $100 \mu \mathrm{L}$ para verificação do perfil lipídico das cápsulas. Os ácidos graxos foram metilados conforme descrito na determinação de ácidos graxos no item 4.1.4. 


\subsubsection{Cápsulas de vitamina $\mathrm{E}$}

As cápsulas de vitamina E foram fabricadas pela Empresa Relthy Cápsulas Moles situada no município de Indaiatuba - São Paulo. A matéria prima foi fornecida pela Archer Daniels Midland Company (ADM).

Cada cápsula continha $400 \mathrm{mg}$ de vitamina E, pertencia ao lote 1000677 , fabricação em 12/2006 com validade até 12/2009 (data de embalagem 18/01/2007).

As cápsulas foram envasadas no Laboratório de Técnica Dietética da Faculdade de Saúde Pública/USP, sob condições controladas de higiene e foram acondicionadas em frasco branco opaco de polietileno, com tampa lacre da marca Frascolex, modelo All 100 com capacidade de $100 \mathrm{~mL}$. Os frascos receberam 30 cápsulas/cada e foram devidamente etiquetados e distribuídos à população (Figuras 3 e 4).

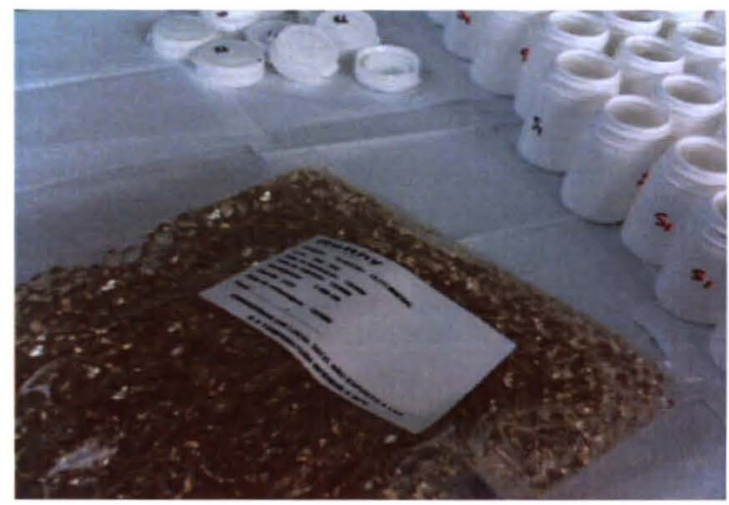

Figura 3 - Cápsulas para suplementação

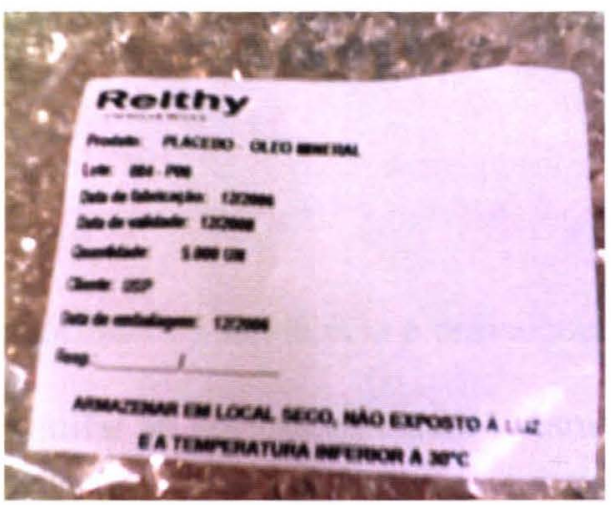

Figura 4 - Cápsulas placebo

\subsubsection{Cápsulas placebo}

As cápsulas placebo foram igualmente fornecidas pela Empresa Relthy Cápsulas Moles, situada no município de Indaiatuba - São Paulo. Cada cápsula foi preenchida com óleo mineral e nelas foram mantidas as características físicas e aparências das cápsulas contendo óleo de peixe e das cápsulas contendo vitamina E. Pertenciam ao lote 
084-P06, fabricação em 12/2006 com validade até 12/2008 (data de embalagem 18/01/2007).

O produto foi envasado no Laboratório de Técnica Dietética da Faculdade de Saúde Pública/USP, sob condições controladas de higiene, cada frasco com tampa lacre inviolável, marca Frascolex, modelo All 100 com capacidade de $100 \mathrm{~mL}$, recebeu 30 cápsulas e foi devidamente etiquetado e posteriormente distribuídos à população de estudo.

Inexistiram conflitos de interesses com as empresas fornecedoras dos suplementos.

\subsection{MÉTODO ESTATÍSTICO}

Os resultados dos tempos (M0 M1 e M2) são apresentados nas formas de valor médio \pm erro padrão

\section{Estimativa do tamanho da amostra}

O tamanho amostral foi determinado pela fórmula de incidência e prevalência de dislipidemias e estresse oxidativo na população similar ao estudo realizado. O tamanho da amostra foi estimado em 10 pacientes por grupo de estudo (suplementação) perfazendo um total de 30 pacientes para cada etnia. O cálculo foi feito assumindo-se $\alpha=5 \%$ e $\beta=20 \%$.

A análise de todas as informações coletadas nesta pesquisa foi inicialmente feita de forma descritiva.

Para as variáveis de natureza quantitativa foram calculadas algumas medidasresumo, como a média, desvio-padrão, entre outras, e confeccionados gráficos do tipo boxplot (BUSSAB e MORETTIN, 2006). 
As variáveis de natureza qualitativa foram analisadas através do cálculo de frequiências absolutas e relativas, além da construção de gráficos de barras (BUSSAB e MORETTIN, 2006).

A análise inferencial empregada com o intuito de confirmar ou refutar evidências encontradas na análise descritiva foi a Análise de variância com medidas repetidas, além das comparações múltiplas pelo método LSD, quando necessário (NETER et al, 1996).

Em todas as conclusões obtidas através das análises inferenciais foi utilizado o nível de significância $\alpha$ igual a 5\%.

Os dados foram digitados em planilhas do Excel 2000 for Windows para o adequado armazenamento das informações. As análises estatísticas foram realizadas com os softwares Statistical Package for Social Sciences (SPSS) versão 13.0 for Windows e Statistica versão 5.0. 


\subsection{RESULTADOS E DISCUSSÃO}

\section{População de estudo e casuística}

Inicialmente, oitenta e sete mulheres foram selecionadas para participar deste estudo (52 de etnia branca e 35 de etnia negra) destas, 13 se recusaram a participar da pesquisa (11 de etnia branca e 2 de etnia negra) (26,43\%). As recusas tiveram os seguintes motivos: dificuldade de acesso ao PSF, medo do procedimento laboratorial, falta de tempo e horário inadequado para coleta de sangue.

Dentre as pacientes que aceitaram participar do estudo, 4 (de etnia branca) desistiram após 30 dias: 2 alegaram desconforto gastrintestinal, 1 esqueceu de fazer a suplementação adequada referente ao período e 1 não compareceu à consulta seguinte não alegando motivo.

Decorridos 45 dias, duas mulheres que participavam do estudo mudaram de residência, deixando de fazer parte do PSF e duas foram submetidas à intervenção cirúrgica, fatos esses que as impossibilitaram de continuar como participantes do estudo. No último momento da coleta (M2) sete pacientes não compareceram e quando contatadas, 3 não alegaram motivo para a desistência, 2 se sentiram incomodadas com a ingestão das cápsulas e 2 esqueceram de tomar o suplemento. Sendo assim o estudo finalizou com 59 mulheres ( 30 da etnia branca e 29 da etnia negra).

A maior dificuldade encontrada para a seleção da população foi a formação do grupo de etnia negra. No primeiro convite, poucas mulheres negras compareceram sendo necessário novo convite exclusivo para mulheres referenciadas como negras no prontuário. Somente após duas novas reuniões foi completado o numero necessário de pacientes para formação do grupo dessa etnia. 


\section{Caracterização da população em estudo}

A amostra selecionada foi composta de 59 mulheres, sendo $30(50,84 \%)$ de etnia branca e $29(49,16 \%)$ de etnia negra. A Tabela 1 apresenta a distribuição dessas mulheres segundo a etnia e suplementação recebida.

Tabela 1 - População de estudo segundo etnia e suplementação.

Pindamonhangaba - SP, 2007.

\begin{tabular}{cccc}
\hline \hline \multirow{2}{*}{ Suplemento } & \multicolumn{3}{c}{ Etnia } \\
\cline { 2 - 4 } & Branca & Negra & Total \\
\hline \multirow{2}{*}{$\mathrm{S} 1+\mathrm{S} 1$} & 9 & 9 & 18 \\
& $30,0 \%$ & $31,0 \%$ & $30,5 \%$ \\
$\mathrm{~S} 3+\mathrm{S} 1$ & 12 & 10 & 22 \\
& $40,0 \%$ & $34,5 \%$ & $37,3 \%$ \\
$\mathrm{~S} 3+\mathrm{S} 2$ & 9 & 10 & 19 \\
& $30,0 \%$ & $34,5 \%$ & $32,2 \%$ \\
\hline Total & 30 & 29 & 59 \\
& $100 \%$ & $100 \%$ & $100 \%$ \\
\hline \hline
\end{tabular}

$\mathbf{S 1}+\mathbf{S 1}$ - Grupo controle (placebo)

$\mathbf{S 3}+\mathbf{S 1}$ - Grupo com intervenção à base de óleo de peixe e placebo;

$\mathbf{S 3}+\mathbf{S 2}$ - Grupo com intervenção à base de óleo de peixe e cápsula de vitamina E.

A idade da população em estudo variou entre 40 e 67 anos. O grupo de etnia negra apresentou média maior de idade $(52,32 \pm 8,06)$ em relação ao grupo de etnia branca $(50,94 \pm 7,66)(\mathrm{p} \leq 0,046)$. No tocante ao suplemento, as duas etnias mostraram idade maior entre pacientes do grupo placebo $(\mathrm{S} 1+\mathrm{S} 1)$. Esses dados estão apresentados no Gráfico 1. 
Gráfico 1 - Boxplot da população segundo idade e suplemento.

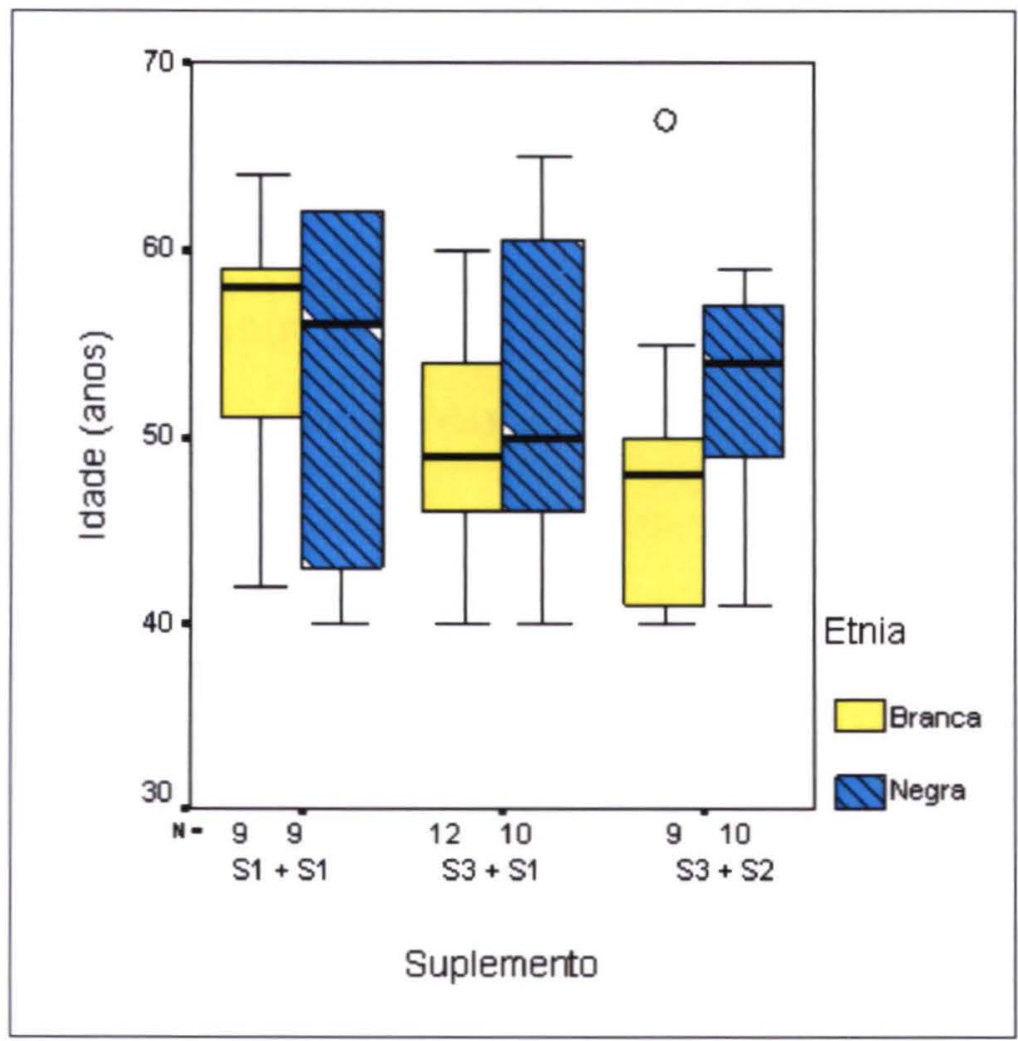

$\mathbf{S 1}+\mathbf{S 1}$ - Grupo controle (placebo)

S3 + S1 - Grupo com intervenção à base de óleo de peixe e placebo;

$\mathbf{S 3}+\mathbf{S 2}$ - Grupo com intervenção à base de óleo de peixe e vitamina $\mathrm{E}$.

A Tabela 2 apresenta resultados de dados comportamentais e antropométricos das pacientes de estudo segundo etnia.

Em relação ao estado nutricional houve homogeneidade quanto ao peso. Mulheres de etnia branca e negra apresentaram sobrepeso e mulheres eutróficas totalizaram $(12 \%)$ das participantes. Foi observada co-relação entre IMC e paridade ( $\mathrm{p}<0,042)$. O número de filhos variou entre os grupos, mulheres com mais de 50 anos apresentaram paridade aumentada em relação às mulheres entre 40 e 50 anos e as mulheres de etnia branca declararam paridade maior que as declaradas pela etnia negra. 
Tabela 2 - Dados antropométricos (média \pm desvio padrão) e comportamentais da população de estudo (\%) segundo etnia - Pindamonhangaba - SP, 2007.

\begin{tabular}{|c|c|c|}
\hline \multirow{2}{*}{ Variáveis } & \multicolumn{2}{|c|}{ Grupos de estudo } \\
\hline & Etmia branca & Etnia negra \\
\hline Peso (kg) & $70,16( \pm 5,02)$ & $71,04( \pm 7,32)$ \\
\hline Altura (cm) & $158,92( \pm 3,21)$ & $158,42( \pm 2,89)$ \\
\hline IMC $\left(\mathrm{Kg} / \mathrm{m}^{2}\right)$ & $27,72( \pm 6,87)$ & $28,31( \pm 4,22)$ \\
\hline Circunferência abdominal (CA) - (cm) & $94,77( \pm 7,82)$ & $90,24( \pm 5,15)$ \\
\hline Cintura/Quadril (RCQ) - (cm) & $0,91( \pm 3,56)$ & $0,93( \pm 5,17)$ \\
\hline \multicolumn{3}{|l|}{ Número de gestações (\%) } \\
\hline 0 & 3,37 & 7,90 \\
\hline 1 & 9,25 & 12,90 \\
\hline 2 & 28,12 & 19,35 \\
\hline 3 & 46,87 & 51,41 \\
\hline$\geq 4$ & 9,38 & 8,45 \\
\hline \multicolumn{3}{|l|}{ Estado civil (\%) } \\
\hline Solteira & 14,28 & 25,00 \\
\hline Casada & 71,43 & 62,50 \\
\hline Viúva & 7,14 & - \\
\hline Separada & 7,14 & 12,50 \\
\hline \multicolumn{3}{|l|}{ Escolaridade * $(\%)$} \\
\hline 0 & 9,37 & 6,45 \\
\hline 1 & 75 & 64,52 \\
\hline 2 & 3,12 & 9,68 \\
\hline 3 & 3,12 & - \\
\hline 4 & 3,12 & 12,9 \\
\hline 5 & 6,25 & 6,45 \\
\hline \multicolumn{3}{|l|}{ Renda familiar (\%) } \\
\hline \multicolumn{3}{|l|}{ (salários mínimos) } \\
\hline$(0) \leq 1$ & 6,25 & 9,68 \\
\hline (1) $1-2$ & 46,87 & 51,61 \\
\hline (2) $3-4$ & 31,25 & 22,58 \\
\hline (3) $5-7$ & 6,25 & 9,68 \\
\hline (4) $>7$ & 9,38 & 6,45 \\
\hline \multicolumn{3}{|l|}{ Tabagismo (\%) } \\
\hline Sim & 15,62 & 16,70 \\
\hline Não & 84,37 & 83,87 \\
\hline \multicolumn{3}{|l|}{ Ingestão alcoólica (\%) } \\
\hline Nunca & 66,67 & 64,54 \\
\hline Às vezes & 30,33 & 32,26 \\
\hline Freqüentemente & 2,01 & 3,20 \\
\hline \multicolumn{3}{|l|}{ Atividade física (\%) } \\
\hline Insuficientemente ativa & 9,37 & 6,45 \\
\hline Ativa & 66,67 & 83,87 \\
\hline Muito ativa & 28,12 & 9,68 \\
\hline
\end{tabular}

* Escolaridade: (0) nenhuma, (1) primário incompleto, (2) primário completo, (3) ginásio incompleto, (4) ginásio completo (5) ensino médio incompleto 
Neste estudo o IMC encontrado foi de 27,72 e 28,31 , respectivamente em etnia branca e negra e está de acordo com os dados de LORENZI et al. (2005) em estudo sobre prevalência de peso e obesidade no climatério em mulheres brancas e não brancas, os autores encontraram $63,7 \%$ de sobrepeso e obesidade, com IMC médio de $27,4 \mathrm{~kg} / \mathrm{m}^{2}$. Na cidade de Cuiabá, onde 354 mulheres foram investigadas, encontrou-se sobrepeso de $71 \%$ (OLIVEIRA et al., 2001), que foi coerente aos valores encontrados na cidade de São Paulo em pesquisa feita com 154 mulheres no climatério residentes no Município (MONTILLA et al., 2003). Estudos demonstram que o ganho de peso nos anos que antecedem a menopausa pode chegar a $0,8 \mathrm{~kg} /$ ano esse aumento após a menopausa pode corresponder a $20 \%$ da gordura corporal. No entanto o ganho de peso não é associado somente à deficiência de estrogênio, mas principalmente ao balanço calórico/energético, pois a mulher tende à redução do metabolismo basal e sedentarismo decorrente do próprio envelhecimento e isso requer adequação entre a ingestão de alimentos e as necessidades calóricas (MONTILLA et al., 2003).

LORENZI et al., (2005) estudaram também relação entre obesidade e estado marital e concluíram que mulheres sem companheiro fixo tendem ao sobrepeso. Neste estudo $71,43 \%$ das mulheres brancas e $62,50 \%$ das mulheres negras se declararam casadas, contudo o sobrepeso se fez presente em ambas as etnias.

Usando dados do estudo de Framingham, ANDERSON et al. (1987) observaram que o risco de enfermidades associadas à DCV em mulheres obesas foi cerca de 2 vezes maior na faixa etária acima de 50 anos.

Outra associação encontrada neste estudo foi entre a idade e o IMC, visto que quanto maior a idade maior a prevalência de sobrepeso e obesidade $(\mathrm{p} \leq 0,002)$.

As medidas de circunferência abdominal (CA) e a razão cintura e quadril (RCQ) aferidas na população não demonstraram diferenças entre as etnias $(p>0,913)$, no 
entanto em ambas as etnias foi observado aumento percentual desses parâmetros, que em mulheres definem distribuição central de gordura e estatisticamente se correlacionam com maior quantidade de gordura visceral (OMS, 2000). Recentemente, foi sugerido que a RCQ define melhor indivíduo de risco para doença cardiovascular (KRAGELUND \& OMLAND, 2005; ESMAILLZADEH, 2004). Outros autores consideram que a medida da cintura é melhor preditor de obesidade, dislipidemia e risco cardiovascular (LEMOS-SANTOS et al., 2004). Em estudo recente, MISRA et al. (2006) atentaram para o fato de que o padrão de distribuição da gordura pode variar de acordo com os grupos étnicos, e recomendaram que essas medidas sejam padronizadas para as diversas etnias.

Para essa população não foi encontrada variação entre raça e escolaridade, nem tampouco ente raça e renda familiar $(\mathrm{p}=0,482)$.

A grande maioria da população $(71,4 \%$ e $62,5 \%)$ era casada ou vivia em união consensual e, quando o item foi tabagismo, $71,4 \%$ e $67,0 \%$ se declararam não fumante ou ex-fumante $(28,6 \%$ e $11,1 \%)$ nas etnias branca e negra, respectivamente.

Em relação à escolaridade, foi mais predominante mulheres com até 4 anos de estudo (75,0\% de etnia branca e $64,52 \%$ de etnia negra), seguido de mulheres com até 8 anos de escolaridade no grupo de etnia negra $(9,68 \%)$ e uma parcela similar entre as etnias chegou ao ensino médio sem portanto, tê-lo concluído $(6,45 \%$ e 6,25\%). Nenhum dos grupos apresentou mulheres com escolaridade acima do ensino médio. Tal fato pode ser justificado pela baixa condição sócio-econômica das pacientes cadastradas no PSF.

De encontro com a literatura, quando foi avaliada a renda familiar, a maioria das mulheres entrevistadas em ambas as etnias afirmaram possuir renda familiar entre um e dois salários mínimos (46,87\% etnia branca e 51,61\% etnia negra). Entre as mulheres brancas $52 \%$ trabalhavam no lar e $33 \%$ das negras relataram o mesmo, o restante $(34 \%)$ 
de ambas as etnias foram enquadradas na categoria de emprego formal. No que tange a ocupação IN e MELEIS (2001), estudando população de mulheres com 25 a 64 anos nos EUA, relataram que mulheres donas de casa tendem a apresentar melhor perfil lipídico e menor ganho de peso ponderal em relação às mulheres com ocupação remunerada, o que atribuíram à possível dificuldade por parte dessas últimas em cuidar de sua alimentação. No nosso estudo essa relação não foi avaliada.

Segundo dados do Ministério da Saúde (2003) aproximadamente 33\% da população brasileira fumam e a maioria dos fumantes tem entre 20 e 49 anos. O tabagismo colabora para o efeito adverso da terapêutica de redução dos lipídios séricos, diminuindo níveis de HDL-C.

O tabagismo esteve presente em $15,62 \%$ das mulheres de etnia branca e $16,70 \%$ na etnia negra. Mulheres ex-tabagistas de ambas as etnias somaram aproximadamente 19,0 \% da população de estudo, não havendo correlação entre tabagismo e etnia (p= 0,675). No entanto, mulheres com idade superior a 50 anos foram mais presentes no grupo de ex-fumantes.

O hábito de ingestão de bebidas alcoólicas foi relatado por 32,34\% das mulheres de etnia branca e $35,46 \%$ das mulheres de etnia negra, sendo que em ambas as etnias as mulheres com hábitos de ingestão freqüentes declararam consumo limite de cinco copos de 300mL por semana e, em caso algum houve referência à bebida destilada.

Em relação à prática e atividade física, as respostas obtidas a partir do questionário demonstram que mulheres de ambas as etnias informaram hábito de caminhada duas a três vezes por semana, caracterizando atividade física leve. Mulheres consideradas insuficientemente ativas perfizeram $9,37 \%$ e $6,45 \%$ respectivamente nas etnias branca e negra. No entanto cabe ressaltar que a baixa renda e pouca escolaridade foram fatores que certamente contribuíram para a ocorrência de nenhuma atividade 
física orientada ou em instituições especializadas. Relatos da literatura têm confirmado que exercícios de baixa intensidade também podem influenciar nos níveis de insulina em jejum e nos níveis de LDL-C, elevando principalmente a fração HDL-C. Também se verificou os efeitos favoráveis dos exercícios brandos sobre o perfil lipoprotéico de pacientes dislipidêmicos (em geral hipertrigliceridêmicos puros ou hipercolesterolemia associada ao LDL-C) (DIOGUARDI et al., 2005).

Os efeitos benéficos da atividade física na prevenção de inúmeros agravos e para a promoção à saúde são inúmeros, principalmente no que diz respeito à $\mathrm{DCV}$, com evidências mostrando diminuição da pressão arterial, dos níveis séricos de LDL-C, triglicérides e inibição da agregação plaquetária (SPIRDUSO, 1995). SIMKINSILVERMAN e WING (2000) enfatizaram a importância da atividade física para a mulher na transição menopausal, apontando o sedentarismo como o fator mais consistentemente relacionado ao ganho de peso, freqüentemente observado nesta fase da vida.

No estudo em questão os relatos positivos para atividade física provavelmente se devem ao trabalho intenso de conscientização para os efeitos negativos do sedentarismo desenvolvido pelos profissionais de saúde do PSF.

Os biomarcadores sanguíneos avaliados incluíram análise de colesterol total e frações e triglicérides. $\mathrm{O}$ índice de risco cardíaco (IRC) foi calculado pela razão entre Colesterol total e HDL.

As informações sobre o colesterol (mg/dL), triglicérides (mg/dL), HDL (mg/dL), VLDL (mg/dL), LDL (mg/dL), IRC, nos três momentos de coleta (0 dia, 45 dias e 90 dias) estão demonstrados na Tabela 3. 
Tabela 3 - Medidas-resumo dos biomarcadores sanguíneos segundo etnia suplemento e momento de coleta ${ }^{1}$. Pindamonhangaba - SP, 2007.

\begin{tabular}{|c|c|c|c|c|c|c|c|c|c|c|c|c|c|c|c|c|c|c|}
\hline \multirow{4}{*}{ Variáveis } & \multicolumn{18}{|c|}{ Grupos de estudo } \\
\hline & \multicolumn{6}{|c|}{$\mathrm{S} 1+\mathrm{S} 1$} & \multicolumn{6}{|c|}{$\mathrm{S} 3+\mathrm{S} 1$} & \multicolumn{6}{|c|}{$\mathrm{S} 3+\mathrm{S} 2$} \\
\hline & \multicolumn{3}{|c|}{ Branca } & \multicolumn{3}{|c|}{ Negra } & \multicolumn{3}{|c|}{ Branca } & \multicolumn{3}{|c|}{ Negra } & \multicolumn{3}{|c|}{ Branca } & \multicolumn{3}{|c|}{ Negra } \\
\hline & M0 & M1 & M2 & M0 & M1 & M2 & M0 & M1 & M2 & M0 & M1 & M2 & M0 & M1 & M2 & M0 & M1 & M2 \\
\hline $\begin{array}{l}\text { Colesterol } \\
\text { total (mg/dL) }\end{array}$ & $\begin{array}{l}253,67 \\
\pm 32,58\end{array}$ & $\begin{array}{l}236,33 \\
\pm 32,43\end{array}$ & $\begin{array}{l}232,78 \\
\pm 46,02\end{array}$ & $\begin{array}{l}235,40 \\
\pm 42,26\end{array}$ & $\begin{array}{l}222,60 \\
\pm 18,45\end{array}$ & $\begin{array}{l}249,70 \\
\pm 29,94\end{array}$ & $\begin{array}{l}269,31 \\
\pm 56,62\end{array}$ & $\begin{array}{l}239,38 \\
\pm 48,08\end{array}$ & $\begin{array}{l}250,69 \\
\pm 57,60\end{array}$ & $\begin{array}{l}248,45 \\
\pm 31,72\end{array}$ & $\begin{array}{l}225,55 \\
\pm 21,44\end{array}$ & $\begin{array}{l}239,64 \\
\pm 44,46\end{array}$ & $\begin{array}{l}222,40 \\
\pm 46,10\end{array}$ & $\begin{array}{l}197,90 \\
\pm 40,60\end{array}$ & $\begin{array}{l}205,80 \\
\pm 49,73\end{array}$ & $\begin{array}{l}236,80 \\
\pm 35,99\end{array}$ & $\begin{array}{l}215,00 \\
\pm 29,26\end{array}$ & $\begin{array}{l}219,10 \\
\pm 37,52\end{array}$ \\
\hline $\begin{array}{l}\text { HDL-C } \\
(\mathrm{mg} / \mathrm{dL})\end{array}$ & $\begin{array}{l}45,22 \\
\pm 10,88\end{array}$ & $\begin{array}{l}46,33 \\
\pm 10,61\end{array}$ & $\begin{array}{l}46,89 \\
\pm 11,86\end{array}$ & $\begin{array}{l}48,50 \\
\pm 14,20\end{array}$ & $\begin{array}{l}52,10 \\
\pm 15,32\end{array}$ & $\begin{array}{l}52,60 \\
\pm 22,86\end{array}$ & $\begin{array}{l}55,08 \\
\pm 17,71\end{array}$ & $\begin{array}{l}55,62 \\
\pm 12,69\end{array}$ & $\begin{array}{l}55,15 \\
\pm 13,34\end{array}$ & $\begin{array}{l}48,50 \\
\pm 14,20\end{array}$ & $\begin{array}{l}52,10 \\
\pm 15,3\end{array}$ & $\begin{array}{l}52,60 \\
\pm 22,86\end{array}$ & $\begin{array}{l}54,20 \\
\pm 14,88\end{array}$ & $\begin{array}{l}59,60 \\
\pm 17,44\end{array}$ & $\begin{array}{l}53,80 \\
\pm 15,77\end{array}$ & $\begin{array}{l}52,36 \\
\pm 6,12\end{array}$ & $\begin{array}{l}57,82 \\
\pm 6,57\end{array}$ & $\begin{array}{l}57,09 \\
\pm 7,27\end{array}$ \\
\hline $\begin{array}{l}\text { VLDL } \\
(\mathrm{mg} / \mathrm{dL})\end{array}$ & $\begin{array}{l}35,86 \\
\pm 14,40\end{array}$ & $\begin{array}{l}33,00 \\
\pm 12,29\end{array}$ & $\begin{array}{l}36,88 \\
\pm 17,51\end{array}$ & $\begin{array}{l}37,78 \\
\pm 13,74\end{array}$ & $\begin{array}{l}42,70 \\
\pm 13,16\end{array}$ & $\begin{array}{l}35,90 \\
\pm 18,77\end{array}$ & $\begin{array}{l}34,91 \\
\pm 16,22\end{array}$ & $\begin{array}{l}33,17 \\
\pm 17,84\end{array}$ & $\begin{array}{l}34,08 \\
\pm 17,78\end{array}$ & $\begin{array}{l}30,55 \\
\pm 11,11\end{array}$ & $\begin{array}{l}26,18 \\
\pm 11,16\end{array}$ & $\begin{array}{l}27,27 \\
\pm 9,20\end{array}$ & $\begin{array}{l}39,90 \\
\pm 11,59\end{array}$ & $\begin{array}{l}35,40 \\
\pm 12,20\end{array}$ & $\begin{array}{l}39,10 \\
\pm 22,77\end{array}$ & $\begin{array}{l}35,63 \\
\pm 19,80\end{array}$ & $\begin{array}{l}37,67 \\
\pm 21,93\end{array}$ & $\begin{array}{l}36,13 \\
\pm 12,80\end{array}$ \\
\hline $\begin{array}{l}\text { LDL-C } \\
(\mathrm{mg} / \mathrm{dL})\end{array}$ & $\begin{array}{l}173,14 \\
\pm 33,18\end{array}$ & $\begin{array}{l}162,29 \\
\pm 24,81\end{array}$ & $\begin{array}{l}143,13 \\
\pm 46,06\end{array}$ & $\begin{array}{l}149,10 \\
\pm 11,22\end{array}$ & $\begin{array}{l}127,89 \\
\pm 17,57\end{array}$ & $\begin{array}{l}159,30 \\
\pm 26,86\end{array}$ & $\begin{array}{l}163,36 \\
\pm 42,99\end{array}$ & $\begin{array}{l}147,42 \\
\pm 48,02\end{array}$ & $\begin{array}{l}153,38 \\
\pm 43,34\end{array}$ & $\begin{array}{l}167,18 \\
\pm 24,60\end{array}$ & $\begin{array}{l}139,27 \\
\pm 15,34\end{array}$ & $\begin{array}{l}155,27 \\
\pm 37,71\end{array}$ & $\begin{array}{l}153,60 \\
\pm 31,75\end{array}$ & $\begin{array}{l}102,80 \\
\pm 25,78\end{array}$ & $\begin{array}{l}118,70 \\
\pm 41,04\end{array}$ & $\begin{array}{l}158,25 \\
\pm 31,75\end{array}$ & $\begin{array}{l}130,44 \\
\pm 40,53\end{array}$ & $\begin{array}{l}132,25 \\
\pm 24,17\end{array}$ \\
\hline $\begin{array}{l}\text { Triglicérides } \\
\text { (mg/dL) }\end{array}$ & $\begin{array}{l}244,11 \\
\pm \\
139,88\end{array}$ & $\begin{array}{l}257,89 \\
\pm \\
217,44\end{array}$ & $\begin{array}{l}266,67 \\
\pm \\
300,78\end{array}$ & $\begin{array}{l}231,70 \\
\pm \\
102,17\end{array}$ & $\begin{array}{l}233,30 \\
\pm \\
68,59\end{array}$ & $\begin{array}{l}209,60 \\
\pm \\
107,77\end{array}$ & $\begin{array}{l}250,00 \\
\pm \\
199,67\end{array}$ & $\begin{array}{l}209,92 \\
\pm \\
174,16\end{array}$ & $\begin{array}{l}200,46 \\
\pm \\
136,12\end{array}$ & $\begin{array}{l}153,64 \\
\pm \\
60,32\end{array}$ & $\begin{array}{l}133,18 \\
\pm \\
60,16\end{array}$ & $\begin{array}{l}140,45 \\
\pm \\
53,01\end{array}$ & $\begin{array}{l}201,50 \\
\pm \\
57,77\end{array}$ & $\begin{array}{l}178,80 \\
\pm \\
61,24\end{array}$ & $\begin{array}{l}174,30 \\
\pm \\
65,58\end{array}$ & $\begin{array}{l}249,00 \\
\pm \\
184,45\end{array}$ & $\begin{array}{l}221,70 \\
\pm \\
143,43\end{array}$ & $\begin{array}{l}244,90 \\
\pm \\
144,27\end{array}$ \\
\hline $\begin{array}{l}\text { Índice de } \\
\text { Castelli }\end{array}$ & $\begin{array}{l}5,65 \\
\pm 1,39\end{array}$ & $\begin{array}{l}5,29 \\
\pm 1,30\end{array}$ & $\begin{array}{l}4,99 \\
\pm 1,65\end{array}$ & $\begin{array}{l}4,61 \\
\pm 1,08\end{array}$ & $\begin{array}{l}4,58 \\
\pm 1,40\end{array}$ & $\begin{array}{l}5,04 \\
\pm 1,56\end{array}$ & $\begin{array}{l}4,77 \\
\pm 1,71\end{array}$ & $\begin{array}{l}4,25 \\
\pm 1,23\end{array}$ & $\begin{array}{l}4,58 \\
\pm 1,60\end{array}$ & $\begin{array}{l}4,78 \\
\pm 1,01\end{array}$ & $\begin{array}{l}3,93 \\
\pm 0,72\end{array}$ & $\begin{array}{l}4,21 \\
\pm 0,92\end{array}$ & $\begin{array}{l}4,26 \\
\pm 1,14\end{array}$ & $\begin{array}{l}3,51 \\
\pm 0,93\end{array}$ & $\begin{array}{l}4,11 \\
\pm 1,63\end{array}$ & $\begin{array}{l}4,48 \\
\pm 1,23\end{array}$ & $\begin{array}{l}4,24 \\
\pm 0,75\end{array}$ & $\begin{array}{l}3,95 \\
\pm 0,85\end{array}$ \\
\hline
\end{tabular}

Talores - expressão como média \pm desvio padrão (DP) 
Os resultados inferenciais, indicados pelo valor de $p$ revelaram que os níveis médios de Triglicérides (TG) (mg/dL), HDL-C (mg/dL) e VLDL (mg/dL) não foram influenciados pela etnia, suplemento e momento de coleta (Tabela 4).

Tabela 4 Resultados inferenciais (p) na comparação de TG (mg/dL), HDL-C (mg/dL) e VLDL (mg/dL), segundo etnia, suplemento e momento de coleta.

\begin{tabular}{lccc}
\hline \hline \multirow{2}{*}{ Biomarcadores } & \multicolumn{3}{c}{ Variáveis } \\
\cline { 2 - 4 } & Etnia & Suplemento & Momento de coleta \\
\hline Triglicérides & 0,496 & 0,405 & 0,235 \\
HDL-C & 0,827 & 0,109 & 0,495 \\
VLDL & 0,599 & 0,266 & 0,371 \\
\hline \hline
\end{tabular}

JOHNSON et al. (2004) em estudo com gênero e etnia relataram valores de TG, LDL e VLDL mais elevados em mulheres de etnia branca em relação às de etnia negra de mesma idade (55 \pm 5 anos). Os autores reafirmam a importância da diferença no perfil das subclasses em relação aos riscos para DCV.

HARRIS (1996) em trabalho de revisão evidenciou 72 estudos controlados por placebo com suplementação de 1 a $7 \mathrm{~g}$ diárias de EPA e DHA por no mínimo, duas semanas. O autor verificou que as concentrações plasmáticas de TG foram reduzidas de 25 a $30 \%$ em geral. O tempo de suplementação é incontestavelmente um fator muito relevante, baixas doses de AGPI $\omega$-3 suplementadas por um longo período de tempo teriam um efeito hipolipidêmico semelhante ao encontrado em suplementações por períodos mais curtos e com altas doses.

Embora os valores de TG não tenham sido influenciados pela suplementação e a outras variáveis do estudo, seus teores demonstraram variação individual maior quando comparadas aos outros biomarcadores. Muitas vezes esse fato se deve por esse biomarcador ser muito sensível e seus valores no mesmo indivíduo poderem variar significativamente. 
Os TG não são essencialmente componentes estruturais da lesão aterosclerótica; no entanto, elevados níveis na concentração de TG no plasma podem promover efeito adverso por modificar a produção de quilomícrons remanescentes que são aterogênicos (ROCHE et al., 1999). Além disso, altas concentrações de TG podem induzir o aumento do teor de ésteres de colesterol na HDL pela ação da enzima CETP (cholesterol ester transfer protein), interferindo no efeito benéfico que a HDL teria no metabolismo do colesterol.

Segundo FERNANDEZ e WEST (2005) os mecanismos pelos quais os AGPI reduzem as concentrações de TG no plasma envolvem o efeito combinado da inibição da lipogênese pela redução na expressão da SREPB-1 (proteína ligante do elemento regulatório do esterol 1) com maior estímulo à oxidação dos ácidos graxos pela ativação dos fatores de transcrição como o PPAR- $\alpha$ (receptor ativado por proliferador de peroxissomo $-\alpha)$.

Ainda sobre o efeito hipotrigliceridêmico dos ácidos graxos polinsaturados $\omega$-3, BOTHAM et al. (2003) sugeriram que pode estar associado à inibição da secreção da VLDL pelo fígado resultante da regulação negativa da expressão de mRNA para ACAT2 (Acid, côa: colesterol aciltransferase 2) enzima responsável pelo fornecimento de colesterol às VLDL.

Em estudos que conseguiram reduzir significativamente os teores de TG com suplementação, as doses administradas foram $\geq 1 \mathrm{~g} /$ dia e os indivíduos sempre hipertrigliceridêmicos (LEIGH-FIRBANK et al., 2002; BUCKEY et al., 2004).

WU et al. (2006), suplementando mulheres na pós-menopausa $(\mathrm{n}=27)$ sem terapia de reposição hormonal (TRH) por oito semanas relataram decréscimo não estatisticamente significante em níveis de TG em relação a outros autores que relataram para as mesmas condições valores de 25-30\% (HARRIS, 1977). 
O efeito não hipotrigliceridêmico observado nesse estudo pode estar relacionado à dieta habitual das pacientes, entretanto uma dosagem de $1000 \mathrm{mg}$ de $\omega$ - 3 equivale ao consumo de peixes ricos em EPA e DHA numa freqüência de três vezes por semana, fato este que na dieta ocidental é considerado um consumo alto. Outro fator relevante na comparação de resultados entre diferentes autores é o modo como a suplementação costuma ser expressa: óleo de peixe, ácidos graxos polinsaturados $\omega-3$ ou EPA + DHA sem descrever a concentração de EPA e DHA presentes no óleo de peixe, dificultando a interpretação dos resultados.

Com relação à concentração sérica de HDL-C, pôde-se observar que os níveis basais médios dessas lipoproteínas nos grupos de mulheres brancas suplementadas com

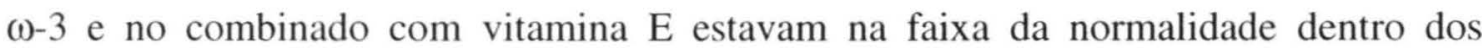
limites desejáveis de acordo com a SBC (2007) e que alguns valores individuais apresentaram aumento durante a suplementação combinada $(\mathrm{S} 3+\mathrm{S} 2)$ e, embora não tenha havido significância estatística no aumento da concentração sérica de HDL-C, a importância clinica dessa alteração está relacionada ao fator de proteção que a HDL-C promove no organismo. CORTI et al. (1995) em estudo envolvendo 2.527 mulheres idosas seguidas por aproximadamente cinco anos com níveis de $\mathrm{HDL}-\mathrm{C}<35 \mathrm{mg} / \mathrm{dL}$ mostraram o dobro do risco para DCV em comparação àquelas com HDL-C > 60 $\mathrm{mg} / \mathrm{dL}$

De maneira similar, ROCHE e GIBNEY (1999) mostraram que a suplementação de $1 \mathrm{~g}$ de AGPI $\omega$-3 por 12 semanas reduziu significativamente as concentrações do perfil lipídico de jejum em $21 \%$. Esse período foi o mesmo obedecido neste estudo e, embora a suplementação com $1 \mathrm{~g}$ de óleo de peixe não tenha modificado significativamente os níveis de triglicérides e HDL, a importância da duração da suplementação é confirmada pelos resultados de outros estudos. SCHMIDT et al. 
(1992) demonstraram que o aporte de 4g de AGPI $\omega$-3 por nove meses também reduziu os valores de HDL-C e TG no plasma. Os trabalhos conduzidos por SAYNOR E GILLIOTT (1992) mostraram redução contínua quando a suplementação acontece por períodos maiores que quatro anos. Com tempo menor e suplementação combinada (quatro meses; AGPI/ $\alpha$-tocoferol e $\beta$ plus $\gamma$-oryzanol/niacina) ACCINNI et al (2005) conseguiram redução nos teores de TG e TC.

Os resultados deste estudo vão ao encontro dos relatados por JOHNSON et al. (2004) que demonstraram não haver diferenças significativas entre etnias branca e negra, embora o autor demonstrou haver tendência de mulheres negras apresentarem níveis mais altos de HDL-C. Da mesma forma estudo, direcionado por VEZI e NAIDOO (2005), mostrou que mulheres negras apresentam um elevado nível de HDLC quando comparadas com outras etnias, os autores citam a necessidade de mais estudos com riscos cardíacos na etnia negra.

Em relação aos teores de colesterol, a etnia também não influenciou os níveis médios desse biomarcador $(\mathrm{p}=0,767)$. $\mathrm{O}$ mesmo não ocorreu quando avaliamos $\mathrm{o}$ suplemento $(\mathrm{p}=0,016)$ e o momento de coleta $(\mathrm{p}<0,001)$, conforme apresentado no resumo da Tabela 5 .

Tabela 5 Resultados inferenciais (p) na comparação de teores de colesterol (mg/dL), segundo suplemento e momento de coleta Pindamonhangaba - SP, 2007.

\begin{tabular}{cc}
\hline \hline Cuplemento & Conclusão \\
\hline Momento de coleta & $(\mathrm{S} 1+\mathrm{S} 1)=(\mathrm{S} 3+\mathrm{S} 1)(\mathrm{p}=0,465)$ \\
$(\mathrm{S} 1+\mathrm{S} 1)>(\mathrm{S} 3+\mathrm{S} 2)(\mathrm{p}=0,046)$ \\
$(\mathrm{S} 3+\mathrm{S} 1)>(\mathrm{S} 3+\mathrm{S} 2)(\mathrm{p}=0,005)$ \\
\\
0 dia $>45 \operatorname{dias}(\mathrm{p}<0,001)$ \\
0 dia $>90 \operatorname{dias}(\mathrm{p}=0,012)$ \\
$45 \operatorname{dias}<90 \operatorname{dias}(\mathrm{p}=0,027)$ \\
\hline \hline
\end{tabular}


Na população de etnia branca, o baseline referente ao colesterol total variou de $245 \mathrm{mg} / \mathrm{dL}$ à $368 \mathrm{mg} / \mathrm{dL}( \pm 46,10)$, enquanto na etnia negra essa variação foi de 239 $\mathrm{mg} / \mathrm{dL}$ à $354 \mathrm{mg} / \mathrm{dL}( \pm 35,99)$. Esse fato vai de encontro à literatura onde autores não conseguiram encontrar diferenças étnicas para os teores de colesterol total, mas notaram uma pequena diminuição nos níveis de colesterol encontrados na etnia negra. JOHNSON et al., (2004) investigaram colesterol em 40 mulheres negras e 108 mulheres brancas e não encontraram diferença significativa para esse marcador bioquímico. Em estudo com adultos hipertensos, O'MEARA et al. (2004) não encontraram diferença significativa nos níveis de colesterol entre mulheres de etnia negra e branca $(210 \pm 48$ $\mathrm{mg} / \mathrm{dL}$ e $215 \pm 39 \mathrm{mg} / \mathrm{dL}$ respectivamente), mas relataram haver prevalência maior de dislipidemia na etnia branca $(64,7 \%$ vs. $49,5 \%$ p $<0,001)$.

Estudos epidemiológicos demonstram que a elevação de $1 \%$ no colesterol plasmático dobra o risco de doença arterial coronária. Correlação entre colesterol sangüíneo e incidência de doenças cardiovasculares demonstra haver risco aumentado quando o colesterol é maior que $200 \mathrm{mg} / 100 \mathrm{~mL}$ de sangue conforme a maior parte dos autores. Entretanto, nos Estados Unidos da América, o National Institute of Health recomenda aconselhamento dietético a partir de $170 \mathrm{mg}$ de colesterol/100 mL de sangue e supervisão rotineira a partir de $185 \mathrm{mg}$ de colesterol/100 $\mathrm{mL}$ de sangue.

O efeito da suplementação com AGPI na redução o perfil lipídico tem sido amplamente estudada (ACCINI et al., 2005). No estudo em questão, percebeu-se que os níveis de colesterol plasmático diminuíram no grupo suplementado com $\omega$-3 $(\mathrm{S} 3+\mathrm{S} 1)$ nos primeiros 45 dias, mas essa diminuição não se manteve após 45 dias (M2). Quando foi avaliado o suplemento $\mathrm{S} 3+\mathrm{S} 2$ (combinado $\omega-3+\alpha$-tocoferol) os níveis de colesterol baixaram nos primeiros 45 dias (M1), mas não apresentaram diferenças 
significativas. O fato de os valores determinados no baseline dos três momentos apresentarem índices similares nos teores de colesterol total permite interpretar esses resultados como promissores, no entanto necessitando de maior tempo de suplementação.

Observando teores de CT, ACCINI et al., (2005) conseguiram respostas com efeitos benéficos na suplementação com óleo de peixe em pacientes dislipidêmicos. Por outro lado, é importante ressaltar que o colesterol plasmático é altamente influenciado pela dieta. Estudos clínicos estabelecem diferenças entre indivíduos em relação às alterações de colesterolemias: alguns indivíduos mostram resposta acentuada ou moderada e outros, resposta modesta ou nula e essas diferenças podem estar relacionadas à capacidade das células em suprimirem a síntese de colesterol em resposta ao conteúdo de colesterol celular e a diferença na regulação da atividade do receptor de LDL-C, além do nível de eficiência na absorção e no aumento da excreção fecal de esteróis, também pode estar associada a fatores tais como etnia, e hiperlipidemia (SBC, 2001).

Na avaliação do risco cardíaco medido por meio do Índice de Castelli, não foi observado diferenças para as variáveis etnia e suplemento, porém o momento de suplementação demonstrou uma redução no IRC após suplementação de 45 dias $(\mathrm{p}<0,001)$.

Tabela 6 Resultados inferenciais (p) na comparação de IRC segundo etnia, suplemento e momento de coleta. Pindamonhangaba - SP, 2007.

\begin{tabular}{c|ccc}
\hline \multirow{2}{*}{ IRC } & \multicolumn{3}{|c}{ Variáveis } \\
\cline { 2 - 4 } & Etnia & Suplemento & Momento de coleta \\
& 0,733 & 0,053 & 0,014 \\
\hline \hline
\end{tabular}


Tabela 7 Resultados inferenciais (p) na comparação de IRC segundo momento de coleta. Pindamonhangaba - SP, 2007.

\begin{tabular}{c|c}
\hline \hline \multirow{4}{*}{ IRC } & Conclusão \\
\cline { 2 - 3 } & 0 dia $>45$ dias $(\mathrm{p}<0,001)$ \\
& 0 dia $=90 \operatorname{dias}(\mathrm{p}=0,059)$ \\
& $45 \operatorname{dias}=90 \operatorname{dias}(\mathrm{p}=0,487)$ \\
\hline
\end{tabular}

Os valores de IRC são calculados pela razão entre colesterol total e HDL, daí ser esperado que as suas tendências acompanhem os resultados demonstrados nos níveis de colesterol. O valor limítrofe desse índice para mulheres é de 4,3 e só é calculado para valores de triglicérides até $400 \mathrm{mg} / \mathrm{dL}$, sendo assim algumas suplementações contaram com número menor de pacientes.

O gráfico 2 demonstra as diferenças apresentadas nos diferentes tempos de coleta para os valores de IRC. 
Gráfico 2 Valores de IRC, segundo etnia, suplemento e momento de coleta. Pindamonhangaba - SP, 2007.

Etnia Branca

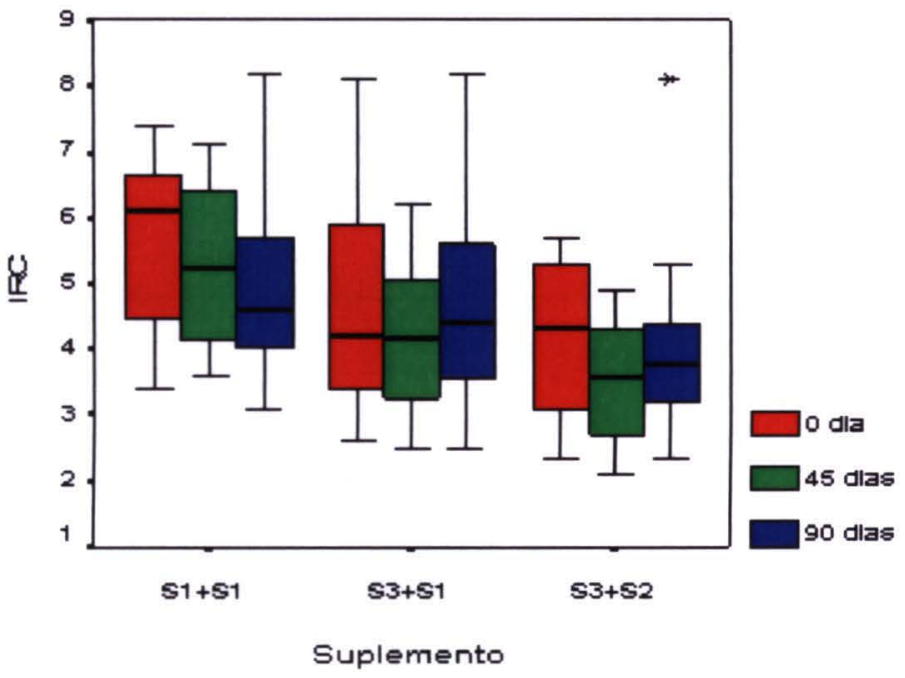

Etnia Negra

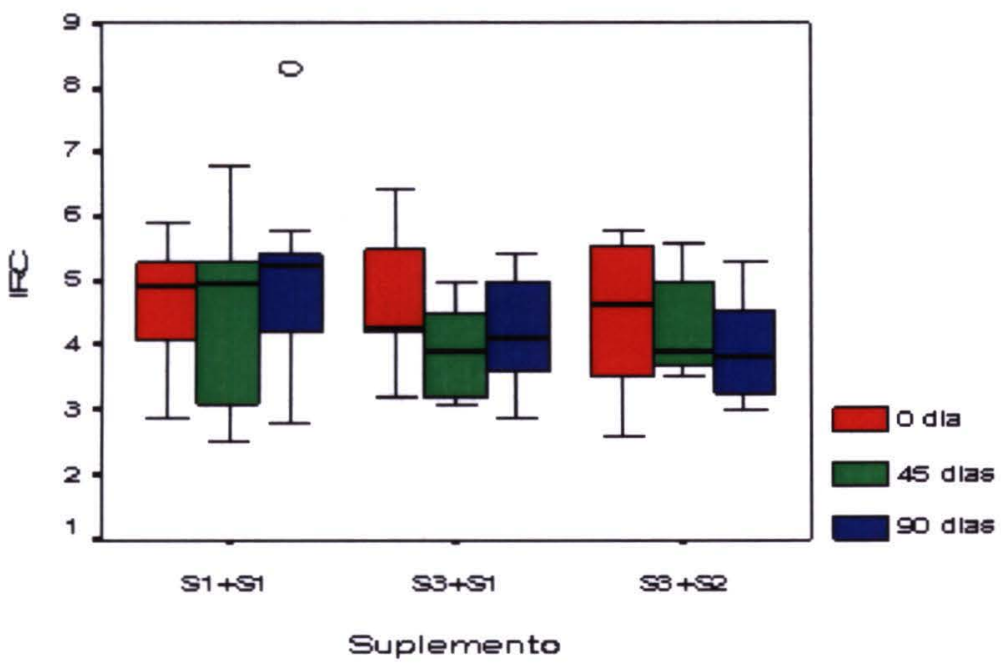


Os resultados inferenciais na comparação dos valores médios de LDL (mg/dL) revelam efeito no momento de coleta como estão demonstrados nos Gráficos 3 e na Tabela 8.

Gráfico 3 Teores de LDL (mg/dL), segundo etnia, suplemento e momento de coleta. Pindamonhangaba - SP, 2007.

Etnia Branca

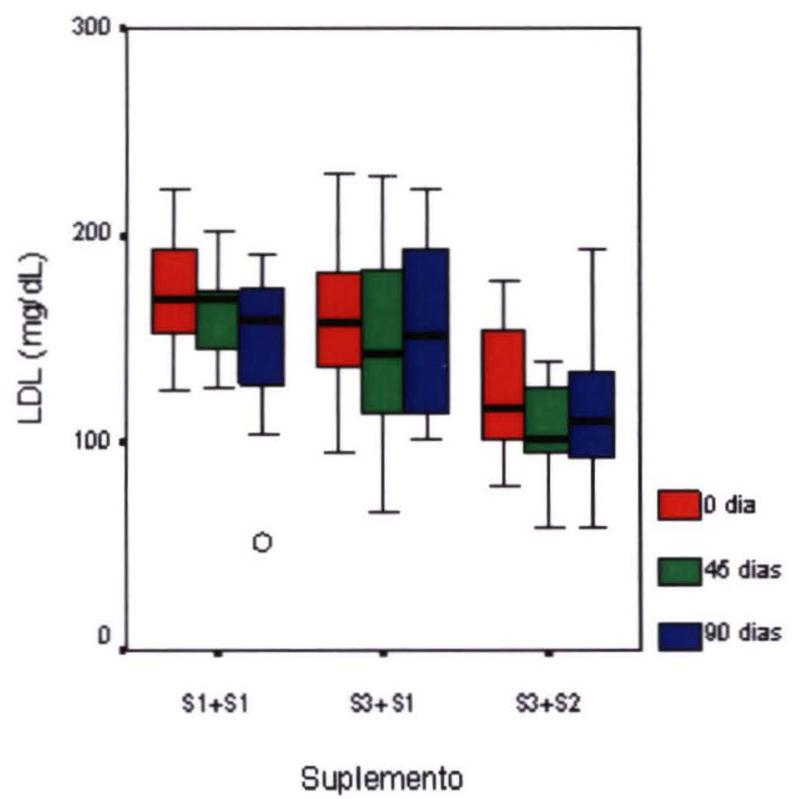

Etnia Negra

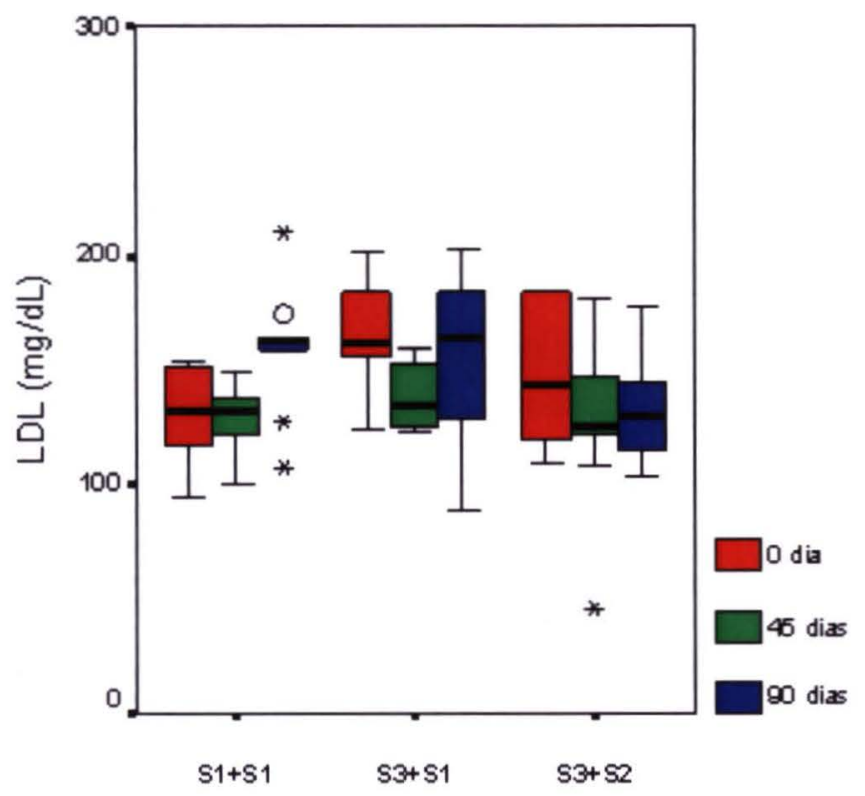

Suplemento 
Tabela 8 Resultados inferenciais (p) na comparação de LDL (mg/dL), segundo momento de coleta - Pindamonhangaba - SP, 2007.

\begin{tabular}{c}
\hline Conclusão \\
\hline 0 dia $>45 \operatorname{dias}(\mathrm{p}<0,001)$ \\
$0 \operatorname{dia}=90 \operatorname{dias}(\mathrm{p}=0,078)$ \\
$45 \operatorname{dias}<90 \operatorname{dias}(\mathrm{p}=0,042)$ \\
\hline
\end{tabular}

Também em relação à LDL-C, os resultados inferenciais detectaram interação entre etnia e suplemento. Etnia branca suplementada com óleo de peixe os níveis de LDL foram maiores que na população suplementada com óleo de peixe + vitamina E, o mesmo comportamento não foi encontrado na etnia negra onde não houve diferenças signioficativas entre os suplementos; desta forma, as comparações foram feitas entre os suplementos para cada etnia (Tabela 9).

Tabela 9 Resultados inferenciais (p) na comparação de LDL-C (mg/dL), segundo etnia e suplemento - Pindamonhangaba - SP, 2007.

\begin{tabular}{lc}
\hline \hline Etnia & Comparação entre suplementos \\
\hline Branca & $(\mathrm{S} 1+\mathrm{S} 1)=(\mathrm{S} 3+\mathrm{S} 1)(\mathrm{p}=0,324)$ \\
& $(\mathrm{S} 1+\mathrm{S} 1)>(\mathrm{S} 3+\mathrm{S} 2)(\mathrm{p}<0,001)$ \\
& $(\mathrm{S} 3+\mathrm{S} 1)>(\mathrm{S} 3+\mathrm{S} 2)(\mathrm{p}=0,003)$ \\
& \\
Negra & $(\mathrm{S} 1+\mathrm{S} 1)=(\mathrm{S} 3+\mathrm{S} 1)(\mathrm{p}=0,201)$ \\
& $(\mathrm{S} 1+\mathrm{S} 1)=(\mathrm{S} 3+\mathrm{S} 2)(\mathrm{p}=0,860)$ \\
& $(\mathrm{S} 3+\mathrm{S} 1)=(\mathrm{S} 3+\mathrm{S} 2)(\mathrm{p}=0,290)$ \\
\hline \hline
\end{tabular}

A concentração de partículas de LDL tende a ser mais elevadas em homens que em mulheres e são também mais elevadas em mulheres brancas quando comparadas com mulheres de etnia negra. Em relação ao tamanho, mulheres brancas e negras apresentam partículas grandes e maiores que as apresentadas por homens. Nos estudos 
de FREEDMAN et al., (1998) foram encontradas associações entre o tamanho da partícula da LDL e o nível de triglicérides, o mesmo foi relatado por KULLER et al. (2002).

Em sua revisão, MANOLIO et al. (1996) pesquisaram diversos estudos incluindo 86.000 mulheres e revelaram que existe um risco relativo aumentado de DCV em associação com o nível de CT e LDL-C entre as mulheres com idade inferior a 65 anos, acima dessa idade somente a HDL-C $(<50 \mathrm{mg} / \mathrm{dL})$ associou-se com a mortalidade por DCV.

Neste estudo os valores iniciais referentes aos níveis de LDL foram mais elevados em mulheres brancas $(167,81 \pm 41,65)$ comparadas às mulheres negras $(156$, $51 \pm 29,74)$ esse fato pode ter influenciado na resposta diferente aos momentos do estudo.

WU et al. (2006) estudando um grupo de 27 mulheres na pós-menopausa relataram não haver mudanças nas partículas de LDL após suplementação, esses resultados foram diferentes dos encontrados neste estudo que relatou diferença entre as etnias estudas. As mulheres de etnia branca responderam de forma diferente ao suplemento contendo $\omega-3$ mostrando $(p>0,001$ e $p>0,003)$ valores mais baixos no $\mathrm{M} 1(\mathrm{p}<0,001)$. Ao analisar os momentos, percebeu-se que aos 45 dias os valores encontrados para LDL-C foram os mais baixos e, que o M0 igualou-se ao M2, embora houvesse uma leve diminuição nos valores isolados. No trabalho com suplementação realizado por ACCINNI et al. (2005) foi encontrado maior decréscimo da LDL-C no grupo suplementado com $\omega$-3 e vitamina $\mathrm{E}$, o que vem ao encontro aos achados deste estudo onde os resultados de maiores baixas da LDL-C foram atribuídos à suplementação combinada com vitamina $\mathrm{E}$, isso pode ter ocorrido devido ao baseline mais elevado encontrado no plasma das mulheres suplementadas somente com $\omega$-3. 
Os ácidos graxos polinsaturados $\omega$-3 (AGPI $\omega$-3) vêm atraindo a atenção de inúmeros pesquisadores pelo seu papel em estimular o metabolismo lipídico e turnover de lipoproteínas. Além disso, a maior ingestão de AGPI $\omega$-3 vem acompanhada de aumento da concentração desses ácidos graxos no plasma, o que, por sua vez, pode ser importante para a dinâmica imunológica do indivíduo e na proteção contra eventos cardiovasculares (OLCHAWA et al., 2004).

As concentrações proporcionais dos diferentes ácidos graxos determinados no plasma dos indivíduos a partir da análise cromatográfica estão demonstradas na Tabela 10. 
Tabela 10 Proporção de ácidos graxos no plasma (\%) dos grupos experimentais nos momentos M1, M2 e M3 - Pindamonhangaba - SP, 2007.

\begin{tabular}{|c|c|c|c|c|c|c|c|c|c|c|c|c|c|c|c|c|c|c|}
\hline \multirow{5}{*}{ Ácidos Graxos (\%) } & \multicolumn{18}{|c|}{ Grupos de estudo } \\
\hline & \multicolumn{6}{|c|}{$\mathrm{S} 1+\mathrm{S} 1$} & \multicolumn{6}{|c|}{ S3+S1 } & \multicolumn{6}{|c|}{$\mathrm{S} 3+\mathrm{S} 2$} \\
\hline & \multicolumn{3}{|c|}{ Branca } & \multirow{2}{*}{\multicolumn{2}{|c|}{$\begin{array}{l}\text { Negra } \\
\text { M1 }\end{array}$}} & \multirow{3}{*}{ M2 } & \multicolumn{3}{|c|}{ Branca } & \multicolumn{3}{|c|}{ Negra } & \multicolumn{3}{|c|}{ Branca } & \multicolumn{3}{|c|}{ Negra } \\
\hline & M0 & & M2 & & & & M0 & & M/2 & M0 & & M2 & M0 & & M2 & M0 & & M2 \\
\hline & & $\mathrm{n}=9$ & & & $\mathrm{n}=9$ & & & $\mathrm{n}=12$ & & & $\mathrm{n}=10$ & & & $n=9$ & & & $\mathrm{n}=10$ & \\
\hline \multicolumn{19}{|c|}{ Saturados } \\
\hline \multirow{2}{*}{ Esteárico (C18:0) } & 7,02 & 6,80 & 6,65 & 6,07 & 6,00 & 7.53 & 6,67 & 5,30 & 6,14 & 7,01 & 5,97 & 4,38 & 6,85 & 6,70 & 6,98 & 6,52 & 6,41 & 4,12 \\
\hline & $\pm 2,45$ & $\pm 1,13$ & $\pm 1,20$ & $\pm 1,79$ & $\pm 0,83$ & $\pm 0,71$ & $\pm 1,00$ & $\pm 1,52$ & $\pm 1,05$ & $\pm 1,09$ & $\pm 1,28$ & $\pm 1,33$ & $\pm 1,30$ & $\pm 1,21$ & $\pm 1,06$ & $\pm 2,10$ & $\pm 1,09$ & $\pm 0,73$ \\
\hline \multirow{2}{*}{ Palmítico (C16:0) } & 23,84 & 22,31 & 20,92 & 23,09 & 19,22 & 18,67 & 21,99 & 19,42 & 21,37 & 26,77 & 24,18 & 19,30 & 24,34 & 21,71 & 22,79 & 24.30 & 21,83 & 16,39 \\
\hline & $\pm 3,17$ & $\pm 2,44$ & $\pm 2,58$ & $\pm 3,25$ & $\pm 1,50$ & $\pm 3,40$ & $\pm 2,65$ & $\pm 5,19$ & $\pm 4,25$ & $\pm 4,27$ & $\pm 3,47$ & $\pm 2,42$ & $\pm 3,45$ & $\pm 3,25$ & $\pm 2,14$ & $\pm 3,54$ & $\pm 2,51$ & $\pm 4,73$ \\
\hline \multirow[t]{2}{*}{ Total } & 31,96 & 30,23 & 29,19 & 32,82 & 35,19 & 32,82 & 37,17 & 36,55 & 30,30 & 24,35 & 31,21 & 30,49 & 19,69 & 31,19 & 30,54 & 25,81 & 29,19 & 32,82 \\
\hline & $\pm 4,18$ & $\pm 4,06$ & $\pm 3,62$ & $\pm 5,06$ & $\pm 3,91$ & $\pm 5,06$ & $\pm 7,88$ & $\pm 10,48$ & $\pm 4,89$ & $\pm 6,63$ & $\pm 3,39$ & $\pm 3,75$ & $\pm 4,31$ & $\pm 5,27$ & $\pm 5,03$ & \pm 4.78 & $\pm 3,62$ & $\pm 4,56$ \\
\hline \multicolumn{19}{|c|}{ Monoinsaturados } \\
\hline \multirow{2}{*}{ Palmitoléico (C16:1) } & 2,18 & 2,46 & 2,82 & 1,02 & 2,03 & 2,17 & 2,42 & 3,64 & 1,36 & 3,90 & 2,31 & 2,10 & 3,03 & 2,18 & 1,41 & 3,29 & 2,18 & 2,08 \\
\hline & $\pm 1,84$ & $\pm 0,74$ & $\pm 1,89$ & $\pm 0,96$ & $\pm 0,58$ & $\pm 0,28$ & $\pm 1,12$ & $\pm 1,46$ & $\pm 1,12$ & $\pm 1,75$ & $\pm 0,99$ & $\pm 0,15$ & $\pm 1,16$ & $\pm 0,73$ & $\pm 0,58$ & $\pm 1,08$ & \pm 0.19 & $\pm 0,23$ \\
\hline \multirow{2}{*}{ Oléico (C16:1 $\omega 9 \mathrm{cis})$} & 16,45 & 16,73 & 16,34 & 21,65 & 14,04 & 13,76 & 18,14 & 18,48 & 18,44 & 20,27 & 17,71 & 15,41 & 16,65 & 18,59 & 18,69 & 19,54 & 17,02 & 15,63 \\
\hline & $\pm 2,90$ & $\pm 1,23$ & $\pm 2,89$ & $\pm 1,45$ & $\pm 1,42$ & $\pm 2,33$ & $\pm 5,50$ & $\pm 4,40$ & $\pm 3,40$ & $\pm 5,25$ & $\pm 2,56$ & $\pm 3,08$ & $\pm 2,39$ & $\pm 3,29$ & $\pm 1,40$ & $\pm 2,43$ & $\pm 3,51$ & $\pm 4,02$ \\
\hline \multirow{2}{*}{ Total } & 19,38 & 18,82 & 20,30 & 22,84 & 22,05 & 23,52 & 21,74 & 22,27 & 20,07 & 25,18 & 20,06 & 20,97 & 21,25 & 21,32 & 20,23 & 21,12 & 21,11 & 19,92 \\
\hline & $\pm 4,88$ & $\pm 2,90$ & $\pm 4,48$ & $\pm 4,77$ & $\pm 4,51$ & $\pm 3,56$ & $\pm 10,76$ & $\pm 3,21$ & $\pm 3,22$ & $\pm 7,15$ & $\pm 4,68$ & $\pm 6,28$ & $\pm 2,32$ & $\pm 4,69$ & $\pm 4,84$ & $\pm 5,55$ & $\pm 4,81$ & $\pm 3,79$ \\
\hline & & & & & & & & olinsatu & $\operatorname{ados}$ & & & & & & & & & \\
\hline w6 & & & & & & & & & & & & & & & & & & \\
\hline Linoléico (C18:2) & 33,13 & 27,63 & 30,40 & 35,17 & 31,44 & 30,17 & 28,64 & 28,26 & 33,46 & 25,12 & 33,17 & 33,74 & 30,79 & 31,15 & 33,55 & 33,02 & 31,14 & 32,88 \\
\hline & $\pm 6,09$ & $\pm 6,53$ & $\pm 4,78$ & $\pm 6,48$ & $\pm 4,13$ & $\pm 6,11$ & $\pm 4,32$ & $\pm 6,70$ & $\pm 3,18$ & $\pm 4,35$ & $\pm 9,90$ & $\pm 5,17$ & $\pm 4,9$ & $\pm 4,7$ & $\pm 5,2$ & $\pm 4,54$ & $\pm 3,32$ & $\pm 5,22$ \\
\hline Araquidônico (C20:4) & 7,63 & 7,08 & 7,41 & 4,08 & 5,37 & 3,90 & 7,21 & 5,92 & 5,33 & 4,98 & 6,14 & 6,15 & 7,68 & 4,48 & 6,52 & 6,19 & 6,23 & 6,31 \\
\hline & $\pm 1,63$ & $\pm 1,87$ & $\pm 2,44$ & $\pm 2,58$ & $\pm 0,88$ & $\pm 1,22$ & $\pm 2,34$ & $\pm 2,44$ & $\pm 1,37$ & $\pm 1,07$ & $\pm 2,02$ & $\pm 1,59$ & $\pm 2,06$ & $\pm 0,30$ & $\pm 1,69$ & $\pm 1,33$ & $\pm 2,44$ & $\pm 1,18$ \\
\hline Total & 42,48 & 37,25 & 40,41 & 39,45 & 37,41 & 34,69 & 35,88 & 35,95 & 39,16 & 34,52 & 40,96 & 39,88 & 42,17 & 36,39 & 40,78 & 42,00 & 37,40 & 39,81 \\
\hline & $\pm 6,18$ & $\pm 5,37$ & $\pm 6,56$ & $\pm 6,04$ & $\pm 6,88$ & $\pm 8,25$ & $\pm 7,14$ & $\pm 6,31$ & $\pm 1,37$ & $\pm 16,42$ & $\pm 8,20$ & $\pm 5,68$ & $\pm 5,52$ & $\pm 7,38$ & $\pm 6,04$ & $\pm 7,74$ & $\pm 11,92$ & $\pm 8,97$ \\
\hline w3 & & & & & & & & & & & & & & & & & & \\
\hline Linolênico(C18:3) & 1,09 & 0,78 & 0,99 & 1,25 & 0,32 & 1,12 & 0,97 & 0,69 & 0,87 & 0,71 & 0,37 & 1,15 & 0,94 & 0,89 & 1,21 & 1,52 & 0,11 & 0,37 \\
\hline & $\pm 0,84$ & $\pm 0,52$ & $\pm 0,23$ & $\pm 3,61$ & $\pm 2,36$ & $\pm 1,32$ & $\pm 0,37$ & $\pm 0,35$ & $\pm 0,36$ & $\pm 0,02$ & $\pm 0,46$ & $\pm 0,85$ & $\pm 0,42$ & $\pm 0,51$ & $\pm 0,62$ & $\pm 0,54$ & $\pm 0,02$ & $\pm 0,56$ \\
\hline EPA (C20:5) & 0,21 & 0,58 & 0,59 & 1,19 & 1,47 & 1,02 & 0,11 & 0,52 & 2,75 & 0,99 & 1,31 & 2,01 & 0,38 & 0,69 & 0,82 & 2,56 & 0,85 & 0,98 \\
\hline & $\pm 0,07$ & $\pm 0,22$ & $\pm 0,21$ & $\pm 2,56$ & $\pm 2,21$ & $\pm 0,56$ & $\pm 0,09$ & $\pm 2,32$ & $\pm 0,23$ & $\pm 0,27$ & $\pm 1,02$ & $\pm 1,31$ & \pm 013 & $\pm 0,28$ & $\pm 0,23$ & $\pm 0,23$ & $\pm 0,09$ & $\pm 0,06$ \\
\hline DHA (C22:6) & 5,36 & 9,78 & 7,06 & 2,41 & 3,34 & 6,80 & 5,62 & 7,23 & 7,58 & 2,04 & 7,00 & 12,20 & 4,03 & 7,89 & 9,11 & 1,46 & 11,30 & 11,23 \\
\hline & $\pm 4,64$ & $\pm 4,60$ & $\pm 2,99$ & $\pm 2,09$ & $\pm 3,40$ & $\pm 2,24$ & $\pm 6,90$ & $\pm 5,08$ & $\pm 5,37$ & $\pm 4,71$ & $\pm 6,45$ & $\pm 7,25$ & $\pm 4,79$ & $\pm 5,33$ & $\pm 4,57$ & $\pm 0,43$ & $\pm 6,09$ & $\pm 4,66$ \\
\hline Total & 6,19 & 12,67 & 10,11 & 4,89 & 5,38 & 8,98 & 7,28 & 8,26 & 11,30 & 3,76 & 8,68 & 15,40 & 5,36 & 10,77 & 11,10 & 5,69 & 10,33 & 12,60 \\
\hline & $\pm 6,96$ & $\pm 6,11$ & $\pm 6,69$ & $\pm 3,68$ & $\pm 6,34$ & $\pm 8,00$ & $\pm 6,82$ & $\pm 5,24$ & $\pm 4,89$ & $\pm 4,01$ & $\pm 5,37$ & $\pm 6,42$ & $\pm 3,54$ & $\pm 6,20$ & $\pm 8,81$ & $\pm 3,14$ & $\pm 8,15$ & $\pm 8,46$ \\
\hline Relação w6/w3 & 6,86 & 2,94 & 4,00 & 8,06 & 6,95 & 3,86 & 4,35 & 6,58 & 3,46 & 9,18 & 4,72 & 2,59 & 7,86 & 3,38 & 3,67 & 7,38 & 3,62 & 3,15 \\
\hline & $\pm 3,45$ & $\pm 1,25$ & $\pm 3,21$ & $\pm 10,32$ & $\pm 11,11$ & $\pm 2,32$ & $\pm 3,21$ & $\pm 4,68$ & $\pm 6,71$ & $\pm 2,17$ & $\pm 3,16$ & $\pm 3,01$ & $\pm 12,14$ & $\pm 1,23$ & $\pm 2,92$ & $\pm 5,02$ & $\pm 3,72$ & $\pm 2,13$ \\
\hline Relação P/S & 1,52 & 1,65 & 1,73 & 1,35 & 1,22 & 1,33 & 1,43 & 1,33 & 1,36 & 1,05 & 1,64 & 2,27 & 1,52 & 1,54 & 2,63 & 1,53 & 1,56 & 2,03 \\
\hline & $\pm 0,42$ & $\pm 0,38$ & $\pm 0,42$ & $\pm 0,42$ & $\pm 0,24$ & $\pm 0,37$ & $\pm 0,70$ & $\pm 0,37$ & $\pm 1,20$ & $\pm 0,39$ & $\pm 0,41$ & $\pm 1,20$ & $\pm 0,38$ & $\pm 0,26$ & $\pm 0,59$ & $\pm 0,58$ & $\pm 0,49$ & $\pm 1,18$ \\
\hline
\end{tabular}

${ }^{1}$ Valores expressos como média \pm desvio padrão (DP). S1 + S1 - Grupo controle (grupo placebo), S3 + S1 - Grupo com intervenção à base de óleo de peixe e cápsula placebo; S3 + S2 - Grupo com intervenção à ba de óleo de peixe e cápsula de vitamina E. 
Quando se analisou os ácidos graxos, os resultados inferenciais revelaram que os níveis médios de AGMI (\%) e $\omega-6$ (\%) não foram influenciados pela etnia, suplemento e momento de coleta (Tabela 11).

Tabela 11 Resultados inferenciais (p) na comparação dos AGMI e $\omega$-6, segundo etnia, suplemento e momento de coleta - Pindamonhangaba - SP, 2007.

\begin{tabular}{cccc}
\hline \hline Variável & Etnia & Suplemento & Momento de coleta \\
\hline AGMI $(\%)$ & 0,105 & 0,577 & 0,482 \\
$\omega-6(\%)$ & 0,823 & 0,480 & 0,436 \\
\hline \hline
\end{tabular}

Apesar de não demonstrarem diferenças significativas em relação as variáveis, os AGMI mostraram valores menores ao longo do tempo esse fato pode ser decorrente da menor dessaturação dos ácidos graxos esteárico e palmítico (CURI, 2003).

Igualmente aos resultados deste estudo, WU et al. (2006) encontraram discreta diminuição do colesterol em mulheres suplementadas com DHA e não observaram mudanças quando essa suplementação foi à base de óleo de peixe.

Quanto à variável AGS (\%), os resultados inferenciais revelaram efeito de interação entre momento de coleta, suplemento e etnia $(\mathrm{p}=0,023)$, mulheres negras no M2 (90 dias) apresentaram teores de AGS inferiores aos demonstrados no basal e M1 (45 dias), esse comportamento ocorreu quando o suplemento foi à base de óleo de peixe $(\mathrm{p}=0,001)$ e quando combinado com vitamina $\mathrm{E}(\mathrm{p}=0,009)$, porém o mesmo não ocorreu com a população de etnia branca.

Na Tabela 12 estão demonstras as comparações entre os suplementos, fixando a etnia e o momento de coleta. O Gráfico 4 ilustra o comportamento médio do AGS (\%), segundo momento de coleta, etnia e suplemento. 
Os ácidos graxos saturados elevam a LDL-C no plasma em maior extensão do que o observado pelo aumento do colesterol dietético. Os AGS quando associados, produzem um efeito sinergético sobre a LDL-C, pois inibem a síntese e atividade dos receptores de LDL-C elevando a concentração circulante dessa partícula favorecendo a sua oxidação (KRUMMEL, 1988; SBC, 2001).

Tabela 12 Resultados inferenciais na comparação do AGS segundo momento de coleta, suplemento e etnia - Pindamonhangaba - SP, 2007.

\begin{tabular}{|c|c|c|c|c|c|c|}
\hline \multirow{6}{*}{$\underset{3}{2}$} & \multicolumn{6}{|c|}{ GRUPOS DE ESTUDO } \\
\hline & \multicolumn{2}{|c|}{0 DIAS } & \multicolumn{2}{|c|}{45 DIAS } & \multicolumn{2}{|c|}{90 DIAS } \\
\hline & Branca & Negra & Branca & Negra & Branca & Negra \\
\hline & $\begin{array}{c}(\mathrm{S} 1+\mathrm{S} 1)=(\mathrm{S} 3+\mathrm{S} 1) \\
(\mathrm{p}=0,259)\end{array}$ & $\begin{array}{c}(\mathrm{S} 1+\mathrm{S} 1)=(\mathrm{S} 3+\mathrm{S} 1) \\
(\mathrm{p}=0,783)\end{array}$ & $\begin{array}{c}(\mathrm{S} 1+\mathrm{S} 1)=(\mathrm{S} 3+\mathrm{S} 1) \\
(\mathrm{p}=0,234)\end{array}$ & $\begin{array}{c}(\mathrm{S} 1+\mathrm{S} 1)=(\mathrm{S} 3+\mathrm{S} 1) \\
(\mathrm{p}=0,061)\end{array}$ & $\begin{array}{c}(\mathrm{S} 1+\mathrm{S} 1)=(\mathrm{S} 3+\mathrm{S} 1) \\
(\mathrm{p}=0,925)\end{array}$ & $\begin{array}{c}(\mathrm{S} 1+\mathrm{S} 1)>(\mathrm{S} 3+\mathrm{S} 1) \\
(\mathrm{p}=0,001)\end{array}$ \\
\hline & $\begin{array}{c}(\mathrm{S} 1+\mathrm{S} 1)=(\mathrm{S} 3+\mathrm{S} 2) \\
(\mathrm{p}=0,783)\end{array}$ & $\begin{array}{c}(\mathrm{S} 1+\mathrm{S} 1)=(\mathrm{S} 3+\mathrm{S} 2) \\
(\mathrm{p}=0,536)\end{array}$ & $\begin{array}{c}(\mathrm{S} 1+\mathrm{S} 1)=(\mathrm{S} 3+\mathrm{S} 2) \\
(\mathrm{p}=0,923)\end{array}$ & $\begin{array}{c}(\mathrm{S} 1+\mathrm{S} 1)=(\mathrm{S} 3+\mathrm{S} 2) \\
(\mathrm{p}=0,081)\end{array}$ & $\begin{array}{c}(\mathrm{S} 1+\mathrm{S} 1)=(\mathrm{S} 3+\mathrm{S} 2) \\
(\mathrm{p}=0,619)\end{array}$ & $\begin{array}{c}(\mathrm{S} 1+\mathrm{S} 1)>(\mathrm{S} 3+\mathrm{S} 2) \\
(\mathrm{p}=0,009)\end{array}$ \\
\hline & $\begin{array}{c}(\mathrm{S} 3+\mathrm{S} 1)=(\mathrm{S} 3+\mathrm{S} 2) \\
(\mathrm{p}=0,386)\end{array}$ & $\begin{array}{c}(\mathrm{S} 3+\mathrm{S} 1)>(\mathrm{S} 3+\mathrm{S} 2) \\
\quad(\mathrm{p}=0,039)\end{array}$ & $\begin{array}{c}(\mathrm{S} 3+\mathrm{S} 1)=(\mathrm{S} 3+\mathrm{S} 2) \\
(\mathrm{p}=0,262)\end{array}$ & $\begin{array}{c}(\mathrm{S} 3+\mathrm{S} 1)=(\mathrm{S} 3+\mathrm{S} 2) \\
(\mathrm{p}=0,925)\end{array}$ & $\begin{array}{c}(\mathrm{S} 3+\mathrm{S} 1)=(\mathrm{S} 3+\mathrm{S} 2) \\
(\mathrm{p}=0,523)\end{array}$ & $\begin{array}{c}(\mathrm{S} 3+\mathrm{S} 1)=(\mathrm{S} 3+\mathrm{S} 2) \\
(\mathrm{p}=0,579)\end{array}$ \\
\hline
\end{tabular}

Gráfico 4 Distribuição dos valores médios de AGS (\%), segundo momento de coleta, etnia e suplemento.
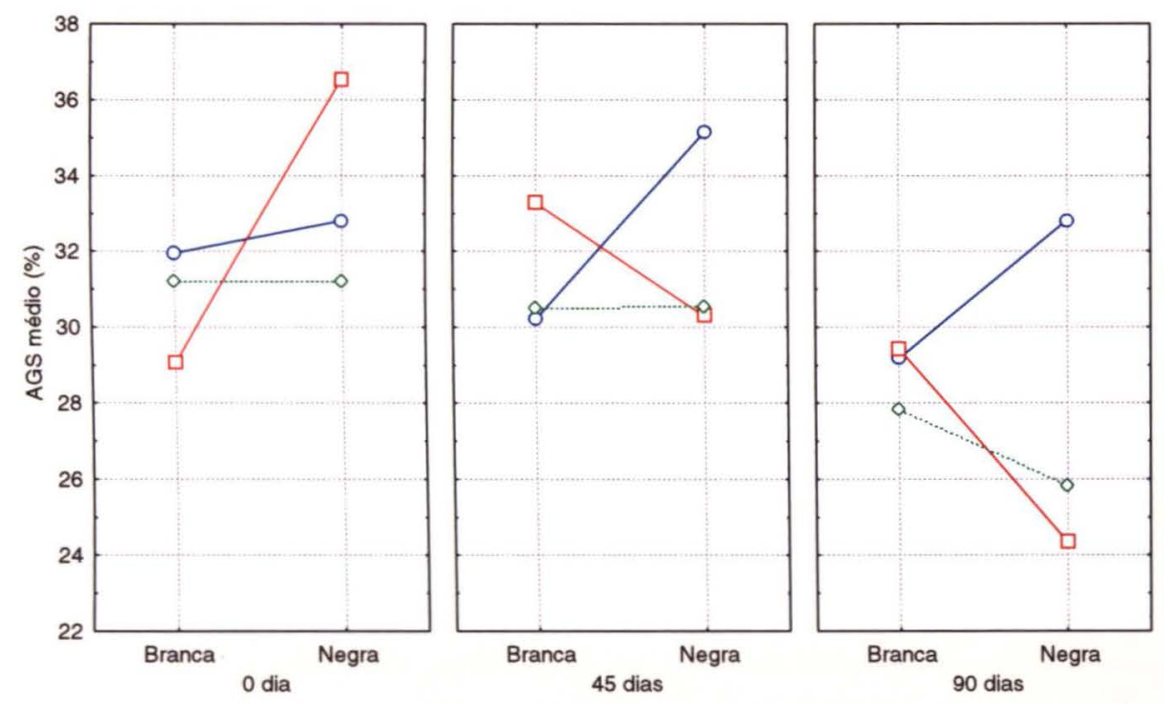

$-\mathrm{S} 1+\mathrm{S} 1$

-ㅁ- $\mathrm{S} 3+\mathrm{S} 1$

$\rightarrow \mathrm{S} 3+\mathrm{S} 2$ 
Os níveis médios do P/S, $\omega-3(\%)$ e $\omega-6 / \omega-3$ foram estatisticamente os mesmos entre os suplementos e etnia, por outro lado foi encontrada relação significativa quando essas variáveis foram comparadas com os momentos de coleta, conforme resumem as Tabelas 13 e 14

Tabela 13 Resultados inferenciais (p) na comparação do P/S, $\omega-3$ (\%) e $\omega-6 / \omega-3$, segundo etnia, suplemento e momento de coleta - Pindamonhangaba - SP, 2007.

\begin{tabular}{cccc}
\hline \hline Variável & Etnia & Suplemento & Momento de coleta \\
\hline $\mathrm{P} / \mathrm{S}$ & 0,850 & 0,283 & $=0,003$ \\
$\omega-3(\%)$ & 0,634 & 0,589 & $<0,001$ \\
$\omega-6 / \omega-3$ & 0,785 & 0,482 & $<0,001$ \\
\hline \hline
\end{tabular}

No Brasil, a média de consumo de pescado é por volta de $6,4 \mathrm{~kg} /$ per capita ao ano (BRASIL, 2002), o que corresponde ao consumo de 17,5g/per capita diários. Sendo assim, a suplementação oferecida neste estudo corresponde a um aumento de aproximadamente $128 \%$ na dieta; esse valor teve influência significativa para modificar a razão $\mathrm{P} / \mathrm{S}$ nos momentos $\mathrm{M} 0$ e $\mathrm{M} 1$.

Segundo CUPPARI (2002) os ácidos graxos da família $\omega$-3 atuam na prevenção das doenças cardiovasculares causando redução da lipemia pós-prandial, que está relacionada com a progressão da aterosclerose. No entanto, os $\omega$-3 só mostram efeitos favoráveis na redução de triglicérides plasmáticos quando administrados em doses diárias superiores a $1 \mathrm{~g} / \mathrm{dL}$, o que mais uma vez corrobora os resultados encontrados neste estudo. 
Tabela 14 Resultados inferenciais (p) na comparação do P/S, $\omega-3$ (\%) e $\omega-6 / \omega-3$, segundo momento de coleta - Pindamonhangaba - SP, 2007.

\begin{tabular}{cc}
\hline \hline Variável & Conclusão \\
\hline $\mathrm{P} / \mathrm{S}$ & $0 \operatorname{dia}=45 \operatorname{dias}(\mathrm{p}=0,369)$ \\
& $0 \operatorname{dia}<90 \operatorname{dias}(\mathrm{p}=0,005)$ \\
& $45 \operatorname{dias}<90 \operatorname{dias}(\mathrm{p}=0,004)$ \\
& $0 \operatorname{dia}<45 \operatorname{dias}(\mathrm{p}=0,001)$ \\
& 0 dia $<90 \operatorname{dias}(\mathrm{p}<0,001)$ \\
& $45 \operatorname{dias}=90 \operatorname{dias}(\mathrm{p}=0,160)$ \\
& 0 dia $>45 \operatorname{dias}(\mathrm{p}<0,001)$ \\
& 0 dia $>90 \operatorname{dias}(\mathrm{p}<0,001)$ \\
& $45 \operatorname{dias}=90 \operatorname{dias}(\mathrm{p}=0,185)$ \\
\hline \hline
\end{tabular}

A etnia $(\mathrm{p}=0,556)$ não influenciou os níveis médios de AGPI (\%). O efeito de interação entre suplemento e o momento de coleta foi detectado na análise desta variável $(\mathrm{p}=0,021)$. A Tabela 15 demonstra as concentrações de AGPI $(\%)$ relacionando suplemento e diferentes momentos de coleta, complementado os resultados ilustrados no Gráfico 5. 
Tabela 15 Resultados inferenciais (p) do AGPI (\%), segundo momento de coleta e suplemento - Pindamonhangaba - SP, 2007.

\begin{tabular}{c|cc}
\hline \hline & Momento de coleta & \multicolumn{1}{c}{ Suplementos } \\
\cline { 2 - 3 } & 0 dia & $(\mathrm{S} 1+\mathrm{S} 1)>(\mathrm{S} 3+\mathrm{S} 1)(\mathrm{p}=0,011)$ \\
& $(\mathrm{S} 1+\mathrm{S} 1)=(\mathrm{S} 3+\mathrm{S} 2)(\mathrm{p}=0,680)$ \\
& $(\mathrm{S} 3+\mathrm{S} 1)<(\mathrm{S} 3+\mathrm{S} 2)(\mathrm{p}=0,003)$ \\
& & \\
& & $(\mathrm{S} 1+\mathrm{S} 1)=(\mathrm{S} 3+\mathrm{S} 1)(\mathrm{p}=0,881)$ \\
& & $(\mathrm{S} 1+\mathrm{S} 1)=(\mathrm{S} 3+\mathrm{S} 2)(\mathrm{p}=0,761)$ \\
& & $(\mathrm{S} 3+\mathrm{S} 1)=(\mathrm{S} 3+\mathrm{S} 2)(\mathrm{p}=0,864)$ \\
& & $(\mathrm{S} 1+\mathrm{S} 1)<(\mathrm{S} 3+\mathrm{S} 1)(\mathrm{p}=0,026)$ \\
& & $(\mathrm{S} 1+\mathrm{S} 1)<(\mathrm{S} 3+\mathrm{S} 2)(\mathrm{p}=0,041)$ \\
& & $(\mathrm{S} 3+\mathrm{S} 1)=(\mathrm{S} 3+\mathrm{S} 2)(\mathrm{p}=0,916)$ \\
\hline \hline
\end{tabular}

Gráfico 5 Distribuição dos valores médios de AGPI (\%), segundo momento de coleta e suplemento - Pindamonhangaba - SP, 2007.

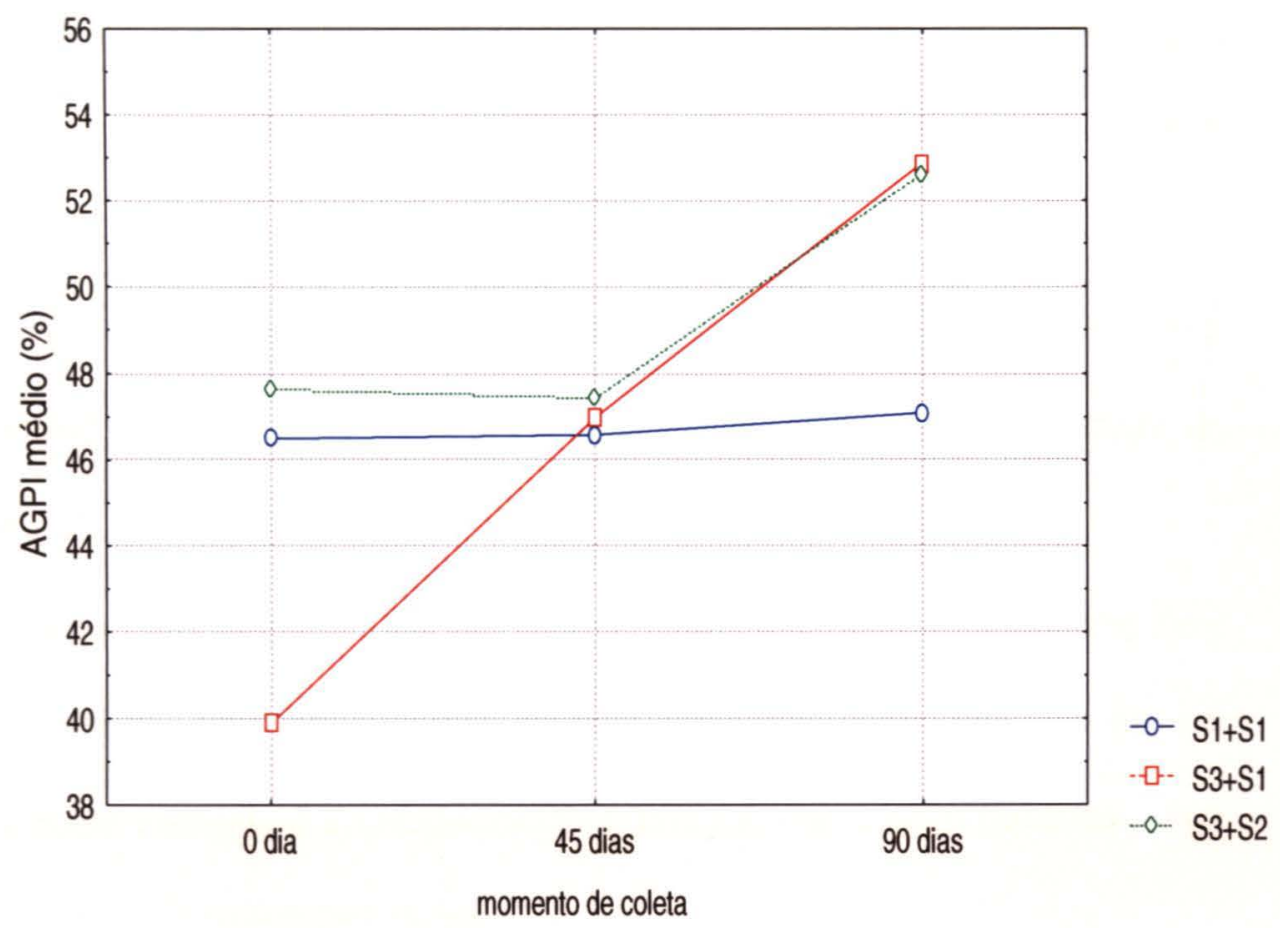

Após a suplementação com óleo de peixe combinado com vitamina E, foi observado aumento na concentração plasmática de EPA e DHA; antagonicamente observou-se pequena redução nos níveis de ácidos graxos araquidônico da família $\omega-6$, 
isso mostra que o modelo de suplementação proposto nesse estudo refletiu na ingestão dietética sendo capaz de proporcionar níveis de ácidos graxos $\omega-3$ no sangue, compatíveis para verificar alterações fisiológicas e bioquímicas no organismo. Esses resultados confirmam os estudos de FOULON et al. (1999) e ANDRADE et al. (2006).

Segundo BROUGHTON e WADE (2002) embora o ácido araquidônico seja preferencialmente metabolizado pela via de cicloxigenase, os ácidos graxos $\omega$-3 inibem competitivamente a atividade da cicloxigenase, o que faz com que a ingestão aumentada de óleo de peixe, rico em ácidos graxos $\omega$-3 resulte na diminuição plasmática de ácido araquidônico.

O perfil dos AGPI no plasma se refere à inter-relação complexa de um grande número de fatores, entre eles a composição da dieta e a taxa de oxidação dos ácidos graxos antes de serem incorporados aos lipídios (VERLENGIA e MARTINS de LIMA, 2003). Nos resultados encontrados neste estudo os indivíduos suplementados com AGPI apresentaram aumento na concentração plasmática de TBA no momento M2 com o suplemento $\omega$-3. Em relação à etnia observou-se que em mulheres de etnia branca os efeitos mais expressivos foram encontrados na suplementação com $\omega$-3 combinado com vitamina $E(p=0,037)$, enquanto na etnia negra essa diferença foi mais acentuada no suplemento $\omega$-3 e placebo $(\mathrm{p}=0,049)$.

As funções biológicas dos AGPI são muitas e, em sua maioria, não estão bem definidas. Acerca disso, CLARKE (2001) mostrou que os AGPI não são apenas utilizados como fonte energética e componente estruturais, mas atuam também como importantes mediadores de expressão gênica.

Segundo pesquisas com esse enfoque, TOBOREK et al. (2002) relataram que as funções mais importantes parecem ser relacionadas à manutenção da integridade das células endoteliais prevenindo a aterosclerose e alterações cardiovasculares. 


\subsection{CONCLUSÕES}

Embora a literatura esteja repleta de trabalhos divergentes, é evidente que os ácidos graxos polinsaturados apresentam grande potencial em afetar a função da fisiologia dos lipídios. Contudo, em relação à suplementação, há divergências entre as faixas de recomendação desses ácidos graxos para humanos e os efeitos das doses suplementadas. Neste estudo ficou demonstrado que:

- A ingestão de óleo de peixe modifica o perfil lipídico de mulheres com dislipidemias no climatério;

- A etnia não foi fator de diferença para a dislipidemia mista, mas demonstra diferenças nas frações isoladas;

- Variáveis categóricas podem influenciar a medida de biomarcadores de dislipidemias;

- A estratégia de combinação de diferentes componentes pode trazer resultados positivos para as frações de colesterol e,

- Mais pesquisas envolvendo o uso e os possíveis benefícios dos ácidos graxos polinsaturados na dinâmica imune e inflamatória similar à população deste estudo necessitam ser conduzidas. 
CAPÍTULO 3

Peroxidação lipídica e auto-anticorpos anti LDL oxidada no plasma em dois grupos étnicos de mulheres com dislipidemias no climatério 
APÍTULO 3 - Peroxidação lipídica e avaliação de auto-anticorpos anti LDL oxidada no plasma em dois grupos étnicos de mulheres com dislipidemias no climatério.

\subsection{INTRODUCÃO}

As últimas décadas têm representado um período de mudanças importantes nas condições de vida e de saúde da população brasileira com ênfase aumentada na população do sexo feminino. A população está mais velha, com um padrão de trabalho e lazer modificados, além de ter promovido profundas transformações na qualidade e quantidade dos alimentos ingeridos (MONTEIRO, 2000).

Essas transformações, inter-relacionadas, têm produzido um padrão de saúde e doença desafiador para os gestores da saúde pública, pela concomitância de rápidas transições demográficas, nutricionais e epidemiológicas que se traduzem em um aumento das doenças e agravos não transmissíveis (OMS, 2003).

O climatério na mulher marca a fase de vida em que ocorre o período reprodutivo ou fértil para o não reprodutivo.

No referente às diferenças étnicas no climatério, vários são os autores que têm direcionado seus estudos às possíveis influências da etnia nas doenças cardiovasculares e doenças associadas (JOHNSON, 2004; LOO, et al., 2004; NAIDOO, 2005; MEARA et al., 2006).

GEORGIOS LYRATZOPOULOS et al. (2005) fizeram estudo comparativo transversal analisando riscos cardíacos em homens e mulheres, Caucasianos Ingleses e Sul-Asiáticos, com idade de 35 a 60 anos e concluíram que caucasianos têm níveis mais altos de exposição aos fatores de riscos estudados. 
DAVIS, et al. (2001) compararam perfil lipídico e pressão arterial em pacientes com diabetes tipo 2 de duas diferentes etnias: Caucasiana e Afro-caribenha, encontrando um prevalência aumentada do perfil lipídico na população de etnia Afro-caribenha.

Em estudo "cross-seccional" com base nos dados de SWAN (Study of Women's Health Across the Nation), AVIS et al. (2001) estudaram sintomatologia da menopausa em diferentes grupos étnicos, não encontrando diferenças significativas ente os grupos.

\section{Risco cardiovascular no climatério}

No Brasil, aproximadamente 2/3 das mulheres que sofrem morte súbita por DCV não apresentam sintomas prévios. Em mulheres negras brasileiras as mortes por DCV são $34 \%$ maiores que em mulheres de etnia branca, entre outros motivos, os mais alarmantes são referentes a prevalência aumentada de obesidade, diabetes e dislipidemias.

A menopausa produz modificações pró-aterogênicas no metabolismo lipídico. Análises cronológicas demonstram que a elevação das concentrações da partícula LDL do colesterol e a redução do colesterol HDL ocorrem de forma gradual e se iniciam antes da menopausa natural (JENSEN et al., 1990). Outro fator importante é que o início da equivalência nas taxas de eventos cardiovasculares entre os sexos coincide com o advento da menopausa e, conseqüentemente, com a privação estrogênica. Essa privação leva a disfunção do endotélio vascular. Desse modo, tem sido atribuídos aos hormônios estrogênios a proteção cardiovascular feminina até a menopausa.

Apesar de dieta rica em peixes contendo ácidos graxos da família $\omega$-3, ser sugerida no decréscimo do risco de doenças cardiovasculares, os lipídios presentes nos AGPI são altamente susceptíveis à deterioração oxidativa (D’AQUINO et al., 1991). Sabe-se, também, que a HDL é extremamente resistente à oxidação, mas em contrapartida a LDL e a [Lp(a)] se oxidam facilmente (HERTOG et al., 1993; KNEKT 
et al., 1996; CRAIG, 1997), sendo que a LDL oxidada (LDL-ox) se torna completamente diferente da LDL nativa e o metabolismo da LDL-ox acarreta na formação de estrias lipídicas (CURI et al., 2002). Na ausência de antioxidantes apropriados, os AGPI formam radicais livres e podem ter efeito pró-oxidante significativo, levando à depleção da vitamina E, como também ao aumento dos produtos de oxidação (MEYDANI, 1996). Daí é necessária uma administração suplementar de antioxidantes para acompanhar consumo elevado de AGPI, uma vez que são exaustivos os estudos confirmando os efeitos benéficos dos mesmos. Por outro lado, ainda não há consenso se o maior aporte de AGPI da família $\omega$-3 aumenta o estresse oxidativo no organismo e, quais seriam as consequiências desse aumento no desenvolvimento de doenças crônicas não transmissíveis na população ocidental, cujo consumo real de peixe está muito abaixo do recomendado.

Além dos efeitos no perfil lipídico, há vários outros efeitos estrogênicos descritos. A atividade antioxidante também tem sido descrita como influenciada pelo estrogênio. Comparativamente, a atividade antioxidante do estrogênio é igual ou superior ao tocoferol e betacaroteno. As funções do estrogênio como antioxidantes incluem a oxidação da LDL, que diminui a quantidade de LDL oxidada incorporada à placa aterosclerótica (SUBBIAH, 1998).

Em todas as formas os tocoferóis são antioxidantes, e isso parece ser a base dos efeitos biológicos dessa vitamina (YOUNGSON, 1995).

Estudos consistentes têm demonstrado que a elevação isolada nos níveis de LDL, por si só, não é capaz de explicar a totalidade dos processos envolvidos na aterosclerose (DAMASCENO et al., 2002; FERNVIK et al., 2004). De encontro a esses achados XAVIER et al (2004) revelaram que os valores de LDL-ox em pacientes com histórico de infarto agudo do miocárdio, em relação ao grupo controle, se mostraram quatro vezes 
mais elevados, dessa forma, os autores sugeriram ser a LDL-ox circulante um marcador de gravidade em eventos cardiovasculares.

Em sua função antioxidante, a vitamina $\mathrm{E}$ age interrompendo as reações em cadeia (com radicais livres) que ocorrem quando a porção lipídica das células (membranas) entra em peroxidação, apresentando uma ação “chain-breaking”, destruindo a cadeia de lipoperoxidação (AMAYA-FARFAN et al., 2001). Os mesmos autores citam que esta vitamina é o antioxidante natural mais abundante no sistema lipossolúvel e, em razão da sua lipossolubilidade, é encontrada em associação com todas as estruturas ricas em lipídios.

Dados experimentais vêm demonstrando que a vitamina $\mathrm{E}$ tem o efeito mais significativo dos antioxidantes na prevenção das coronariopatias e reduz a lesão aterosclerótica induzida pela LDL oxidada (LDL-ox), impedindo o início e a propagação da mesma (O’KEEFE et al., 1996). Também, PÓVOA FILHO (2000) relatou que há correlação inversa entre tocoferol plasmático e mortalidade por cardiopatia isquêmica.

Nos animais, os antioxidantes como o probucol, vitamina E ou hidroxibutilato de tolueno inibem a formação de alterações semelhantes às da aterosclerótica e a suplementação com vitamina $\mathrm{E}$ aumenta a resposta imune e a resistência do hospedeiro a microorganismos (SUN et al., 1997).

Em seres humanos, os antioxidantes como beta-caroteno e $\alpha$-tocoferol (vitamina E) protegem a LDL da oxidação. Ainda, BAYNES e DOMINICZAK (2000) observaram que a proliferação de células do músculo liso do endotélio e do coração causada por ação de ácidos graxos peroxidados pode ser bloqueada pelas vitaminas $\mathrm{C}$ e $\mathrm{E}$.

A vitamina E ainda pode modular a positivamente a resposta imunológica pelo aumento da proporção dos linfócitos $\mathrm{CD} 4 / \mathrm{CD} 8$, da contagem total dos linfócitos, da 
resposta imune humoral, da atividade das células natural killer, da fagocitose e da atividade mitogênica (LIANG, et al., 1996; BATTERTHAM et al., 2002).

MARTIN et al. (1998) realizaram estudos in vitro e verificaram que as células humanas da aorta endotelial tratadas com altas doses de $\alpha$-tocoferol tiveram significativa diminuição na produção de prostaciclina, que é produzida como resposta ao estresse oxidativo induzido pela LDL oxidada.

No entanto, a associação entre doenças e desordens na deficiência de vitamina E, na dieta humana, ainda não está bem determinada, mas há indícios de que a sua deficiência está associada com elevado risco de aterosclerose e outras doenças crônicas não transmissíveis (DESHPANDE et al., 1996).

Com a longevidade aumentada a população do sexo feminino, vive em média cinco a oito anos a mais do que a população masculina, com isso o número absoluto de co-morbidades e mortes é significativamente maior entre as mulheres. Considerando a longevidade e os prejuízos decorrentes da deficiência dos hormônios sexuais na menopausa, é relevante o estudo sobre a peroxidação lipídica e sua relação com os fatores de risco para doenças cardiovasculares em seres humanos, incluindo deficiência de antioxidantes. 


\subsection{OBJETIVOS}

\subsubsection{Geral}

- Avaliar as alterações dos biomarcadores de estresse oxidativo em mulheres com dislipidemias no climatério.

\subsubsection{Específicos}

- Avaliar teores de $\alpha$-tocoferol no plasma sanguíneo de mulheres suplementadas ou não $\operatorname{com} \alpha$-tocoferol;

- Determinar alterações nas lipoproteínas séricas e biomarcadores oxidativos no plasma;

- Determinar o nível de auto-anticorpos anti LDL-ox nos plasmas das pacientes estudadas e,

- Avaliar o efeito da suplementação com $\alpha$-tocoferol na presença de autoanticorpos anti-LDL-ox. 


\subsection{CASUÍSTICA e MÉTODOS}

\subsubsection{População e local do estudo}

A amostra de estudo foi constituída por indivíduos do sexo feminino, voluntárias, de etnia branca e negra com idade entre 40 e 65 anos e com diagnóstico prévio de dislipidemias. Todas as pacientes estavam cadastradas no Programa Saúde da Família (PSF) do município de Pindamonhangaba/SP.

\subsubsection{Desenho do estudo}

O estudo foi do tipo randomizado controlado por placebo, com coletas de dados primários (PEREIRA, 1995; FILHO e ROUQUAYRIOL, 2003).

O tamanho amostral foi estimado em 10 pacientes por grupo de estudo em cada suplemento, perfazendo um total de 60 pacientes, com 30 em cada grupo étnico. Esse cálculo foi feito assumindo-se $\alpha=5$ e $\beta=20 \%$ baseado na fórmula de incidência de estresse oxidativo em população similar à população desse estudo. As análises estatísticas foram realizadas com os softwares Statistical Package for Social Sciences (SPSS) versão 13.0 for Windows e Statistica versão 5.0.

\subsubsection{Critérios de seleção e exclusão}

Foram selecionadas 87 pacientes dentre as pacientes do prontuário do PSF que atenderam aos critérios de inclusão (previamente descritos no item 3.2 do capítulo 1). 59 pacientes completaram o estudo, 30 de etnia branca e 29 de etnia negra. O projeto de pesquisa recebeu parecer favorável do Comitê de Ética em Pesquisa da Faculdade de Saúde Pública de São Paulo (ANEXO 1) e pelo Programa de Saúde da Família (PSF) de Pindamonhangaba. O consentimento esclarecido por escrito ou impressão digital foi obtido de todas as participantes do estudo (ANEXO 2). 


\subsubsection{Variáveis de estudo}

3.3.4.1 Caracterização da população

Para descrever as características da população de estudo foi realizado questionário investigativo onde as pacientes responderam questões de caráter sócioeconômico e comportamental (ANEXO 4).

\subsubsection{Variáveis Bioquímicas}

Para avaliação da peroxidação lipídica do plasma sangüíneo foram tomados os resultados das frações LDL do plasma através da equação de FRIEDEWALD e realizadas as análises para determinar teores de alfa-tocoferol, substâncias reativas ao ácido tiobarbitúrico (TBARS) e detecção de auto-anticorpos anti-LDL:

As amostras de sangue foram colhidas pelo sistema "vacutainer". Os pacientes obedeceram 12 horas de jejum, visando reduzir as modificações oxidativas durante o armazenamento $\left(-20^{\circ} \mathrm{C}\right)$. Os tubos com plasma, destinados à análise de $\alpha$-tocoferol foram envoltos em papel alumínio para proteção da luz, mantido sob refrigeração em caixas isotérmicas e centrifugados em até uma hora após a coleta. Um mililitro do plasma foi aliqüotado em microtubos eppendorff para as análises de autoanticorpos anti LDL-ox e, nessas alíquotas foram acrescentados os seguintes inibidores de protease: aprotinina $(10,0 \mu \mathrm{g} / \mathrm{mL})$, benzamidina $(10,0 \mu \mathrm{gmL})$, fluoreto de fenilmetilsulfonilaPMSF $(5,0 \mu \mathrm{g} / \mathrm{mL})$ e o antioxidante 2,6 di-ter-butil-p-hidroxitolueno BHT (100,0 $\mu \mathrm{M})$. Todos os reagentes foram de marca Sigma Chemical ® (ST, Louis, MO, USA). Após a inibição de protease foram reservados à $-30^{\circ} \mathrm{C}$ até a realização da análise. 


\subsection{Determinação de alfa-tocoferol:}

\section{Extração de $\alpha$-tocoferol}

As amostras de plasma foram descongeladas à temperatura ambiente e no escuro para evitar a degradação da vitamina E, o preparo para análise e a injeção foram realizados no mesmo dia. Antes do início da corrida das amostras, uma vez por dia, foram realizadas injeções de alguns pontos da curva de calibração de corridas em branco.

Para extração do $\alpha$-tocoferol da amostra, $200 \mu$ mol do plasma foram colocados em um microtubo âmbar de 2,0 mL, juntamente com $200 \mu$ mol da solução de etanol (Vetec). A mistura foi agitada por 5 segundos em Vórtex (Biomixer-MVS-1), acrescentados $5 \mathrm{~mL}$ de hexano (Merck) e novamente levado ao Vórtex por 2 minutos. Após esse período foi submetida à centrifugação a 3000 RPM (700xg), centrífuga Eppendorf ${ }^{\circledR}$ (Centrifuge 5415C) por aproximadamente 5 minutos, finalizado o processo, $250 \mu \mathrm{L}$ do sobrenadante foram retirados e estocados em tubo de $10 \mathrm{~mL}$ recoberto com papel alumínio e protegido da luz, a amostra sofreu evaporação por nitrogênio e foi reconstituída em $200 \mu \mathrm{L}$ da fase móvel e injetada imediatamente (MORIEL, 2000).

A injeção foi manual em injetor de marca Rheodyne e foram utilizados $20 \mu \mathrm{L}$ de volume para a injeção, tanto para os pontos de curva de quantificação quanto para as amostras.

A quantificação de $\alpha$ tocoferol foi realizada em equipamento de cromatografia líquida (HPLC), no laboratório de Bioquímica da Faculdade de Saúde Pública da Universidade de São Paulo. 
$\mathrm{O}$ equipamento de cromatografia líquida consiste em 01 Solvent Delivery Module LC-10ADVP, 01 System Controller SCL-10AVP da marca Shimadzu e 01 detector fluorescência de marca Merck Hitachi L7480. No detector por fluorescência foi empregado comprimento de excitação de 295 nm e emissão de 325 nm para o $\alpha$ tocoferol. A fase estacionária da coluna cromatográfica utilizada foi C18 num fluxo isocrático de $1,0 \mathrm{~mL} / \mathrm{min}$. O tempo total da análise após a injeção no HPLC foi de aproximadamente 5 minutos para cada amostra.

A fase móvel para separação do $\alpha$-tocoferol foi composta por $70 \%$ Acetonitrila (Vetec), 10\% Metanol (Merck) e 20\% Diclorometano (Merck), ressaltando-se que todos os reagentes utilizados na análise foram grau HPLC.

\subsection{Mensuração de substâncias reativas ao ácido tiobarbitúrico (TBARS)}

A concentração de TBARS foi mensurada para indicar a ocorrência de peroxidação lipídica no plasma. Um mililitro de solução de TBA (TBA 0,046 mol/L; TCA $0,092 \mathrm{~mol} / \mathrm{L}$ e HCL $0,25 \mathrm{~mol} / \mathrm{L}$ ) foi adicionado em $500 \mu \mathrm{L}$ de plasma (diluição 1:10 em PBS $0.02 \mathrm{M}$ pH=7.4). Em seguida as amostras foram colocadas em banhomaria em ebulição por 30 minutos. Após este procedimento as amostras foram submetidas à centrifugação refrigerada Sigma ${ }^{\circledR}$ 318-K (rotação de $3000 \mathrm{rpm}$, a $4^{\circ} \mathrm{C}$ por 15 minutos). A absorbância do sobrenadante foi lida em espectrofotômetro Shimadzu UV 1650 PC com comprimento de onda de $535 \mathrm{~nm}$ contra o branco (todos os reagentes, exceto as amostras). A quantificação foi feita usando-se curva de calibração 1,1,3,3 tetraetoxipropano-TEP (ANTOLOVICH et al., 2002; CIRICO e OMAYE , 2006; MURSU et al., 2005) e expressa como $\mu \mathrm{mol}$ de TBARS/mL de plasma. Todas as amostras foram realizadas em duplicata. 


\subsection{Detecção de auto-anticorpos anti-LDL}

A caracterização do anticorpo monoclonal anti-LDL' foi baseado no protocolo de DAMASCENO et al (2002).

A determinação dos auto-anticorpos anti-LDLox foi realizada por meio de ELISA de captura de anticorpo. Em um primeiro momento as placas foram sensibilizadas com $\mathrm{LDL}^{-}$, isoladas por FPLC, previamente diluídas em tampão carbonato-bicarbonato $(0,25 \mathrm{M}, \mathrm{pH} 9,6)$ até a concentração final de $0,5 \mu \mathrm{g}$ de proteína/poço e incubada 12 horas a $4^{\circ} \mathrm{C}$. Após esse período os espaços livres foram bloqueados com leite desnatado a 5\% diluído em tampão fosfato salina 0,01 M (PBS $\mathrm{pH} 7,4)$ e incubados à $37^{\circ} \mathrm{C}$ por mais 2 horas. Seguido a esse procedimento as placas foram lavadas com PBS-Tween $(0,05 \%)$ por quatro vezes em lavadora automática para microplacas e tiras ELISA (THERMO PLATER WASHER). As amostras de plasma, em triplicata e diluição de 1:800 em PBS foram incubadas a $37^{\circ} \mathrm{C}$ por 2 horas. Depois de nova lavagem, seguindo a programação descrita acima, foi adicionado $50,0 \mu \mathrm{L}$ poço de anti IgG humano marcado com peroxidase (Sigma Chemical - St. Louis, MO - USA) (1:1000) diluído em PBS. As placas foram novamente incubadas a $37^{\circ} \mathrm{C}$ por 1 hora e 30 minutos e em seguida sofreram nova lavagem com repetição por quatro vezes. A reação de cor foi desenvolvida através da adição de substrato composto por 3,3,5,5 tetrametilbenzima (TMB) tampão citrato-fosfato (0,1M; pH 0,2$)$ e $\mathrm{H}_{2} \mathrm{O}_{2} \quad(30 \%)$ $(250 / 12 / 10, \mu \mathrm{L} / \mathrm{mL} / \mu \mathrm{L}$, respectivamente). As placas foram incubadas por 30 minutos em temperatura ambiente e protegidas da luz com papel alumínio. A reação foi bloqueada com $50 \mu \mathrm{L}$ /poço de $\mathrm{H}_{2} \mathrm{SO}_{4}(2,0 \mathrm{M})$ e a absorbância monitorada por leitor de

placa (Spectra Count, Camberra Company, Meriden, CT) em 450nm. Para a determinação dos resultados usou-se a média das absorbâncias menos o controle aplicados à equação da curva padrão de IgG humana (Sigma Chemical - St. Louis, MO 
- USA) $(0,18$ - 11,7 mg/mL), sendo expressas em equivalentes de anti-IgG humana anti $\mathrm{LDL}^{-}$

\subsection{MÉTODO ESTATÍSTICO}

A análise de todas as informações coletadas nesta pesquisa foi inicialmente feita de forma descritiva.

Para as variáveis de natureza quantitativa foram calculadas algumas medidasresumo, como a média, desvio-padrão, entre outras, e confeccionados gráficos do tipo boxplot (BUSSAB e MORETTIN, 2006).

A análise inferencial empregada com o intuito de confirmar ou refutar evidências encontradas na análise descritiva foi a análise de variância com medidas repetidas, além das comparações múltiplas pelo método LSD, quando necessário (NETER et al, 1996).

Em todas as conclusões obtidas através das análises inferenciais foi utilizado o nível de significância $\alpha$ igual a 5\%.

Os dados foram digitados em planilhas do Excel 2000 for Windows para o adequado armazenamento das informações. As análises estatísticas foram realizadas com os softwares Statistical Package for Social Sciences (SPSS) versão 13.0 for Windows e Statistica versão 5.0. 


\subsection{RESULTADOS e DISCUSSÃO}

\section{População de estudo e casuística}

A amostra selecionada foi composta por 59 mulheres, sendo $30(50,84 \%)$ de etnia branca e $29(49,16 \%)$ de etnia negra. A população de estudo foi caracterizada de forma detalhada no item 5.1 do Capítulo 2.

O Gráfico 1 mostra a distribuição segundo etnia e suplemento recebido.

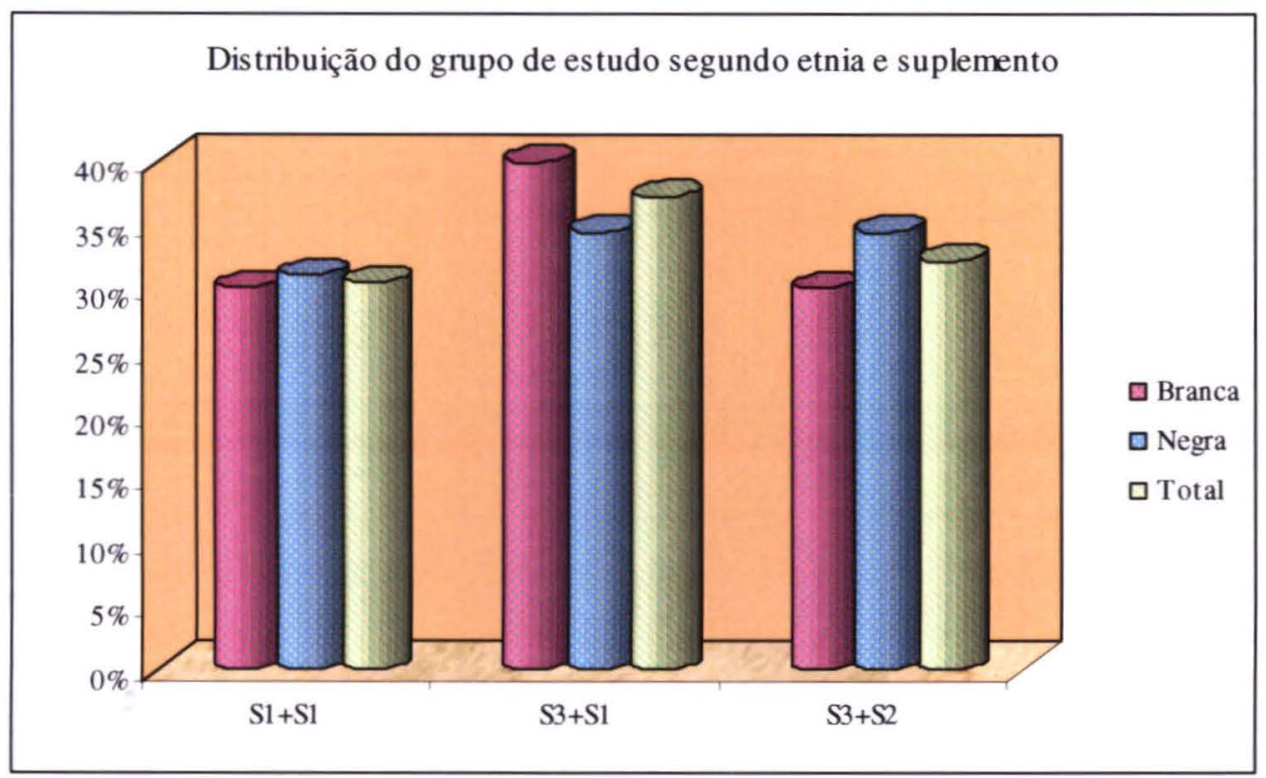

Gráfico 1 Distribuição do grupo de estudo, segundo etnia e suplemento. $(\mathrm{S} 1+\mathrm{S} 1$ = placebo $; \mathrm{S} 3+\mathrm{S} 1=$ óleo de peixe+placebo, $\mathrm{S} 3+\mathrm{S} 2=$ óleo de peixe + vitamina $\mathrm{E})$.

\section{Biomarcadores sanguíneos}

Os biomarcadores sanguíneos avaliados incluíram análise de colesterol total e frações LDL, auto-anticorpos anti-LDL' $\alpha$-tocoferol $(\mu \mathrm{Mol} / \mathrm{mL})$ e TBARS $(\mu \mathrm{Mol} / \mathrm{mL})$.

A oxidação do plasma foi avaliada pelo teste de substâncias reativas ao ácido tiobarbitúrico (TBARS) e foi comparada com os teores de $\alpha$-tocoferol e com o parâmetro para os resultados e auto-anticorpos anti-LDL-ox.

As informações sobre LDL $(\mathrm{mg} / \mathrm{dL}), \alpha$-Tocoferol $(\mu \mathrm{mol} / \mathrm{L})$ e TBARS $(\mu \mathrm{mol} / \mathrm{L})$ nos três momentos de coleta ( 0,45 e 90 dias) estão relatadas na Tabela 1 . 
Tabela 1 - LDL, parâmetros oxidativos e alfa-tocoferol plasmático ${ }^{1}$ - Pindamonhangaba - SP, 2007.

\begin{tabular}{|c|c|c|c|c|c|c|c|c|c|c|c|c|c|c|c|c|c|c|}
\hline \multirow{4}{*}{ Variáveis } & \multicolumn{18}{|c|}{ Grupos de estudo } \\
\hline & \multicolumn{6}{|c|}{$\mathrm{S} 1+\mathrm{S} 1$} & \multicolumn{6}{|c|}{$\mathrm{S} 3+\mathrm{S} 1$} & \multicolumn{6}{|c|}{$\mathrm{S} 3+\mathrm{S} 2$} \\
\hline & \multicolumn{3}{|c|}{ Branca } & \multicolumn{3}{|c|}{ Negra } & \multicolumn{3}{|c|}{ Branca } & \multicolumn{3}{|c|}{ Negra } & \multicolumn{3}{|c|}{ Branca } & \multicolumn{3}{|c|}{ Negra } \\
\hline & M0 & M1 & M2 & M0 & M1 & M2 & M0 & MI & M2 & M0 & M1 & M2 & M0 & M1 & M2 & M0 & M1 & M2 \\
\hline LDL (mg/dL) & $\begin{array}{l}173,14 \\
\pm 33,18\end{array}$ & $\begin{array}{l}162,29 \\
\pm 24,81\end{array}$ & $\begin{array}{l}143,13 \\
\pm 46,06\end{array}$ & $\begin{array}{l}149,10 \\
\pm 11,22\end{array}$ & $\begin{array}{l}127,89 \\
\pm 17,57\end{array}$ & $\begin{array}{l}159,30 \\
\pm 26,86\end{array}$ & $\begin{array}{l}163,36 \\
\pm 42,99\end{array}$ & $\begin{array}{l}147,42 \\
\pm 48,02\end{array}$ & $\begin{array}{l}153,38 \\
\pm 43,34\end{array}$ & $\begin{array}{l}167,18 \\
\pm 24,60\end{array}$ & $\begin{array}{l}139,27 \\
\pm 15,34\end{array}$ & $\begin{array}{l}155,27 \\
\pm 37,71\end{array}$ & $\begin{array}{l}153,60 \\
\pm 31,75\end{array}$ & $\begin{array}{l}102,80 \\
\pm 25,78\end{array}$ & $\begin{array}{l}118,70 \\
\pm 41,04\end{array}$ & $\begin{array}{l}158,25 \\
\pm 31,75\end{array}$ & $\begin{array}{l}130,44 \\
\pm 40,53\end{array}$ & $\begin{array}{l}132,25 \\
\pm 24,17\end{array}$ \\
\hline $\begin{array}{l}\text { TBARS } \\
(\mu \mathrm{Mol} / \mathrm{L})\end{array}$ & $\begin{array}{l}0,07 \\
\pm 0,05\end{array}$ & $\begin{array}{l}0,07 \\
\pm 0,04\end{array}$ & $\begin{array}{l}0,06 \\
\pm 0,04\end{array}$ & $\begin{array}{l}0,05 \\
\pm 0,04\end{array}$ & $\begin{array}{l}0,05 \\
\pm 0,04\end{array}$ & $\begin{array}{l}0,04 \\
\pm 0,02\end{array}$ & $\begin{array}{l}0,03 \\
\pm 0,05\end{array}$ & $\begin{array}{l}0,05 \\
\pm 0,06\end{array}$ & $\begin{array}{l}0,08 \\
\pm 0,04\end{array}$ & $\begin{array}{l}0,04 \\
\pm 0,02\end{array}$ & $\begin{array}{l}0,07 \\
\pm 0,04\end{array}$ & $\begin{array}{l}0,09 \\
\pm 0,03\end{array}$ & $\begin{array}{l}0,03 \\
\pm 0,03\end{array}$ & $\begin{array}{l}0,05 \\
\pm 0,04\end{array}$ & $\begin{array}{l}0,04 \\
\pm 0,04\end{array}$ & $\begin{array}{l}0,06 \\
\pm 0,04\end{array}$ & $\begin{array}{l}0,07 \\
\pm 0,04\end{array}$ & $\begin{array}{l}0,06 \\
\pm 0,03\end{array}$ \\
\hline $\begin{array}{l}\text { Auto-LDL } \\
(\mathrm{mg} / \mathrm{mL})\end{array}$ & $\begin{array}{r}47,61 \\
\pm 3,59\end{array}$ & $\begin{array}{l}45,65 \\
\pm 3,96\end{array}$ & $\begin{array}{c}35,84 \\
\pm 7,10\end{array}$ & $\begin{array}{l}39,69 \\
\pm 7,10\end{array}$ & $\begin{array}{l}42,39 \\
\pm 5,92\end{array}$ & $\begin{array}{l}35,87 \\
\pm 4,76\end{array}$ & $\begin{array}{l}48,89 \\
\pm 4,27\end{array}$ & $\begin{array}{l}45,95 \\
\pm 3,58\end{array}$ & $\begin{array}{l}38,03 \\
\pm 3,56\end{array}$ & $\begin{array}{l}48,58 \\
\pm 3,20\end{array}$ & $\begin{array}{l}46,55 \\
\pm 2,61\end{array}$ & $\begin{array}{l}39,66 \\
\pm 4,62\end{array}$ & $\begin{array}{l}49,35 \\
\pm 3,79\end{array}$ & $\begin{array}{l}43,15 \\
\pm 5,62\end{array}$ & $\begin{array}{l}36,52 \\
\pm 2,84\end{array}$ & $\begin{array}{l}47,10 \\
\pm 4,34\end{array}$ & $\begin{array}{l}42,95 \\
\pm 4,04\end{array}$ & $\begin{array}{l}37,75 \\
\pm 4,01\end{array}$ \\
\hline $\begin{array}{l}\alpha \text {-tocoferol } \\
(\mu \mathrm{Mol} / \mathrm{L})\end{array}$ & $\begin{array}{l}14,24 \\
\pm 5,26\end{array}$ & $\begin{array}{l}11,36 \\
\pm 4,17\end{array}$ & $\begin{array}{l}15,24 \\
\pm 5,50\end{array}$ & $\begin{array}{l}14,92 \\
\pm 3,03\end{array}$ & $\begin{array}{l}17,13 \\
\pm 6,29\end{array}$ & $\begin{array}{l}23,20 \\
\pm 10,92\end{array}$ & $\begin{array}{l}14,74 \\
\pm 3,72\end{array}$ & $\begin{array}{l}14,26 \\
\pm 2,53\end{array}$ & $\begin{array}{l}14,27 \\
\pm 6,90\end{array}$ & $\begin{array}{l}15,66 \\
\pm 4,37\end{array}$ & $\begin{array}{l}16,48 \\
\pm 3,85\end{array}$ & $\begin{array}{l}17,55 \\
\pm 3,85\end{array}$ & $\begin{array}{l}15,00 \\
\pm 4,95\end{array}$ & $\begin{array}{l}16,83 \\
\pm 2,14\end{array}$ & $\begin{array}{l}20,44 \\
\pm 10,17\end{array}$ & $\begin{array}{l}14,92 \\
\pm 4,59\end{array}$ & $\begin{array}{l}18,53 \\
\pm 8,97\end{array}$ & $\begin{array}{l}20,25 \\
\pm 11,07\end{array}$ \\
\hline
\end{tabular}

Valores expressos como média \pm desvio padrão $(\mathrm{DP}) ;(\mathrm{S} 1+\mathrm{S} 1)=$ grupo placebo; $(\mathrm{S} 3+\mathrm{S} 1)=$ grupo óleo de peixe+placebo; $(\mathrm{S} 3+\mathrm{S} 2)=$ grupo óleo de peixe + vitamina $\mathrm{E}$. $(\mathrm{M} 0)=$ baseline $;(\mathrm{M} 1)=45$ dias; $(\mathrm{M} 2)=90$ dias. 
A oxidação da LDL é considerada o principal evento de iniciação do desenvolvimento da aterosclerose (CHISOLM e STEINBERG, 2000; LULIANO, 2001). A LDL oxidada (LDL-ox) age como fator quimiotático para monócitos que, transformados em macrófagos túrgidos com lipídios (células espumosas), exerce efeitos citotóxicos sobre as células endoteliais, aumentando a ativação de plaquetas, estimulando a migração e a proliferação de células musculares lisas (SMC) e antagonizando os efeitos vasodilatadores do óxido nítrico (CHISOLM e STEINBERG, 2000). Diversos autores têm mostrado que a HDL reduz significativamente as modificações oxidativas da LDL (KONTUSH et al, 2003; FREDENRICH e BAYER, 2003). Os autores explicam que a inibição da oxidação da LDL pela HDL é comumente atribuída ao seu conteúdo de antioxidante ( $\alpha$-tocoferol, licopeno).

Neste estudo, os resultados inferenciais na comparação dos valores médios de LDL (mg/dL) revelaram efeito do momento de coleta (Tabela 2), demonstrando que o Momento 1 (45 dias) apresentou a melhor resposta ao suplemento. Além disso, também foi detectada interação entre etnia e suplemento, desta forma as comparações foram feitas entre os suplementos para cada etnia conforme ilustra o Gráfico 2.

Tabela 2 Resultados inferenciais (p) na comparação da LDL (mg/dL), segundo momento de coleta - Pindamonhangaba - SP, 2007.

\begin{tabular}{c}
\hline Conclusão \\
\hline $0 \operatorname{dia}>45 \operatorname{dias}(\mathrm{p}<0,001)$ \\
$0 \operatorname{dia}=90 \operatorname{dias}(\mathrm{p}=0,078)$ \\
$45 \operatorname{dias}<90 \operatorname{dias}(\mathrm{p}=0,042)$ \\
\hline
\end{tabular}


Gráfico 2 Boxplots da LDL (mg/dL), segundo etnia, suplemento e momento de coleta. Pindamonhangaba - SP, 2007.

Etnia Branca

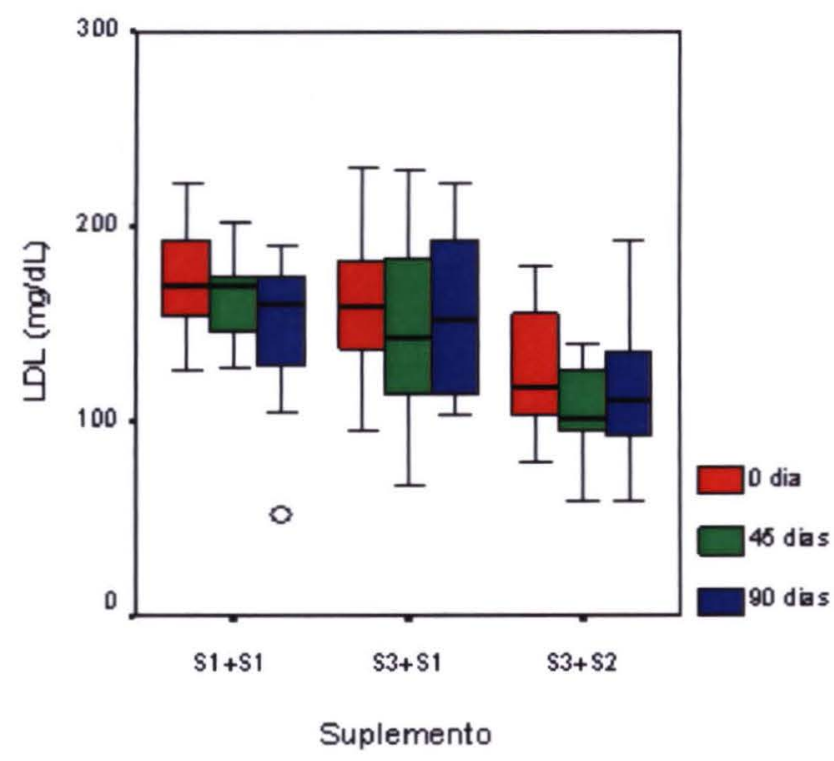

Etnia Negra

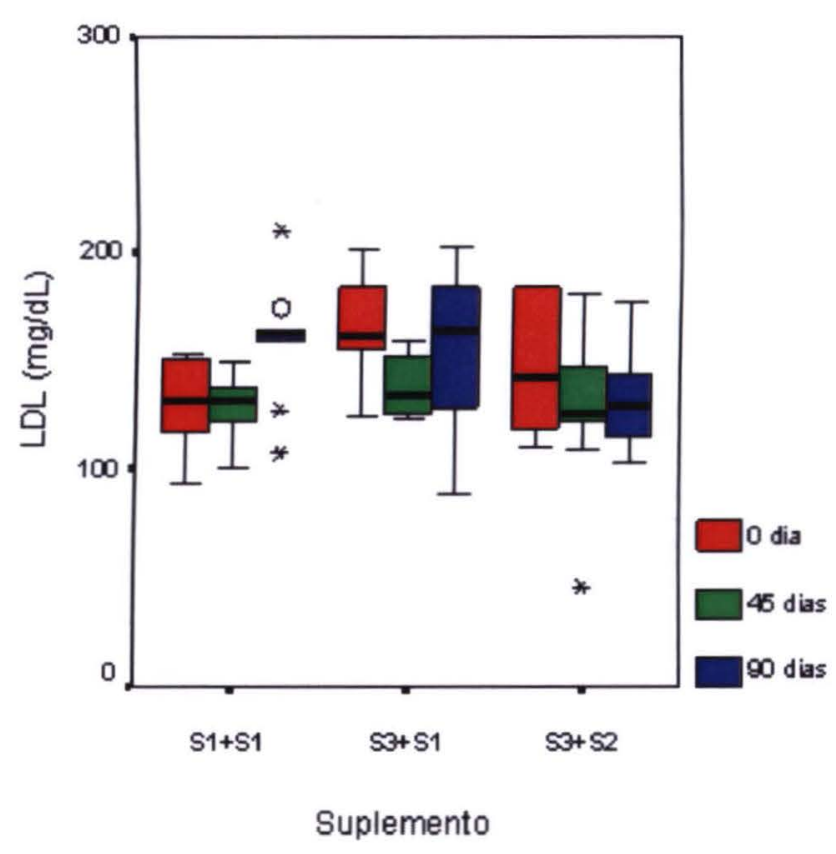


Neste estudo os resultados inferenciais na comparação dos valores médios de detecção de auto-anticorpos anti LDL-ox $(\mathrm{mg} / \mathrm{mL})$ revelaram efeito de interação entre momento de coleta e suplemento $(\mathrm{p}=0,036)$, foram observados maiores índices de autoanticorpos anti LDL-ox no suplemento com $\omega$-3 combinado com placebo; da mesma forma constatou-se que a etnia branca, no basal, apresentou maiores índices de autoanticorpos anti LDL-ox $(p=0,006)$; diferença essa que não foi detectada durante a suplementação.

As Tabelas 3 e 4 trazem, respectivamente, os resultados das comparações entre os suplementos e etnias em todos os momentos de coleta. O Gráfico 3 demonstra a distribuição dos valores médios de detecção de auto-anticorpos anti LDL-ox (mg/mL) nos diversos momentos de coleta, segundo suplemento e etnia, respectivamente.

Tabela 3 Resultados inferenciais (p) na comparação de detecção de auto- anticorpos anti LDL-ox (mg/mL), segundo momento de coleta e suplemento Pindamonhangaba - SP, 2007.

\begin{tabular}{l|ccc}
\hline \hline & \multicolumn{3}{|c}{ Momento de coleta } \\
\cline { 2 - 4 } & 0 DIAS & 45 DIAS & DIAS \\
\cline { 2 - 4 } & $\begin{array}{c}(\mathrm{S} 1+\mathrm{S} 1)<(\mathrm{S} 3+\mathrm{S} 1) \\
(\mathrm{p}<0,001)\end{array}$ & $\begin{array}{c}(\mathrm{S} 1+\mathrm{S} 1)=(\mathrm{S} 3+\mathrm{S} 1) \\
(\mathrm{p}=0,113)\end{array}$ & $\begin{array}{c}(\mathrm{S} 1+\mathrm{S} 1)<(\mathrm{S} 3+\mathrm{S} 1) \\
(\mathrm{p}=0,008)\end{array}$ \\
\cline { 2 - 4 } & $\begin{array}{c}(\mathrm{S} 1+\mathrm{S} 1)<(\mathrm{S} 3+\mathrm{S} 2) \\
(\mathrm{p}<0,001)\end{array}$ & $\begin{array}{c}(\mathrm{S} 1+\mathrm{S} 1)=(\mathrm{S} 3+\mathrm{S} 2) \\
(\mathrm{p}=0,658)\end{array}$ & $\begin{array}{c}(\mathrm{S} 1+\mathrm{S} 1)=(\mathrm{S} 3+\mathrm{S} 2) \\
(\mathrm{p}=0,194)\end{array}$ \\
\cline { 2 - 4 } & $\begin{array}{c}(\mathrm{S} 3+\mathrm{S} 1)=(\mathrm{S} 3+\mathrm{S} 2) \\
(\mathrm{p}=0,484)\end{array}$ & $\begin{array}{c}\mathrm{S} 3+\mathrm{S} 1)>(\mathrm{S} 3+\mathrm{S} 2) \\
(\mathrm{p}=0,042)\end{array}$ & $\begin{array}{c}\mathrm{S} 3+\mathrm{S} 1)=(\mathrm{S} 3+\mathrm{S} 2) \\
(\mathrm{p}=0,181)\end{array}$ \\
\hline \hline
\end{tabular}


Tabela 4 Resultados inferenciais (p) na comparação de detecção de auto-anticorpos anti LDL-ox (mg/mL), segundo momento de coleta e etnia Pindamonhangaba - SP, 2007.

\begin{tabular}{cl}
\hline \hline Momento de coleta & Comparação entre etnias \\
\hline 0 dia & Branca $>$ Negra $(\mathrm{p}<0,001)$ \\
45 dias & Branca $=$ Negra $(\mathrm{p}=0,215)$ \\
90 dias & Branca $=$ Negra $(\mathrm{p}=0,285)$ \\
\hline \hline
\end{tabular}

Gráfico 3 Distribuição dos valores médios de detecção de auto-anticorpos anti LDLox $(\mathrm{mg} / \mathrm{mL})$, segundo momento de coleta e etnia - Pindamonhangaba SP, 2007.

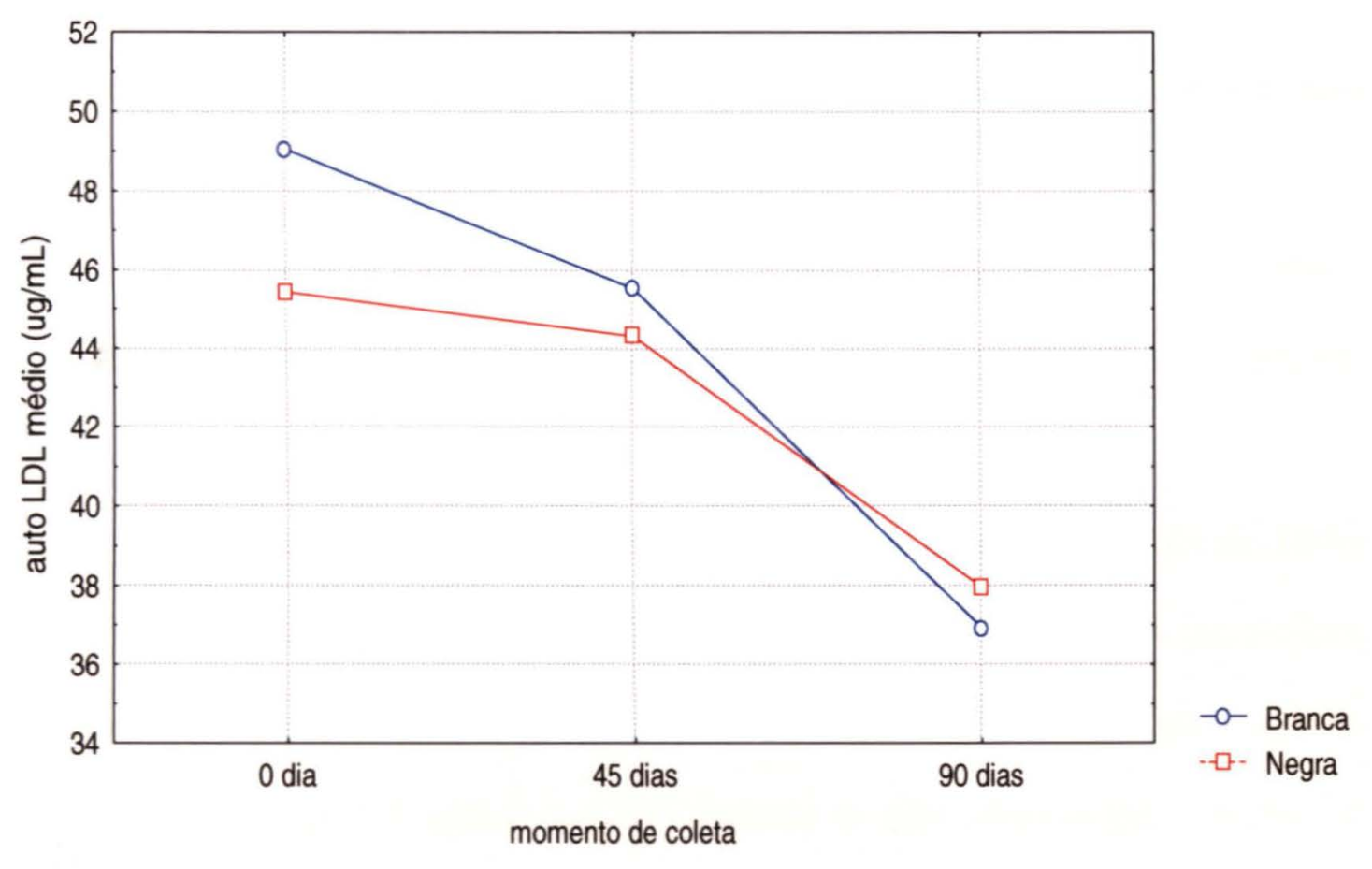


A LDL modificada por oxidação denominada, LDL-ox, é um importante fator aterogênico. TOSHIMA et al. (2000) mostraram ser esse marcador bioquímico um fator de risco independente para DCV uma vez que não há associação com níveis de colesterol, tabagismo, sexo ou etnia.

Por outro lado, sabe-se que a formação de auto-anticorpos anti LDL-ox é dependente da suscetibilidade individual de base genética e de outros fatores, entre eles a concentração de antioxidantes e dos ácidos graxos insaturados na LDL (TINAHONES et al., 2005).

Os resultados encontrados neste estudo podem ser atribuídos à suplementação com óleo de peixe e $\alpha$-tocoferol. De acordo com a literatura (BARROS, 2006) essa variação de geração de auto-anticorpos pode ser explicada pelo aumento de imunocomplexos no plasma, outra explicação pode ser dada pela resposta imunológica individual perante aos antígenos (ROSSI et al., 2003).

Sabendo-se que a LDL-C é sensível à oxidação lipídica (HSU et al., 2004), percebeu que os valores para oxidação revelam LDL-C menos oxidada no suplemento combinado $(\mathrm{S} 3+\mathrm{S} 2)$ em mulheres de etnia branca $(\mathrm{p} \leq 0,002)$

O aumento do estresse oxidativo é induzido por consumo alterado de ácidos graxos $\omega-3$, mas seria compensado pelo aumento da atividade do sistema antioxidante endógeno. HIGGINS et al. (2001) suplementaram indivíduos com diferentes doses de AGPI $(0,3 ; 0,6$ ou $0,9 \mathrm{~g} / \mathrm{dia})$ por 16 semanas e não observaram aumento da suscetibilidade à oxidação da LDL, sugerindo que o efeito adaptativo poderia modificar o efeito antioxidante endógeno, justificando o aumento mais freqüente da oxidação em estudos que suplementam por um curto período de tempo, por volta de até seis semanas.

Observou-se uma correlação entre os índices de LDL e a geração de autoanticorpos antiLDL-ox. No entanto, segundo OLIVEIRA et al. (2006) o total de massa 
lipídica na circulação não é um fator determinante para a geração de anticorpos específicos e os auto-anticorpos anti LDL-ox parecem representar um potencial fator de risco cardiovascular independente.

Os resultados inferenciais revelaram que os níveis médios de $\alpha$-tocoferol $(\mu \mathrm{mol} / \mathrm{L})$ foram estatisticamente os mesmos entre os suplementos e etnia, mas não entre os momentos de coleta, demonstrando aumento de $\alpha$-tocoferol no plasma durante a suplementação, conforme resumem as Tabelas 5 e 6.

Tabela 5 Resultados inferenciais na (p) comparando $\alpha$-tocoferol, segundo etnia, suplemento e momento de coleta. Pindamonhangaba - SP, 2007.

\begin{tabular}{c|ccc}
\hline \hline \multirow{2}{*}{$\boldsymbol{\alpha}$-Tocoferol } & \multicolumn{3}{|c}{ Variável } \\
\cline { 2 - 4 } & Etnia & Suplemento & Momento de coleta \\
\cline { 2 - 4 } & 0,084 & 0,723 & 0,001 \\
\hline \hline
\end{tabular}

Tabela 6 Resultados inferenciais na (p) comparando $\alpha$-tocoferol e momento de coleta. Pindamonhangaba - SP, 2007.

\begin{tabular}{c|c}
\hline \hline \multirow{4}{*}{$\boldsymbol{\alpha}$-Tocoferol } & Conclusão \\
\cline { 2 - 2 } & 0 dia $=45 \operatorname{dias}(\mathrm{p}=0,133)$ \\
& 0 dia $<90 \operatorname{dias}(\mathrm{p}=0,002)$ \\
& $45 \operatorname{dias}<90 \operatorname{dias}(\mathrm{p}=0,003)$ \\
\hline \hline
\end{tabular}

A dose de vitamina E utilizada na suplementação das pacientes deste estudo foi de $400 \mathrm{mg} /$ dia. Essa dose foi equivalente às utilizadas como suplementação em estudos anteriores (KIYOSE et al., 1997). Também foi observado que os valores detectados no baseline de todos os grupos variaram dentro da normalidade, não sendo observado estado de deficiência para essa vitamina. 
Estudos de intervenção clássicos como o CHAOS (Cambridge Heart Antioxidant Study) (NESS et al., 1999) e o GISSI (The Grouppo Italiano per lo Studio Della Sopravvivenza nell'Infarto Miocardito) (FRANZOSI et al., 1998) abordaram o efeito da vitamina E sobre a incidência de doenças cardiovasculares e alguns resultados foram avaliados como positivos. No estudo CHAOS a dose de vitamina E utilizada foi de 400UI e 800UI, o resultado demonstrou uma redução de doenças cardiovasculares e infarto do miocárdio (IAM) não fatal, mas esses resultados foram influenciados pela proteção conferida ao risco para IAM, havendo um aumento não significativo de mortes por doenças cardiovasculares no grupo suplementado com $\alpha$-tocoferol, o fato tornou os resultados gerais do estudo controversos. Considerações em estudos posteriores atribuíram os resultados à dose de vitamina $\mathrm{E}(>400 \mathrm{UI})$.

O estudo GISSI utilizou uma concentração de vitamina E de $300 \mathrm{mg} / \mathrm{dL}$ e obteve a redução de $11 \%$ do risco de morte, infarto do miocárdio não fatal e derrames. No entanto, essa redução não foi estatisticamente significante (NEUZIL et al., 2001).

Neste estudo, os resultados encontrados no M2 (90 dias) mostraram que houve diferença $(\mathrm{p}<0,003)$ na suplementação com $\alpha$-tocoferol comparada ao M1 (45 dias) o que confirma a aderência à suplementação, no entanto quando se analisou IRC os teores de $\alpha$ tocoferol aumentados não tiveram correlação $(\mathrm{p}=0,059)$ para pacientes de ambas as etnias nos momentos M1 e M2. A correlação só foi percebida entre o basal e o M1 (p>0,001).

Em sua revisão sobre estudos epidemiológicos EICHLOLZER et al (2001) não encontraram associação significativa entre ingestão de alfa tocoferol e diminuição de doenças cardiovasculares. Apesar de mencionarem que há trabalhos de caráter epidemiológico que apresentam resultados positivos para essa associação, os autores consideraram os resultados para vitamina $\mathrm{E}$ quanto à prevenção de $\mathrm{DCV}$ inconclusivos. 
Estudos mostram que $\alpha$-tocoferol está relacionado com a idade (WILLET, 1983; BRUNNER, 2001; TALEGAWKAR, 2007), mas esse fato só é percebido em análise de dieta sem suplementação (EL-SOHEMY et al., 2001; DIXON et al., 2006) o que confirma os resultados do estudo em questão, mulheres do grupo controle com idade mais avançada (> 59 anos) mostraram níveis mais baixos de vitamina E, isso confere menor proteção cardíaca.

Os resultados inferenciais na comparação dos valores médios de TBARS $(\mu \mathrm{mol} / \mathrm{L})$ revelaram dois efeitos de interação: entre momento de coleta e suplemento, demonstrando que o suplemento $\omega$-3 combinado com vitamina $\mathrm{E}$ atuou na proteção oxidativa da LDL (Tabela 7 e Gráfico 4) e entre etnia e suplemento (Tabela 8) .

Tabela 7 Resultados inferenciais na (p) comparando TBARS ( $\mu \mathrm{mol} / \mathrm{L})$, segundo momento de coleta e suplemento. Pindamonhangaba - SP, 2007.

\begin{tabular}{c|c|c|c}
\hline & \multicolumn{3}{|c}{ TBARS $(\mu \mathrm{mol} / \mathrm{L})$} \\
\cline { 2 - 4 } & $\mathbf{0}$ DIAS & $\mathbf{4 5}$ DIAS & 90 DIAS \\
\cline { 2 - 4 } & $\begin{array}{c}(\mathrm{S} 1+\mathrm{S} 1)>(\mathrm{S} 3+\mathrm{S} 1) \\
(\mathrm{p}=0,006)\end{array}$ & $\begin{array}{c}(\mathrm{S} 1+\mathrm{S} 1)=(\mathrm{S} 3+\mathrm{S} 1) \\
(\mathrm{p}=0,999)\end{array}$ & $\begin{array}{c}(\mathrm{S} 1+\mathrm{S} 1)<(\mathrm{S} 3+\mathrm{S} 1) \\
(\mathrm{p}<0,001)\end{array}$ \\
\cline { 2 - 4 } & $\begin{array}{c}(\mathrm{S} 1+\mathrm{S} 1)=(\mathrm{S} 3+\mathrm{S} 2) \\
(\mathrm{p}=0,075)\end{array}$ & $\begin{array}{c}(\mathrm{S} 1+\mathrm{S} 1)=(\mathrm{S} 3+\mathrm{S} 2) \\
(\mathrm{p}=0,675)\end{array}$ & $\begin{array}{c}\mathrm{S} 1)=(\mathrm{S} 3+\mathrm{S} 2) \\
(\mathrm{D}=0,665)\end{array}$ \\
\cline { 2 - 4 } & $\begin{array}{c}(\mathrm{S} 3+\mathrm{S} 1)=(\mathrm{S} 3+\mathrm{S} 2) \\
(\mathrm{p}=0,352)\end{array}$ & $\begin{array}{c}(\mathrm{S} 3+\mathrm{S} 1)>(\mathrm{S} 1)=(\mathrm{S} 3+\mathrm{S} 2) \\
(\mathrm{p}=0,661)\end{array}$ \\
\hline \hline
\end{tabular}


Gráfico 4 Valores médios de TBARS ( $\mu \mathrm{mol} / \mathrm{L}$ ), segundo momento de coleta e suplemento. Pindamonhangaba - SP, 2007.

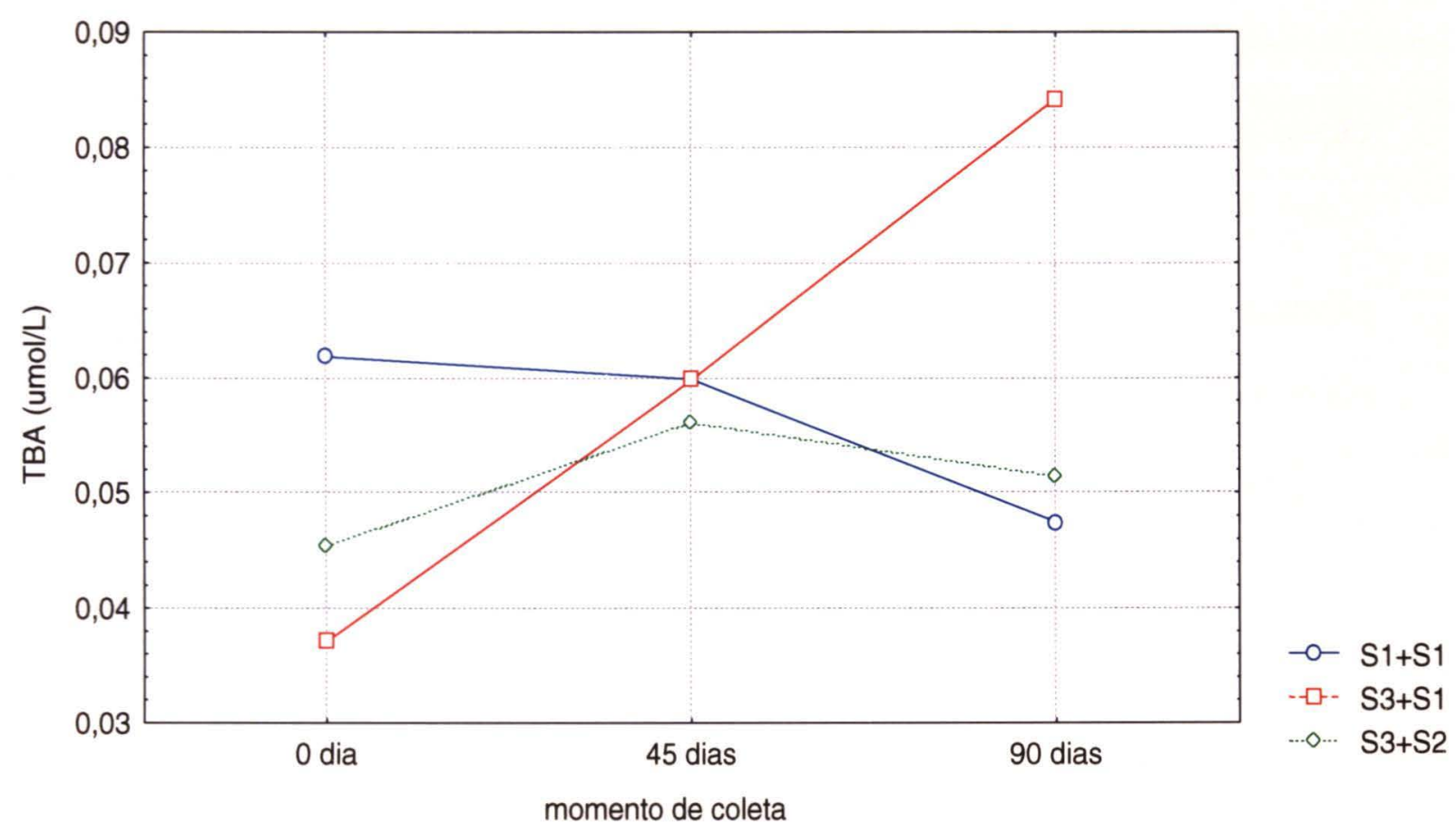

Tabela 8 Resultados inferenciais (p) na comparação do TBARS ( $\mu \mathrm{mol} / \mathrm{L})$, segundo etnia e suplemento. Pindamonhangaba - SP, 2007.

\begin{tabular}{cc}
\hline \hline Etnia & Conclusão \\
\hline \multirow{3}{*}{ Branca } & $(\mathrm{S} 1+\mathrm{S} 1)=(\mathrm{S} 3+\mathrm{S} 1)(\mathrm{p}=0,177)$ \\
& $(\mathrm{S} 1+\mathrm{S} 1)>(\mathrm{S} 3+\mathrm{S} 2)(\mathrm{p}=0,037)$ \\
& $(\mathrm{S} 3+\mathrm{S} 1)=(\mathrm{S} 3+\mathrm{S} 2)(\mathrm{p}=0,381)$ \\
& \\
& $(\mathrm{S} 1+\mathrm{S} 1)<(\mathrm{S} 3+\mathrm{S} 1)(\mathrm{p}=0,049)$ \\
Negra & $(\mathrm{S} 1+\mathrm{S} 1)=(\mathrm{S} 3+\mathrm{S} 2)(\mathrm{p}=0,182)$ \\
& $(\mathrm{S} 3+\mathrm{S} 1)=(\mathrm{S} 3+\mathrm{S} 2)(\mathrm{p}=0,533)$ \\
\hline \hline
\end{tabular}

Neste estudo, valores de TBA, sumarizados na Tabela 1, mostram que houve proteção à oxidação lipídica que pode ser atribuída à suplementação com $\alpha$-tocoferol, uma vez que esses valores aumentaram $(\mathrm{p}=0,002)$ após a suplementação. 
RUMLEY et al. (2004), estudando oxidação do plasma, mostraram forte ligação de peroxidação lipídica com os níveis de triglicérides, sugerindo que essas partículas poderiam promover a oxidação da LDL.

Em relação à oxidação, vários são os trabalhos mostrando sua forte correlação com as doenças cardiovasculares (FOULON et al., 1999; RAMLEY et al., 2004; NAZIROGLU, 2004), no entanto esses trabalhos não foram conclusivos na elucidação do mecanismo envolvendo auto-anticorpos anti LDL-ox, sendo necessária caracterização das possíveis intervenções e principalmente modulações imunológicas desse marcador. 


\subsection{CONCLUSÕES}

- Não houve diferença significativa no tocante à etnia para titulação de autoanticorpos anti LDL-ox;

- A administração de $\alpha$-tocoferol na dose de $400 \mathrm{mg} /$ dia por 90 dias aumentou as concentrações de $\alpha$-tocoferol dos indivíduos suplementados;

- As doses para suplementação com vitamina E precisam ser melhores estudadas;

- O grupo suplementado com vitamina E demonstrou menores índices de autoanticorpos anti-LDL-ox.

- O teste de substâncias reativas ao ácido tiobarbitúrico (TBARS) se mostrou um instrumento fraco para análise de oxidação no plasma, uma vez que não teve correlação com os teores de auto-anticorpos anti LDL-ox. 


\section{PERSPECTIVAS}

Os resultados apresentados nesse estudo sugerem que suplementação com óleo de peixe modifica o perfil lipídico e o uso da vitamina $\mathrm{E}$ atua na diminuição dos danos oxidativos, contudo os resultados para esse marcador não são conclusivos. Assim, considerando-se as limitações e dificuldades encontradas no decorrer desse estudo deixamos como novas metas:

1) Realização de novos estudos com maior casuística;

2) Analise de outras variáveis relacionadas ao estresse oxidativo, como atividade de enzimas antioxidantes, e outras relacionadas ao processo anti e próinflamatório;

3) Realização de estudos com controle de dieta;

4) Análise s onde se possa avaliar a função endotelial;

5) Utilização de outros testes de oxidação uma vez que o TBA apresenta limitações, sugerimos a realização de óxido de colesterol e,

6) Realização de estudos elucidando o mecanismo dos auto-anticorpos, uma vez que o metabolismo dos imunocomplexos ainda não é conclusivo. 
Referências Bibliográficas

Referências Bibliográficas 
Referências Bibliográficas

\section{REFERÊNCIAS BIBLIOGRÁFICAS*}

Accini R, Rosina M, Bamonti F, Della Noce C, Tonini A, et al. Effects of combined dietary supplementation on oxidative and inflammatory status in dyslipidemic subjects. Nutrition, Metabolism and Cardiol Diseases 2005; 16: 121-127.

Ackman RG. Fatty acids. In: Marine Biogenic Lipids, Fats and Oils. Ackman RG, (Ed.) 1989a; (1):103-137.

[AHA] - AMERICAN HEART ASSOCIATION, Scientific Statment: Summary of scientific conference on dietary fatty acids and cardiovascular health. Conference summary from the nutrition committee of the American Heart Association. Circulation 2001; 103(7): 1034-1039.

Aldrighi JM, Calvoso Junior R, Faludi AA, Mansur AP. Climatério e menopausa. In: Aldrighi JM, Faludi AA, Mansur AP (Eds) Doença cardiovascular no climatério. São Paulo; Atheneu, 2005; 219-230.

Aldrighi JM, Aldrighi CMS, Aldrighi APS. Alterações sistêmicas no climatério. Rev Bras Med 2002; 59: 15-21.

Aldrighi JM, Asakura L. Consumo alimentar e o climatério. Rev Assoc Med Bras 2001; 47(3): 33-39.

Alves RJ, Diament J, Amancio RF, Forti N, Maranhão RC. Ausência de efeito do captopril no metabolismo de uma emulsão lipídica artificial semelhante aos quilomícrons em pacientes hipertensos e hipercolesterolêmicos Arq Bras Cardiol 2004; 83(6).

Amaral L, Menopausa: produção de crise? Associação Psicanalítica de Curitiba em Revista 2002; 5: 114-130.

\footnotetext{
* De acordo com as normas do Guia de apresentação de Teses. Biblioteca/CIR - Centro de Informação e referências em Saúde Pública. São Paulo; 2006.
} 
Amaya-Farfan J. Domene SMA, Padovani RM. DRI: Síntese comentada das novas propostas sobre recomendações nutricionais para antioxidantes. Rev Nutr 2001; 14(1): 7178.

Anderson KM, Castelli W.P, Levy D. Cholesterol and mortality 30 years follow up from Framingham study . JAMA 1987; 257: 2176-2180.

Andrade PMM, Ribeiro BG, CARMO MGT. Suplementação de ácidos graxos ômega 3 em atletas de competição:impacto nos mediadores bioquímicos elacionados com 0 metabolismo lipídico. Rev Bres Med Esporte 2006; 12(6): 339-344.

Antolovich M, Prenzler PD, Patsalides E, McDonald S, Robards K. Methods for testing antioxidant activity. Analyst 2002(127): 183-198.

[ANVISA] Agência Nacional de Vigilância Sanitária. Norma Técnica de 15/03/1995: dispões sobre complemento nutricional. Diário Oficial da União, Brasília, 16/03/1995.

Araújo DV, Ferraz MB. Impacto econômico do tratamento da cardiopatia isquêmica crônica no Brasil. O desafio da incorporação de novas tecnologias cardiovasculares. Arq Bras Cardiol 2005; 85(1): 1-2.

Aviram M, Billecke S, Sorenson R, Bisgaier C, Newton R, Rosenblat M, et al. Paraoxonase active site required for protection against LDL oxidation involves its free sulfhydryl group and is different from that required for arylesterse/paraoxonase activities. Arterios Thromb and Vasc Biol 1998a; 18: 1617-1624.

Aviram M, Rosenblat M, Bisgaier CL, Newton RS, Primo-Parmo SL, Ladu BN. Paraoxonase inhibits high-density lipoprotein oxidation and preserves its functions. A possible role for paraoxonase. J Clin Investigation 1998b; 101: 1581-1590. 
Avis NE, Mckinlay SM. A longitudinal analysis of women's attitudes toward the menopause: results from the Massachusetts Women's Health Study. Maturitas 1991; $13(65)$.

Avis NE, Stellato R, Crawford S, Bromberger J, Ganz P, Cain V, Kagawa-Singer M. Is there a menopausal syndrome? Menopausal status and symptoms across racial/ethnic groups. Soc Scien and Med 2001; 52: 345-356.

Barros MRAC, Bertolami MC, Abdalla DSP, Ferreira WP. Identification of mildly oxidized low-density lipoprotein (electronegative LDL) and its auto-antibodies (IgG in children and adolescent hypercolesterolemic offsprings. Atheroscler 2006; 184: 103-107.

Battertham RL, Cowley M, Small CJ, Herzog H, Cohen MA, Dakin CL, et al. Gut hormone PY-Y3-36 physiologically inhibits food intake. Nature 2002; 418: 650-654.

Baynes J, Dominiczak M. H. Bioquímica Médica. São Paulo 2000; ABBA.

Berliner J.A, Heinecke J.W. The role of oxidized lipoprotein in atherogenesis. Free Radical Biology \& Medicine 1996; 20(5): 707-727.

Berwanger $\mathrm{O}$. Metanálises e recentes estudos na mulher. In: Risco cardiovascular na mulher. Xavier, HT. São Paulo; BBS 2005; 167-183.

Bianchini-Pontuschka R, Penteado MVC. Vitamina E. In: Penteado, MVC. Vitaminas: aspectos nutricionais, bioquímicos, clínicos e analíticos. Barueri, Manole 2003; 121-164.

Botham K.M, Zheng X, Napolitano M, Avella M, Cavallari C. et al. The effects of dietary n-3 polyunsatured fatty acids delivered in chilomicrom remmants on the transcription of genes regulation sybthesis and secretion by the liver modulation by on cellular oxidation state. Exp Biol and Med 2003; 228(2): 143-151. 
Bouchard C. Loos RJF. Obesity - is it a genetic disorder? J Int Med 2003; 254 (5): 401425 .

Brasil. Ministério da Saúde Datasus. Informação de saúde. Disponível em: http://www.datasus.gov.br, 2002. Acesso em 08/01/08.

Brasil. Ministério da Saúde Datasus. Informação de saúde. Disponível em: http://www.datasus.gov.br, 2003. Acesso em 08/01/08.

Brasil. Ministério da Saúde Datasus: Informações de Saúde. Disponível em URL:http://www.datasus.gov.br 2005. Acesso em 08/01/08.

BRASIL Ministério da Saúde: Sistema de Informação da Atenção Básica. Disponível em URL:http//www.datasus.gov.Br/siab/siab.html (2005 out 1b).

Brinton EA. Lipid abnormalities in the metabolic syndrome. Curr Diab Rep 2003; 3(1): $65-72$.

Bronsgeest-Schoute HC, Van Gent CM, Luten JB, Ruitter A. The efect of various intakes of n-3 fatty acids on the blood lipid composition in health human subjects. Am J Clin Nutr 1981; 34: 1752-1757.

Broughton KS, Wade JW. Total fat and (n-3):(n-6) Fat ratios influence eicosanoid production in mice. J Nutr 2002; 32: 88-94.

Brunner E, Stallone D, Juneja M, Bingham S, Marmot M. Dietary assessment in Whitehall II: comparison of 7 diet diary and food frequency questionnaire and validity against biomarkers. Br J Nutr 2001; 86: 405-414. 
Buckey R, Shewrig B, Turner R, Yaqoob P, Minihane AM. Circulating triacylglycerol and apoE levels in response to EPA and docosahexaenoic acid suplemetation in adult human subjects. Br J Nutr 2004; 92(3): 477-483.

Budowski P. Nutritional effects of n-3 polyunsaturated fatty acids. Isr J Med Sci 1981; 17: 223-231

Burton GW et al. Human plasma and tissuea - tocopherol concentrations in response to supplementation with deuterated natural and synthetic vitamin E. Am. J. Clin. Nutr 1998; 67:669-684.

Bussab WO, Morettin, PA. Estatística Básica. 5. ed. São Paulo; SARAIVA 2006.

Castelli WP, Abbot RD, Macnamara PM. Summary estimates of cholesterol used to predict coronary heart disease. Circulation 1983; 67(4): 730-734.

Cervato AM, Mazzilli RN, Martins IS, Marucci MFN. Dieta habitual e fatores de risco para doenças cardiovasculares. Rev Saúde Pública 1997; 31(3): 227-235.

Cirico TL, Omaye ST. Aditive or synergetic effects of phenolic compounds on human low density lipoprotein oxidation. Food and Chemical Toxicology; 2006 (44):510-516.

Ciornai S. Da contracultura à menopausa: vivências e mitos da passagem. São Paulo: Oficina de Textos 1999; FAPESP.

Chisolm GM, Steinberg D. The oxidative modification hypothesis of atherogenesis: an overview. Free Radic Biol Med 2000; 28 (12): 1815-1826.

Chopra M, Thurnham DI. Antioxidants and lipoprotein metabolism. Proc Nutr Soc 1999; 58(3): 663-671. 
Chor D, Lima CRA. Epidemiologia das desigualdades raciais em saúde Cad Saúde Pública, Rio de Janeiro, 2005; 21(5): 1586-1594.

Clarke SD. Polyunsaturated Fatty Acid Regulation of Gene Transcription: A Molecular Mechanism to Improve the Metabolic Syndrome. J Nutr 2001; 131: 1129-1132.

[CNS] Conselho Nacional de Saúde Brasil. Resolução nº196/96. Diretrizes e normas regulamentadoras de pesquisas envolvendo seres humanos. Diário Oficial da União, Brasília, 16 out 1996; 21082-21085.

Conor WE. Importance of n-3 fatty acids in health and disease. Am J Clin Nutr 2000; 7(suppl):171-177.

Conti RAS, Solimene MC, Luz PL, Benjó AM et al. Arq Bras Cardiol 2002; 79(5): 510517.

Corti MC, Guralnik JM, Salive ME, Harris T, Field TS, Wallace RB et al. HDL cholesterol predicts coronary Herat disease mortality in older persons. JAMA 1995; 274: 539-544.

Craig WJ. Phytochemicals: guardians of our health. J Am Diet Assoc 1997; 97(suppl 2): 199-204.

Cuppari L. Nutrição clínica no adulto. São Paulo 2002; Manole: 406.

Curi R, Pompéia C, Miyasaka CK, Procópio J. Entendendo as gorduras: os ácidos graxos. $1^{\text {a }}$ ed. São Paulo: 1997; Manole cap 11.

Curi R, Lagranha CJ, Hirabara SM, Folador A, Tchaikovski Jr O, Fernandes LC et al. A limiting step for fatty acids oxidation durinig aerobic exercice: the krebs cycle. R Bras Cienc Mov 2003; 11:(2)87-94. 
Damasceno NRT, Apolinario E, Oliveira JMA, Fernandes I, Abdalla DSP. Biomarcador da modificação oxidativa da LDL in vivo. Rev Bras Clin Rio de Janeiro 2002; 34 (3): 115120.

D'aquino M, Benedetti PC, di Felice M, Gentili V, Tomassi G, Maiorino M, Ursini F. Effect of fish oil and coconut oil on antioxidant defense system and lipid peroxidation in rat liver. Free Radic Res Commun 1991; 12-13 (1): 147-152.

[DATASUS] Informações demográficas e sócio-econômicas [on line]. Ministério da Saúde. 2001. Disponível em URL:http://datasus.gov.br/cgi/tabcgi.exe?ibge/ popsp.def.

[DATASUS] Indicadores e Dados Básicos - Brasil - 2005. IDB-2005 [on line]. Ministério da Saúde. 2005. Disponível em URL:http://datasus.gov.br/cgi/tabcgi.exe?ibge/ popsp.def.

De Lorenzi DRS, Basso E, Fagundes PO, Saciloto B. Prevalência de sobrepeso e obesidade no climatério. Rev Bras Ginecol Obstet 2005; 27(8): 479-484.

Deshpande SS, Deshpande US, Salunkne, DK. Nutritional and health aspects of food antioxidants. In: Madhavi DL, Deshpande SS and Salunkhe DK (Eds.) Food Antioxidants, Technological, Toxicological and Health Perspectives. New York; Marcel Dekker, 1996; $361-470$.

DeVon HA and Zerwick JJ. Differences in the symptoms associated with unstable angina and myocardial infarction. Prog Cardiovasc Nurs 2004; 19 (1): 6-11.

Dioguardi GS, Ghorayeb N, Daher DZ. Atividade física na prevenção e tratamento de doenças cardiovasculares na pós-menopausa. In: Aldrighi JM, Faludi AA, Mansur AP (Eds) Doença cardiovascular no climatério. São Paulo; Atheneu, 2005; 219-230. 
Dixon LV, Subar AF, Wideroff L, Thompson FE, Kahle LL, Potischman N. Carotenoid and tocopherol estimates from de NCI diet history questionnaire are valid compared with multiple recalls and serum biomarkers. J Nutr 2006; 136: 3054-3061.

Dyerberg J. Linoleate: derived polyunsatured fatty acids and prevention of atherosclerosis. Nutr Rev 1986; 44: 125-134.

Dyerberg J, Bang HO, Stoffersen E, Moncada S, Vane Jr. Eicosapentanoic acid and prevention of thrombosis and atherosclerosis. Lancet 1978; 2: 117.

Eichholzer M, Luthy J, Gutzwiller F, Stahelin HB. The role of folate, antioxidant vitamins and other constituents in fruit and vegetables in the preventionof cardiovascular disease- the epidemiological evidence. Int J Vitam Nutr Res 2001; 71(1): 5-17.

El-sohemy A, Raylin A, Ascherio A, Kabagambe E, Spiegelman D, Campos H. Population based study of alpha and gamma-tocopherol in plasma and adipose tissue as biomarkers of intake in Costa Rican adults. Am J Clin Nutr 2001; 74: 356-369.

Emerson SL, Maranhão RC. Rapid, simple-laser-light-scatering method for HDL participle sizing in whole plasma. Clin Chem 2004; 50(6): 1086-1088.

Esterbauer H, Jurgens G, Quehenberger O, Koller E. Autoxidation of human low density lipoprotein loss of polyunsatured fatty acids and vitamin $\mathrm{E}$ and generation of aldehydes. $\mathbf{J}$ Lipid Res 1987; 28(5): 495-509.

Faludi AA, Armagamjan D, Feitosa GS, Forti N. Ácidos graxos n-3, n-6 e prevenção primária. In: Seminário ácidos graxos n-3, n-6 e prevenção de doenças cardiovasculares. Arq Bras Cardiol. 2001; 77: 287-319. 
[FEBRASGO] Federação Brasileira das Associações de Ginecologia e Obstetrícia. Climatério: manual de orientação. Federação Brasileira das Associações de Ginecologia e Obstetrícia, 1995.

Feldman EB. Nutritional needs of climacteric women. In: Notelovitz M. The climateric in perspective. Lancaster 1996; MTP Press.

Ferin M, Jewelewicz R, Warren M. The menstrual cycle: physiology, reproductive disorders and infertility. Oxford 1993; Oxford University Press.

Fernandes JL, Garcia C, Coelho OR, Gidlund M, Blotta MHSL. Diferences in human antioxidized LDL autoantibodies in patients with stable and unstable angina. $\mathbf{J}$ Autoimmunity 2004; 23: 345-352.

Fernandez ML, West KL. Mechanisms by which dietars fatty acids modulated plasma lipids. J Nutr 2005; 135(9): 2075-2078.

Filho NA, Rouquayrol MZ. Elementos de Metodologia Epidemiológica. In: Rouquayrol MZ, Filho NA. Epidemiologia e Saúde. MEDSI 2003; 147-177.

Folsom AR, Demissie Z. Fish intake, marine omega-3 fatty acids and mortality in a cohort postmenopause women. Am J Epidemiol 2004; 160: 1005-1010.

Forti N, Fukushima J, Gianini SD. Perfil lipídico de indivíduos submetidos à cinecoronografia em deferentes regiões do Brasil. Arq Bras Cardiol 1997; 68: 333-342.

Foulon T, Richard MJ, Payen N, Bourrain JL, Beani JC, Laporte F, Hadjan A. Effects of fish oil fatty acids on plasma lipids and lipoproteins and oxidant-antioxidant imbalance in health subjects. Scand J Clin Lab Invest 1999; 59(4): 239-248. 
Franzosi MG, Santoro E, De Vita C, Geraci E, Lotto A, Maggioni AP et al. Ten-year follow-up of the first megatrial testing thrombolytic therapy in patients with acute myocardial infarction results of the Gruppo Iitaliano per lo Studio della Sopravvivenza nell'infarto-1 study. Circulation 1998; 98: 2659-2665.

Freedman D, Otvos J, Jeyarajah E et al. Relation of lipoprotein subclasses as measured by proton nuclear magnetic resonance spectroscopy to coronary artery disease. Arterioscler Thromb Vasc Biol 1998; 18: 1046-1053.

Fredenrich A, Bayer P. Reverse cholesterol transport, high-density lipoproteins and HDL cholesterol: recent data. Diabetes Metab 2003; 29(3): 201-205.

Friedewald WT, Levy RT, Fredickson DS. Estimulation of low density lipoprotein cholesterol in plasma without the use of preparative ultracentrifugue. Clin Chem 1972; 18 : 499-502.

GISSI-Prevenzione Investigators (Gruppo Italiano per lo Studio della Sopravvivenza nell' Infarto miocardico): Dietary supplementation with n-3 polyunsaturated fatty acids and vitamin E after myocardial infarction: results of the GISSI-Prevenzione trial. Lancet 1999; 354: $447-455$.

Goodnight SH Jr, Harris WS, Connor WE, Allingworth RD. Polyunsaturated fatty acids, hyperlipidemia and thrombosis. Artherioscler 1982; 2: 87-113.

Gotto AM Jr. Triglyceride as a risk factor for coronary artery disease. Am J Cardiol 1988; 82(9A): 22Q-25Q.

Gracia CR, Sammel MD, Freeman EW, Lin H, Langan E, Kapoor S, Nelson DB. Defining menopause status: creation of a new definition to identify the changes of the menopause transition. Menopause 2005; 12(2): 128-135. 
Groot L, Staveren WV. Working plan and manual of operation - anthropometry - Nutrition and elderly a concerted action on nutrition health. In: European Community Euro-nut Netherlands, November 1980.

Halbe HW, Fonseca AM. Síndrome do Climatério. In: Halbe HW. Tratado de Ginecologia. $3^{\text {a }}$ ed. São Paulo 2000; Roca: 1519-1557.

Halliwell B, Cross, CE. Oxygen-derived species: their relation to human disease and environmental stress. Environ Health Perspect 1994; 102 (10 Suppl): 5-12.

Halliwell B, Gutteridge JMC. Free radicals in biology and medicine. $3^{\text {th }}$ ed. 1999; Oxford: New York.

Harris WS. n-3 fatty acids and lipoproteins: comparison of results from human and animal studies. Lipids 1996; 31(3): 243-252.

Harris WS. n-3 fatty acids and serum lipoproteins: human studies. Am J Clin Nutr 1977; 65: 1645S-1654S.

Hearn Tl, Sgoutas AS, Hearn JA, Goutas DS. Polyunsaturated fatty acids and fat in fish flesh for selecting species for health benefits. J Food Sci 1987; 52(5): 1209-1211.

Hertog MGL, Feskens EJM, Hollman PCH, Katan MB, Kromhout D. Dietary antioxidant flavonoids and risk of coronary heart disease the Zupthen Elderly Study. Lancet 1993; 342: 1007-1011.

Higgins S, Carrol YL, Mccarthy SN, Corridan BM. et al. Susceptibility of LDL to oxidative modification in health volunteers supplanted with low doses of n-3 polyunsatured fatty acids. Br J Nutr 2001; 85(1): 23-31. 
Ho KKL, Pinsky JL, Kannel WB, et al. The epidemiology of heart failure: the Framingham study. J Am Coll Cardiol 1993; 22(supll A): 6A-13A.

Hulthe J, Fagerberg B. Circulating oxidized LDL is associated with subclinical atherosclerosis development and inflamatory cytokines (AIR Study). Arterioscler Thromb Vasc Biol 2002; 22: 1162-1167.

[IBGE] Fundação Instituto Brasileiro de Geografia e Estatística. Indicadores sociais mínimos. Aspectos demográficos. Estimativas para 1999 extraídas do documento IBGE/DPE/DEPIS “Projeção da população das grandes regiões por sexo e idade 19912020" [on line] 2001. Disponível em URL:http//www.ibge.gov.br/

Im EO, Meleis AL. Women's work and symptoms during midlife: Korean immigrant women. Women Health 2001; 33(1-2): 83-103.

Inoue T, Uchida T, Kamishirado $\mathrm{H}$, Takayanagi $\mathrm{K}$ et al. Clinical significance of antibody against oxidized low density lipoprotein in patients with atherosclerotic coronary artery disease. J Am Coll Cadiol 2001; 37: 775-779.

Jackson MJ, M. Khassaf A, Vasilaki F, Mcardle AM. Vitamin E and the oxidative stress of exercise. Ann N Y Acad Sci 2004; 1031:158-168.

Jensen SK, Engberg RM, Hedemann MS. All-rac- $\alpha$-tocopherol acetateis a better vitamin E source than all-rac- $\alpha$-tocopherol succinate for broilers. J Nutr 1999; 129:1355-1360.

Johnson JL, Slentz CA, Duscha BD, Samsa GP et al. Gender and racial differences in lipoprotein subclass distributions: The STRRIDE study. Atheroscler 2004; 176: 371-377.

Jousilahti P. et al. "Twenty-year dynamics of serum cholesterol in middle-aged population of eastern Finland". Ann Intern Med 1996; 125: 713-722. 
Kiyose C, Muramatsu R, Kameyama Y, Ueda T, Igarash O. Biodiscrimination of $\alpha$ tocopherol stereosomers in human after oral administration. Am J Clin Nutr 1997; 65: 785-789.

Knekt P, Jarwinen R, Reunanen A, Maatela J. Flavonoid intake and coronary mortality in Finland: a cohort study. BMJ 1996; 312: 478-481.

Kontush A et al. Small, dense HDL particles exert potent protection of atherogenic LDL against oxidative stress. Arterioscler Thromb Vasc Biol 2003; 23(10): 1881-1888.

Kragelund C, Omland T. A farewell to body-mass index? Lancet 2005; 366(9497):15891591.

Kris-Etherton PM, Harris SW, Appel JL. Fish consumption, fish oil, omega-3 fatty acids and cardiovascular disease. Arterioscler Thromb Vasc Biol 2003; 23: 20-30.

Krummel D. Nutrição na doença cardiovascular. In: Mahan LK e Escott-Stump SK. Alimentos, nutrição e dietoterapia $9^{a}$ ed São Paulo. Roca 1998; 543-545.

Kuller LH. Implications of the results of the women's health initiative hormone replacement therapy and risk of cardiovascular disease. Arterioscler Thromb Vasc Biol 2002; 23: 11-16.

Laidlaw M, Holub BJ. Effects of supplementation with fish oil-derived n-3 fatty acids and gamma-linolenic acid on circulating plasma lipids and fatty acid profiles in women. Am $\mathbf{J}$ Clin Nutr 2003; 77(1): 37-42.

Leigh-Firbank EC, Minihane AM, Leake DS, Wright JW, Murphy MC, Griffin BA, Williams CM. Eicosapentanoic acid and docosahexaenoic acid from fish oils: differential associations with lipid responses. Brit J Nutr 2002; 87: 435-445. 
Lemos-Santos MG, Valente JG, Gonçalves-Silva RM, Schieri R. Waist circumference and waist-to-hip ratio as predictors of serum concentration of lipids in Brazilian men. Nutrition 2004; 20(10):857-862.

Lima ES \& Couto RD. Estrutura, metabolismo e funções fisiológicas da lipoproteína de alta densidade J Bras Patol Med Lab 2006; 42(3): 169-178.

Lima SMRR. Menopausa In: Aldrighi JM, Buchalla CM, Cardoso MRA. Epidemiologia dos agravos à saúde da mulher. São Paulo 2005; Ed Atheneu.

Lotufo PA. Mortalidade por doenças cardiovasculares no Brasil. Comparação com outros países. Arq Bras Cardiol 1998; 70: 321-325.

Luliano L. The oxidant stress hypothesis of atherogenesis. Lipids 2001; 36: 41-44.

Luzia LA, Sampaio GR, Castellucci CMN, Torres EAFS. The influence of season on the lipid profiles of five commercially important species of Brazilian fish. Food Chem 2003; 83: 93-99.

Lyratzopoulos G, Mcelduff P, Helle RF, Hanily M, Lewis PS. Comparative levels and time trends in blood pressure, total cholesterol, Body Mass Index and smoking among Caucasian and South-Asian participants of a UK primary-care based cardiovascular risk factor screening programme. BMC Public Health 2005; 5: 125.

Macambira R, Poli DM, Canosa HG et al. Aterosclerose - fatores de risco. JBM 2001; 81: 64-68.

Mahan LK \& Escott-Stump SK. Alimentos, nutrição e dietoterapia 9a ed. 1998; São Paulo. Roca: 1179. 
Manolio TA, Pearson TA, Wenger NK, Barret-Connor E, Payne GH, Harlan WR. Cholesterol and heart disease in older person and women. Review of an NHLBI workshop. Amm Epidemiol 1996; 2: 161-176.

Mansur AP, Souza MFM, Timerman A, Ramires JAF. Tendência do risco de morte por doenças circulatórias, cerebrovasculares e isquêmicas do coração em 11 capitais do Brasil, de 1980 a 1998. Arq Bras Cardiol 2002; 79: 269-276.

Mansur AP, Favarato D, Souza MFM, Avakian SD, Aldrighi JM, César LAM et al. Tendência do risco de morte por doenças circulatórias no Brasil de 1979 a 1996. Arq Bras Cardiol 2001; 76: 497-503.

Maranhão RC, Feres MC, Martins MT et al. Plasma kinetics of a chylomicron-like emulsion in patients with coronary artery disease. Atheroscl 1995; 126: 15-25.

Marki KC, Davidison MH, Dicklin KL Ingram KA et al. Bioavailability of eicosapentaenoic and docosahexaenoic n-3 polyunsaturated fatty acids in salmon patties compared with capsules. J Food Science 2003; 68 (3): 761-764.

Marmer WN, Maxwell RJ. Dry columm method for the quantitative extraction and simultaneous class separation of lipids from muscle tissue. Lipids 1981; 16: 365-371.

Martin A, Wu D, Meydane N, Blumberg JB, Meydani M. Vitamin E protects human aortic endothelial cells from cytotoxic injury induced by oxidized LDL in vitro. Nutr Biochem 1998; 9(4): 201-208.

Metcalfe LD, Schmitz AA, Pelka JR. Rapid preparation of fatty acid esters from lipids for gas chromatographic analysis. Anal Chem 1966; 12: 514.

Meydani M. Effect of funtional food ingredients: vitamin E modulation of cardiovascular disease and immune status in the elderly. Am J Clin Nutr 2000; 71(6): 1665S-1668S. 
Meydani SN. Effect of (n-3) polyunsaturated fatty acids on cytokine production and their biologic function. Nutrition 1996; 12: S8-S14.

Misra A, Vikram NK, Gupta R, Pandey RM, Wasir JS, Gupta VP. Waist circumference cut off points and action levels for Asian Indians for identification of abdominal obesity. Int $\mathbf{J}$ Obes (Lond) 2006; 30(1):106-111.

Monteiro CA, Mondini L, Costa RBL. Mudanças na composição e adequação nutricional da dieta nas áreas metropolitanas do Brasil (1988-1996). Rev Saúde Pública 2000; 34(3): 251-258.

Montilla RNG, Marucci MFN, Aldrighi JM. Avaliação do estado nutricional e de consumo alimentar de mulheres no climatério. Rev Ass Méd Bras 2003; 49(1): 91-95.

Mourão DM, Sales NS, Coelho SB, Pinheiro-Santana HM. Biodisponibilidade de vitaminas lipossolúveis. Rev Nutr 2005; 18(4): 529-539.

Mursu J, Voutilainen S, Nurmi T, Helleranta M, Rissanen TH, Nurmi A, Kaikkonen J, Porkkala-Sarataho E, Nyyssonen K, Virtanen JK, Salonen R, Salonen JT. Polyphenol-Rich Phloem Enhances the resistance of total serum lipids to oxidation in men. $\mathbf{J}$ Agric Food Chem 2005; 53(8): 3017-3022.

Nahas MV. Atividade física, saúde e qualidade de vida: conceitos e sugestões para um estilo de vida ativo. Londrina 2001; Midiograf.

[NAMS] North American Menopause Society 2007. Estrogen and progestogen use in peri and postmenopausal women. March 2007 position statement of the North American Menopause Society. Menopause 2007; 14: 168-182. 
[NAMS] North American Menopause Society 2002. Menopause core curriculum study guide. The North American Menopause Society.

Naziroglu M, Simsek M, Simsek H, Aydilek N et al. The effects of hormone replacent therapy combined with vitamins $\mathrm{C}$ and $\mathrm{E}$ on antioxidants levels and lipid profiles in postmenopausal women with type 2 diabetes. Clin Chim Acta 2004; 344, 63-71.

[NCEP] National Cholesterol Education Program. Executive Summary of the Third Report of the National Cholesterol Education Program (NCEP) Expert Panel on detection, evaluation, and treatment of high blood cholesterol in adults (Adult treatment Panel III), JAMA 2001; 285(19): 2486-2497.

[NCHS] National Center for Health Statistics. 2005. Health United States, 2005. Hyattsville, Md.: Centers for Disease Control and Prevention.

[NCHS] National Center for Health Statistic. 1997 CDC Growth charts: United States. Disponível em: http://www.cdc.gov/growthcharts.

Needleman P, Raz A, Minkes MS. Triene prostaglandins:protacyclin and tromboxane biosynthesis and unique biological properties, Proc. Natl Acad Sci 1979; 76: 944.

Nelsen-Vergil J.M. Benefits of fish oil supplementation for hemodialysis patients. Persp in Prat 2003; 9(103): 1774-1777.

Ness A, Smith GD. Mortality in the CHAOS trial. Cambridge Heart Antioxidant Study. Lancet 1999; 353(9157): 1017-1018.

Neter J, Kutner MH, Nachtstheim CJ, Wasserman W. Applied linear statistical models. $4^{\mathrm{a}}$ ed. Boston 1996; Irwin: 1408. 
Nettleton JA, Exler J. Nutrients in wild and farms fish and shellfish. J Food Sci 1992; 57: 257-260.

Neunteufl T, Kostner K, Katzenschlager R, Zehetgruber M. et al. Additional benefit of vitamin E supplementation to Sinvastatin theraphy on vasoreactivity of the brachial artery fo hypercholesterolemic. J AM Col Cardiol 1998; 32: 711-716.

Neuzil J, Weber C, Kontush A. The role of vitamin E in atherogenesis linking the chemical, biological and clinical aspects of the disease. Atheroscl 2001; 157: 257-283.

Nornerg J, Arner ESJ. Reative oxygen species, antioxidants and the mammalian thioredoxin systems. Free Radic Biol Medic 2001; 31(11): 1287-1312.

Notelovitz M. Climateric Medicine and Science: a social need. In: Notelovitz M, ed The Climateric in Perspective. 1988. Lancaster: Mtp.

O'keefe JH, Nelson J, Harris WB. Life style change for coronary artery disease. Postgrad Med 1996; 99(2): 89-106.

Olchawa B, Kingwell BA, Hoang A, Schneider L et al. Physical fitness and reverse cholesterol transport. Arterios Thromb Vascul Biol 2004; 24(6): 1087-1091.

Oliveira VN, Fontes CJF, Medeiros SF. Correlação entre a idade da menopausa e a idade da menarca entre as mulheres climatéricas do distrito centro-oeste de Cuiabá-MT. Reprod Clim 2001; 16(3): 207-210.

Oliveira JA, Sevanian A, Rodrigues RJ, Apollinário E et al. Minimally modified eletronegative LDL and it's autoantibodies in acute and chronic coronary syndromes. Chem Bioch 2006; 39: 708-714. 
O'meara JG, Kardia SRL, Armon JJ, Brown CA et al. Ethnic and sex differences in the prevalence, treatment and control of dyslipidemia among hypertensive adults in the GENOA study. Arch Intern Med 2004; 164: 28.

[OMS] Organização Mundial da Saúde. Statistics Report. 2006, Geneve.

[OMS] Organização Mundial da Saúde. Manual de segurança biológica em laboratório. $3^{\mathrm{a}}$ Ed. 2004.

[OMS] Organização Mundial da Saúde. The World Health Report 2003. Less saturated fats, sugar and salt, more fruit and vegetables and physical exercise, needed to counter cardiovascular diseases, cancer, diabetes and obesity. WHO/FAO release independent Expert Report on diet and chronic disease 2003, Geneve/Rome.

[OMS] Organização Mundial da Saúde. Obesity: preventing and manging the global epidemic - report of a WHO consultation on obesity 2000; Geneva World Health Organization.

[OMS] Organização Mundial da Saúde. The World Health Report 1998. Life in the 21st century: a vision for all. Geneve: World Health Organization; 1998 [51st. World Health Assembly; A 51/3 17 march 1998].

[OMS] Organização Mundial da Saúde. Obesity: preventing and managing the global epidemic (report of a WHO consultation on obesity). Genebra: World Health Organization; 1997; 98.

[OMS] Organización Mundial de la Salud Investigaciones sobre la menopausia en los años noventa: informe de un grupo cientifico de la OMS 1996 (OMS Serie de informes técnicos; 866), Ginebra. 
Pedro AO, Pinto Neto AM, Paiva LHSC, Osis MJ, Hardy E. Idade de ocorrência da menopausa natural em mulheres brasileiras: resultados de um inquérito populacional domiciliar. Cad Saúde Publica 2003; 19(1): 17-25.

Penteado VC. Vitaminas: Aspectos nutricionais, bioquímicos, clínicos e analíticos. São Paulo: MANOLE, 2003.

Pereira SL, Leonard AE, Mukerji P. Recent advances in the study of fatty acid desaturases from animals and lower eukaryotes. Prost Leukot Essent Fatty Ac 1995; 68(2): 97-106.

Piegas LS, Avezum A, Pereira JC et al. AFIRMAR Study Investigators. Risk factors for myocardial infarction in Brazil. Am Heart J 2003; 146: 331-338.

Póvoa Filho H. Radicais livres em patologia humana. IMAGO 2000; 323.

Roche HM. Unsaturated fatty acids. Proceeding of the Nutrition Society. 1999; 58: 397401 .

Roche HM, Gibney MJ. Effect of long-chain n-3 polyunsaturated fatty acids on fasting and postprandial triacylglycerol metabolism. Arq Bras Cardiol 1999; 100: 738-728.

Roland IA, Maranhão RC. Transfers of phospholipids and cholesterol from triglycerids-rich emulsions to HDL in rats treated with alloxan propylthiouracil or ethanol. Braz J Med Biol Res 1993; 26: 109-118.

Ross R, Glonset JA. The pathogenesis of atherosclerosis. N Engl J Med 1996; 295: 369377.

Rossi GP, Cesario M, Tomi RD, Zanchetti M. et al. Antibodies to oxidized low density lipoprotein and angiographically assessed coronary artery disease in white patients; Circulation 2003; 108: 2467-2472. 
Rumley AG, Woodward M. Rmley A, Rumley J, Lowe GDO. Plasma lipid peroxides: relationships to cardiovascular risk factors and prevalent cardiovascular disease. Q J Med 2004; 97(12): 809-816.

Rye KA, Clay MA, Barter PJ. Remodelling of high density lipoprotein by plasma factors. Atheroscl 1999; 145: 227-238.

Sanches IC, Jorge L, Ponciano KR, Pureza DY, Angelis K. Doença cardiovascular na mulher. Integração 2006; 44(XII): 41-48.

Santos RD. III Diretrizes básicas sobre dislipidemias e diretriz de prevenção da aterosclerose do departamento de aterosclerose da Sociedade Brasileira de Cardiologia. Arq Bras Cardiol 2001; 77(supl III).

Santos JE. Terapêutica das hiperlipidemias: como e por quê? Rev Bras Hipertens 1999; $6(2): 158-162$.

Saynor R, Gilliott T. Changes in blood lipids and fibrinogen with a note on safety in a longterm study on the effects of N-3 fatty acids in subjects receiving fish oil supplements and followed for seven years. Lipids 1992; 27: 533-538.

Schmidt EB, Lervang HH, Varming K, Madsen P, Dyerberg J. Long-term supplementation with N-3 fatty acids, II: Effect on blood lipids, haemostasis and blood pressure. Scand J Clin Lab Invest 1992; 52(3): 221-228.

Schwedhelm E, Maas R, Troost R, Boger R.H. Clinical Pharmacokinetics of antioxidants and their impact on systemic oxidative stress. Clin Pharmacokinetic 2003; 42(5): 437459. 
Sevanian A, Asatryan L, Ziouzenkova O. Low density lipoprotein (LDL) modification: Basic concepts and relationship to atherosclerosis. Blood Purif 1999; 17: 66-78.

Sies H, Stahl W, Sevanian A. Nutritional, dietary and postprandial oxidative stress. J Nutr 2005; 135(5): 969-972.

Simkin-Silverman LR, Wing RR, Boraz MA, Kuller LH. Lifestyle intervention can prevent weight gain during menopause: result from a 5-year randomized clinical trial. Ann Behav Méd 2003; 26(3): 212-20.

SOCIEDADE BRASILEIRA DE CARDIOLOGIA IV Diretrizes Brasileiras sobre Dislipidemias e Diretrizes de Prevenção da Aterosclerose do Departamento de Aterosclerose da Sociedade Brasileira de Cardiologia. Arq Bras Cardiol 2007; 88 Supl I: 2-19.

SOCIEDADE BRASILEIRA DE CARDIOLOGIA III diretrizes Brasileiras sobre Dislipidemias e Diretrizes de Prevenção da Aterosclerose do Departamento de Aterosclerose da Sociedade Brasileira de Cardiologia. Arq Bras Cardiol 2001; 77 Supl III: $1-48$.

Solimene MC. Aspectos epidemiológicos da isquemia silenciosa em homens e mulheres. Rev Bras Cardiol 2000; 2: 51-6.

Souza CL. Transição da menopausa: a crise da meia-idade feminina e seus desafios físicos e emocionais. Rev Bras Ter Cogn 2005; 1(2): 87-94.

Spirduso WW. Physical dimensions of aging 1995; Human Kinetics.

SPSS Incorporation Statistical Package for the Social Sciences for Windows Student Version/SPSS [computer program]. Release 13.0. Chicago 2001: SPSS inc. Marketing Department. 
Stampfer MJ, Hennekens CH, Manson JE et al. Vitamin E consumption and risk of coronary disease in women. N Engl J Med 1993; 328 (20): 1444-1449.

Steinerová A, Racek J, Stozicky F, Zima T, et al. Antibodies against oxidized LDL theory and clinical use. Physiol Res 2001; 50(2): 131-141.

Subbiah M. Mechanisms of cardioprotection by estrogens. Proc Soc Exp Biol Med 1998; 217(1): 26-29.

Sun J, Giraud DW, Moxlet RA, Driskell JA. $\beta$-carotene and $\alpha$-tocopherol inhibit the development of atherosclerotic lesion in hypercholesterolemic rabbits. Internat J Vit Nutr Res 1997; 22: 155-163.

Sweets BP, Brower DAS, Tervaert JWC. Patients with sistemics vaseulitis have increased levels of autoantibodies against oxidizes LDL. Clin Exp Immunol 2001; 124(1): 163-167.

Talegawkar SA, Johnson EJ, Carithers T, Taylor Jr HA et al. Total $\alpha$-tocopherol intakes are associated with serum $\alpha$-tocopherol concentrations in African American adults. J Nutr 2007; 2297-2303.

Tanasescu M, Cho EO, Manson JEO, Hu FB. Dietary fat and cholesterol and risk of cardiovascular disease among women with type 2 diabetes. Am J Clin Nutr 2004; 79(6): 999-1005.

Thomas JA. Estresse oxidativo e defesa contra oxidantes. In: Shils ME, Olson JA, Shiki M, Roos AC. Tratado de nutrição moderna na saúde e na doença. $9^{\text {a }}$ Ed São Paulo 2003; Manole 46: 801-811.

Tinahones FJ, Gomez-Zumaquero JM, Garrido-Sanchez L, Garcia-Fuentes E et al. Influence of age and sex on levels of anti-oxidized LDL anti-bodies anti-LDL imune complexes in the general population. J Lipid Res 2005; 46:452-457. 
Toborek M, Lee Y, W, Garrido R, Kaiser S, Hennig B. Unsaturated fatty acids selectively induce an inflammatory environment in human endothelial cells. Am J Clin Nutr 2002; 75: 119-125.

Torng PL, Su TC, Sung FC, Chien KL, Huang SC, Chow SN, Lee YT. Effects of menopause on intraindividual changes in serum lipids, blood pressure, and body weight the Chin-Shan Community Cardiovascular Cohort study. Atheroscl 2002; 161: 409-415.

Toshima S, Hasegawa A, Kurabayashi M, Itabe $\mathrm{H}$ et al. Circulation oxidezed low density lipoprotein levels. A biochemical risk marker for coronary heart disease. Arterioscler Thromb Vasc Biol 2000; 20(10): 2243-2247.

Van Himbergen TM, Roest M, Graaf J, Jansen EAJM, Hattori H, Kastelein JJP et al. Indication that paraxoanase-1 contributes to plasma high density lipoprotein level in familial hypercholesterolemia. J Lipid Res 2005; 46: 445-452.

Verlengia R, Martins de Lima T. Síntese de Ácidos Graxos. In: Curi R, Pompéia C, Miyasaka CK, Procópio J. Entendendo as gorduras: os ácidos graxos 2003; São Paulo:Manole, cap 11.

Vezi ZB, Naidoo DP. Dyslipidaemia among black patients with type 2 diabetes. Cardiov J of South África 2005; 16(4).

Von Schacky C, Angerer P, Kothny W, et al. The effect of dietary omega-3 fatty acids coronary atherosclerosis: a randomized, double-blind, placebo-contolled trial. Ann Int Med 1999; 130: 554-62.

Yla-Hertuala S, Palinski W, Butler SW, Picard S, Steinberg D, Witztum JL. Rabbit and human atherosclerotic lesions contain $\operatorname{IgG}$ that recognizes epitopes of oxidized LDL. Arterioscler Thromb Vasc Biol 1994; 14:32-40. 
Yongson R. Como combater os radicais livres: o programa de saúde dos antioxidantes. Rio de Janeiro 1995; CAMPUS, 168p.

Yusuf S, Hawken S, Ounpuu S et al. Interheart Study Investigators. Effect of potentially modifiable risk factors associated with myocardial infarction in 52 countries (the INTERHEART study): case-control study. Lancet 2004; 364: 937-52.

Wajingarten M, Rodrigues GHP, Gebara OCE. Peculiaridades do infarto agudo do miocárdio com supra de ST em idosos e mulheres. Rev. Soc. Cardiol 2004; 14(6):971-80.

Wanasundara N, Shaid, F. Antioxidant and pro-oxidant activity of green tea extracts in marine oils. Food Chem 1998; Kindligton 63(3): 335-342.

Willet WC, Stampler MJ, Underwood BA, Speizer FF et al. Validation of a dietary questionaire with plasma carotenoid and alpha-tocopherol levels. Am J Clin Nutr 1983; 38:631-9.

Wu D, Koga T, Martín KR, Meydani M. Effect of vitamin E on human aortic endothelial cell production of chemokines and adhesion to monocytes. Atheroscler 1999; 147: 297307.

Wu WH, Lu SC, Wang TE, Jou HJ, Wang TA. Effects of docosahexaenoic acid supplementation on blood lipids, estrogen metabolism, and in vivo oxidative strees in postmenopausal vegetarian women European J of Clin Nutrit 2006; 60: 386-392. 
Anexos 
ANEXO 1 - Comitê de Ética

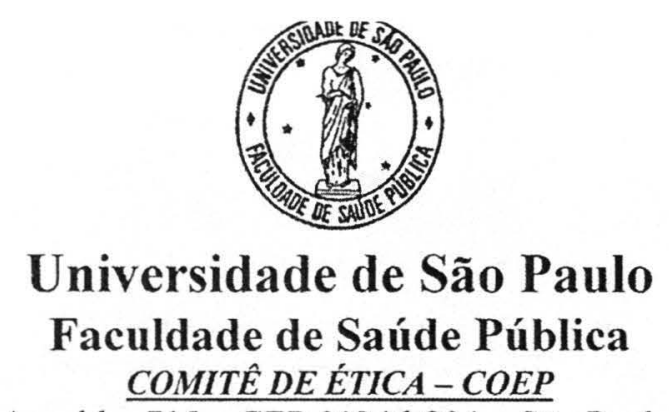

Av. Dr. Arnaldo, 715 - CEP 01246-904 - São Paulo - Brasil

Telefones: (55-11) 306,6-7779/7742-0-e-mail: coep@fsp.usp.br

\section{Of.COEP/90/05}

11 de março de 2005

Pelo presente, informo que o Comitê de Ética em Pesquisa da Faculdade de Saúde Pública da Universidade de São Paulo-COEP, analisou e aprovou com recomendações, em sua 2. ${ }^{2} / 05$ Sessão Ordinária realizada em 09.03.05, de acordo com os requisitos da Resolução CNS/196/96, o Protocolo de Pesquisa n. ${ }^{\circ}$ 1233, intitulado: “EFEITO DO CONSUMO DE PESCADO NO PERFIL LIPÍDICO DE MULHERES MENOPAUSADAS DISLIPIDÊMICAS", apresentado pela pesquisadora Liania Alves Luzia.

Recomenda-se que a pesquisadora informe as fontes doadoras de sardinha em conserva e cápsulas de Vitamina E a serem utilizadas na pesquisa.

Atenciosamente,

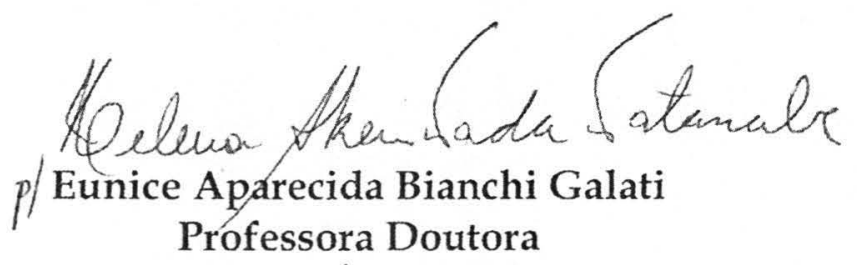

Coordenadora do Comitê de Ética em Pesquisa da FSP-COEP 


\section{ANEXO 2 - TERMO DE CONSENTIMENTO}

TERMO DE CONSENTIMENTO
(Obrigatório para Pesquisas Científicas em Seres Humanos - Resolução nº 196 de 10/10/1996 - CNS).

\section{Pesquisa: "EFEITO DA SUPLEMENTAÇÃO COM ÓLEO DE PEIXE E VITAMINA E NO PERFIL LIPÍDICO DE DOIS GRUPOS ETNICOS DE MULHERES COM DISLIPIDEMIAS NO CLIMATÉRIO"}

Objetivo: Investigar o efeito da suplementação com óleo de peixe em cápsula combinado ou não com vitamina E, no e perfil lipídico e estresse oxidativo de mulheres brancas e negras com dislipidemias no climatério.

A presente pesquisa será desenvolvida pelo Departamento de Nutrição da Faculdade de Saúde Pública - sob a responsabilidade da Bióloga Liania Alves Luzia CRB - 07568-2 e, sob a orientação da Profa. Assoc. Elizabeth AFS Torres.

Foram prestados esclarecimentos sobre todos os procedimentos a serem realizados, eu me submeterei à dieta prescrita (inclusão do consumo semanal de 7 cápsulas de óleo de peixe e vitamina E/semana) durante três meses. Permito a coleta de $20 \mathrm{~mL}$ de sangue venoso, antes do início da suplementação, com 45 dias e com 90 dias da realização da dieta. Estou ciente da importância da pesquisa para estudos de intervenção alimentar em mulheres com dislipidemias na menopausa.

Também foram esclarecidos os seguintes pontos:

$>$ Terei acesso a qualquer momento, às informações sobre procedimentos, riscos e benefícios relacionados á pesquisa, inclusive tendo direito de sanar qualquer tipo de dúvida;

> A participação é voluntária e a desistência não acarretará qualquer tipo de prejuízo ou desconforto de qualquer espécie, nem mesmo interferirá na continuidade da assistência;

$>$ A pesquisadora se compromete a não identificar o indivíduo e a manter o caráter confidencial das informações relacionadas à sua privacidade.

$>$ Caso a paciente apresente problemas de saúde durante o período da pesquisa, sairá do estudo e continuará sendo tratada no PSF.

Declaro que, após ter sido convenientemente esclarecida pela pesquisadora, eu consinto em participar desta pesquisa.

São Paulo,

Assinatura da pesquisadora

assinatura do participante

Maiores informações: Liania Alves Luzia e Profa. Elizabeth AFS Torres - Departamento de Nutrição da Faculdade de Saúde Pública da Universidade de São Paulo. Av. Dr. Arnaldo, 715, ou pelos telefones (11)3066-7701 R -230 e/ou (11) 4411-6349. 
Anexo 3 - Folheto informativo para a população de estudo

\section{PROSAPIN}

Projeto de Saúde de Pindamonhangaba 
Quem é responsável pelo projeto?

O estudo é realizado pela Faculdade de Saúde Pública / USP sob coordenação do Professor Dr. José Mendes Aldrighi e da Professora Dra.

Elizabeth Torres.

\section{Informações}

Departamento de Saúde MaternoInfantil da Faculdade de Saúde Pública / USP

Endereço: Av. Dr. Arnaldo, 715

Cep: 01246-904 São Paulo - SP

Telefone: (11) 3061 7703/7701/7748

(falar com Prof. Aldrighi/ Liania Alves Luzia ou Ana Carolina Schimitt)

E-mail: lianialuzia@usp.br

\section{PROSAPIN}

\section{Projeto de Saúde de} Pindamonhangaba

\section{Coordenação do Projeto:}

José Mendes Aldrighi

Professor Doutor

Faculdade de Saúde Pública / USP

Investigadora:

Ana Carolina Basso Schimitt e

Liania Alves Luzia

Doutorandas em Saúde Pública FSP/USP
Projeto de Saúde de Pindamonhangaba
PROSAPIN

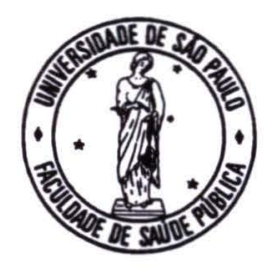




\section{O que é o Prosapin?}

Projeto de Saúde de Pindamonhangaba.

Por que é importante o estudo?

O objetivo é analisar as mudanças na circulação do sangue, hábitos e condições de vida, para reunir informações e elaborar projetos para melhorar a saúde das mulheres.

As informações obtidas serão usadas para compreender o que ocorre com a saúde da mulher nas diferentes fases de sua vida e assim ajudar na prevenção de doenças.

\section{Quem financia o estudo?}

\section{- FAPESP}

Fundação de Amparo à Pesquisa do Estado de São Paulo

\section{QJAPESP}

\section{- CNPq}

Conselho Nacional de Pesquisa

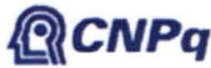

\section{Quem pode participar?}

Mulheres de 35 anos ou mais que morem em Pindamonhangaba.

\section{Como serão feitas as entrevistas?}

As participantes serão contatadas por seu agente comunitário e uma entrevistadora irá até sua casa. Nossas entrevistadoras são treinadas e possuem um documento de identificação com fotografia.

\section{Que tipo de medidas serão feitas?}

As medidas serão aferidas em sua residência e serão:

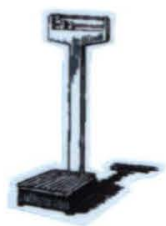

- peso

" pressão arterial

\section{Que tipo de perguntas serão} feitas?

As perguntas serão sobre:
- informações gerais da mulher

- cuidados com a saúde

- atividades do dia a dia

- informações gerais da família

\section{Que tipo de exame será feito?}

Será feito exame de sangue.

\section{A participação nesse estudo é obrigatória?}

Não, a participação é voluntária e as entrevistadas não são obrigadas a responder todas as perguntas. Porém, a colaboração de todas que forem selecionadas é muito importante para realizar esse estudo.

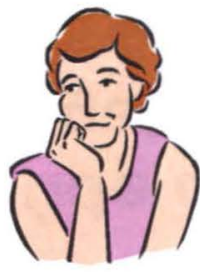

\section{O que acontece com as respostas?}

Todas as respostas serão confidenciais. A identidade das participantes não será revelada. Além disso, será enviado às participantes um comunicado baseado nos resultados para informá-las sobre a utilização dos resultados. 
Anexo 4 - Questionário para caracterização da população de estudo.

FACULDADE DE SAUDE PUBLICA - USP

EFEITO DA SUPLEMENTAC̃̃O COM ÓLEO DE PEIXE E VITAMINA E NO PERFIL LIPÍDICO DE DOIS GRUPOS ETNICOS DE MULHERES COM DISLIPIDEMIAS NO CLIMATÉRIO

\section{FORMULÁRIO DE ENTREVISTA}

ENTREVISTADO $\mathrm{N}^{\mathrm{O}} \mathrm{L}\left|\_\right|$

Data _ _ _ _ N $\quad \mathrm{N}^{\mathrm{o}}$ Prontuário:

\section{A. IDENTIFICAÇÃO}

1. Nome completo:

2. Sexo ( 0 ) F (1)M L $\mid \quad$ idade

3. Data de nascimento:

4. Endereço:

$\mathrm{Rua} / \mathrm{Av}$

Bairro Cidade CEP $\mathrm{N}^{\mathrm{O}}$

5. Estado Civil: ( 0 )Solteira ( 1 )Casada ( 2 )C/companheiro ( 3 )Viúva ( 4 )Separada L_

\section{B. DADOS SÓCIOS ECONÔMICOS}
6. Ocupação: (0)Desempregada
(1)Trabalha
(2)Aposentada

Tipo

7. Renda familiar mensal: ( 0 ) $\leq 1$ SM (1)1-2 SM (2) 3-4 SM ( 3 )5-7 SM ( 4 ) $>7$ SM

8. Quantas pessoas residem na casa?

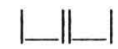

9. Escolaridade: ( 0 )Nenhuma (1)Primário incompleto (2)Primário completo ( 3 )Gin. Incompleto

( 4 )Gin. completo ( 5$) 2^{0}$ grau incompleto ( 6$) 2^{0}$ grau completo ( 7 )superior incompleto

( 8 )superior completo

\section{HÁBITOS}

Hábito de fumar
1. A Sra. fuma? ( 0 ) Não
(1) Sim

2. Caso negativo.

( 0 ) Nunca fumou

(1)Parou de fumar

L_L - L_L |meses

3. Caso positivo, quantos cigarros em média/dia?
( 0 )Até 5
(1)6-11
( 2 ) 12 ou mais

4. Há quanto tempo a Sra. fuma? (em meses)

5. Que tipo de cigarro a Sra. consome ?
1. Cigarros sem filtro
(0)Não (1)Sim
2. Cigarros de palha
(0)Não
(1) $\operatorname{Sim}$ 
3 Cigarros com filtro branco

4. Cigarros com filtro amarelo
(0)Não

(0)Não

(1) Sim

(1)Sim

\section{$\underline{\text { Somente para fumantes }}$}

6. Com que idade a Sra. começou a fumar? anos

7. Quantos cigarros a Sra. fuma por dia? cigarros/dia

$\underline{\text { Para não fumantes atualmente }}$

8. Quantos cigarros fumava por dia? cigarros/dia

9. Com que idade a Sra. começou a fumar? anos

10. Com que idade a Sra. parou de fumar? anos

\section{$\underline{\text { Para todos que já fumaram alguma vez }}$}

11. A Sra. pode me dizer quanto fumava nas seguintes idades?

\begin{tabular}{|l|l|l|l|l|l|}
\cline { 2 - 6 } \multicolumn{1}{l|}{} & \multicolumn{3}{c|}{ IDADE EM ANOS } \\
\cline { 2 - 6 } \multicolumn{1}{l|}{ Quantos cigarros fumava por dia quando tinha: } & & & & & \\
\hline $\begin{array}{l}\text { Que tipo de tabaco consumia quando tinha: } \\
\text { Cigarros sem filtro? } \\
\text { Cigarros de palha? } \\
\text { Cigarros com filtro branco? } \\
\text { Cigarros com filtro amarelo? }\end{array}$ & & & & & \\
\hline Quantos cachimbos fumava por dia quando tinha: & & & & & \\
\hline Quantos charutos fumava por dia quando tinha: & & & & & \\
\hline
\end{tabular}

12. Quando a Sra. fuma ou fumava:

1. Traga ou tragava of fumo profundamente?

2. Traga ou tragava todo o fumo?

(0)Não

(1)Sim

3. Traga ou tragava parte do fumo?

(0)Não (1)Sim

4. Não inala ou inalava o fumo?

(0)Não (1)Sim

5. Não sabe?

(0)Não (1) Sim

Hábito de ingestão de bebidas alcoólicas

13. A Sra. costuma ingerir bebidas alcoólicas?
( 0 )Não
(1)Às vezes
( 2 )Frequentemente

14. Quantidade (em copos)
$(0)<1$
(1) $2-5$
( 2 ) $>7$

15. Tipo de bebida

( 0 )Fermentada

(1)Destilada 


\section{ATIVIDADE FÍSICA}

16. Quanto à sua atividade física

\begin{tabular}{|l|l|l|l|}
\hline & TIPO & DURAÇÃO & FREQUÊNCIA \\
\hline Laborativa & & & \\
\hline Recreativa/lazer & & & \\
\hline Terapêutica & & & \\
\hline
\end{tabular}

$(0)=$ Sedentária

(1)=Leve

$(2)=$ moderada

\section{E. HISTÓRIA DAS DISLIPIDEMIAS}

17. Há quanto tempo a Sra apresentou alterações lipidêmicas? (anos)
$(0) \leq 1$
(1) $1-2$
(2) $3-4$
(3) $5-7$
(4) $8-10$
(5) $11-15$
(6) $16-20$
(7) $>20$

18. Como a Sra. descobriu as alterações lipidêmicas?

19. Tem casos de dislipidemias na família? (0)Não (1)Sim

20. Qual era o seu peso aproximado na descoberta da dislipidemia? $\mathrm{Kg}$.

21. Qual o tratamento utilizado na época do diagnóstico?

22. A Sra. já apresentou alguma complicação decorrente da dislipidemia? (0)Não (1)Sim

23. Se, positivo. Qual(is)?

24. Faz uso de algum medicamento para controle de colesterol? (0)Não (1)Sim

25. Se, positivo. Qual(is)?

26. A Sra. utiliza anti-hipertensivo? (0)Não (1)Sim

27. Se, positivo. Qual(is)?

28. A Sra. utiliza suplemento vitamínico? (0)Não (1)Sim

29. Se, positivo. Qual(is)?

30. Faz uso de outros medicamentos? (0)Não ( 1 )Sim 1 Qual?

31. Quantas refeições a Sra. faz por dia?
(0) 1
(1) 2
(2) 3
(3) 4
(4) 5
(5)6
(6)mais 